NISTIR 5610

\title{
WHITE PAPERS PREPARED FOR THE WHITE HOUSE--CONSTRUCTION INDUSTRY WORKSHOP ON NATIONAL CONSTRUCTION GOALS
}

\section{United States Department of Commerce National Institute of Standards and Technology}

QC

100

.056

N0. 5610 

WHITE PAPERS PREPARED FOR THE

WHITE HOUSE--CONSTRUCTION

INDUSTRY WORKSHOP ON NATIONAL

CONSTRUCTION GOALS

Compiled by:

Andrew J. Fowell, Secretariat

Subcommittee on Construction and Building

Committee on Civilian Industrial Technology

National Science and Technology Council

National Institute of Standards and Technology

December 14-16, 1994

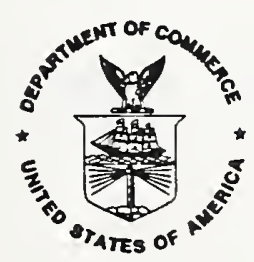

U.S. Department of Commerce

Ronald H. Brown, Secretary

Technology Administration

Mary L. Good, Under Secretary for Technology

National Institute of Standards and Technology

Arati A. Prabhakar, Director 

White Papers Prepared for the White House

Construction Industry Workshop on National Construction Goals

December 14-16 1994

Table of Contents

Introduction

National Construction Goals . . . . . . . . . . . . . . . . . . . . . . . . Al

Authors- Henry Michel, Parsons Brinckerhoff International

Carl Magnel1, Civil Engineering Research Foundation

William B. Reddan, Parsons Brinckerhoff International

Untying the Gordian Knot: Some Thoughts on Liberating the Creativity of America's Design and Construction Industry . . . . . . . . . . . . . . . . B1 Author- Terrence M. McDermott, The American Institute of Architects

Housing Industry Sector Perspective . . . . . . . . . . . . . . . . . . . . Cl Authors- Liza K. Bowles, NAHB National Research Center

Burton Goldberg, NAHB National Research Center

Bringing Tomorrow Into Today's Commercial Buildings . . . . . . . . . . . . D1 Authors- H.J. Parmelee, Turner Construction Company

E.E. DiTomas, Turner Construction Company

An Industry Sector Perspective - Industrial . . . . . . . . . . . . . . . E1 Authors- Philip J. Richter, Fluor Daniel Inc.

Ramzi G. Saaty, Fluor Daniel Inc.

Institutional Buildings . . . . . . . . . . . . . . . . . . . . . . . . . . F1 Author- Ezra D. Ehrenkrantz, FAIA

A Public Works Perspective . . . . . . . . . . . . . . . . . . . . . . . . Gl Author- Albert A. Grant, Consulting Engineer 


\section{INTRODUCTION}

This report contains seven white papers prepared for a December 1994 White House - - Construction Industry Workshop organized by the Civil Engineering Research Foundation on behalf of the National Science and Technology Council's Subcommittee on Construction and Building.

The National Science and Technology Council (NSTC), a cabinet-level group charged with setting Federal technology policy, coordinates R\&D strategies across a broad cross-section of public and private interests. It has established nine research and development committees, including the Committee on Civilian Industrial Technology (CCIT), to collaborate with the private sector in developing a comprehensive national technology policy. The Subcommittee on Construction and Building ( $C \& B$ ) of CCIT coordinates and defines priorities for Federal research, development and deployment related to the industries that produce, operate and maintain constructed facilities, including buildings and infrastructure.

Construction is one of the Nation's largest industries and a critical asset for enhancing the international competitiveness of U.S. industry. In 1994, new construction and renovation combined amounted to $\$ 850$ billion, about $13 \%$ of the GDP, and provided employment for over 10 million persons. Constructed facilities shelter and support most human activities. Their quality is vital to the competitiveness of all U.S. industry, the safety and quality of life of the people, and environmental quality.

The C\&B Subcommittee has studied research priorities expressed by the construction industry in industry fora and in proposals for the Advanced Technology Program of the Department of Commerce. Two priority thrusts, better constructed facilities and health and safety of the construction workforce, were defined for focus of research, development and deployment (RD\&D) in the construction and building area. The C\&B program plans to make technologies and practices capable of achieving the goals under these thrusts available for general use in the construction industry by 2003 . The goals include:

\section{Better Constructed Facilities}

- $50 \%$ reduction in delivery time

- $50 \%$ reduction in operation, maintenance and energy costs

- $30 \%$ increase in productivity and comfort

- $50 \%$ fewer occupant related illnesses and injuries

- $50 \%$ less waste and pollution

- $50 \%$ more durability and flexibility

Health and Safety of Construction Workforce

- $50 \%$ reduction in construction work illnesses and injuries 
The C\&B program and goals were reviewed with a focus group of industry leaders convened on April 5, 1994, by the Civil Engineering Research Foundation. These leaders strongly endorsed the goals.

On December 14-16, 1994 industry leaders held a White House -- Construction Industry Workshop on National Construction Goals organized by the Civil Engineering Research Foundation. The workshop's purpose was to provide an industry perspective on the priorities among proposed construction goals and develop recommendations for an appropriate implementation plan. Participants in the workshop included representatives from design, construction, labor, construction equipment, building materials and mechanical equipment, finance, insurance, owners, codes, etc.

In preparation for the workshop the steering committee asked selected industry leaders to prepare seven white papers on the industry goals, barriers to reaching those goals, and the perspective of five sectors of the industry, residential, commercial, industrial, institutional, and public works. Those white papers are presented in this document.

The results of the workshop are contained in a separate report, "National Construction Goals: A Construction Industry Perspective," prepared by the Civil Engineering Research Foundation. 


\section{White House-Construction Industry Workshop \\ National Construction Goals \\ White Paper}

by:

Henry Michel, Chairman of the Board, Parsons Brinckerhoff International

Carl Magnell, Director of Research. Civil Engineering Research Foundation

William B. Reddan. Vice President. Parsons Brinckerhoff International

\section{A. Introduction}

In this "white paper" we are asked to consider the feasibility, indeed the desirability, of a concept never before contemplated by our industry. Are national construction goals a reasonable strategy for the US construction industry? What benefits can be derived from a set of goals? Who benefits if such goals are attained? What should these goals be? How can they be measured? If goals are desirable, how are they to be attained? This brief paper is not intended to fully answer these questions. The opportunity to do so is a challenge left for you as a participant in this White House/Construction Industry Workshop on National Construction Goals. Let us, however, briefly consider some fundamental issues that are characteristic of our industry, analyze the framework for national construction goals as proposed by the Construction \& Building sub-committee of the National Science and Technology Council (NSTC), and, look at a conceptual template for our industry to implement such goals as may be deemed appropriate. 


\section{B. Background}

In order to implement and successfully attain construction sector goals, we must first understand who we are! Statistics help but they do not tell the whole story. We know, for example, that our construction industry is the nation's second largest economic activity, accounting for approximately 13 percent of the Gross Domestic Product (GDP). We also know that, while the largest component, we are quite unlike others in the manufacturing sector. Many, if not most, of the major "industries" that comprise the manufacturing component of our economy have relatively few firms. Consider, for example, automobiles, aerospace, and computers. We can in all likelihood name most of the firms in these industries. Would anyone attempt to do so for our industry? Unlikely, since we are truly "fragmented", with over one million firms, employing an estimated ten million professional, skilled and semi-skilled workers. Statistics also suggest that we lag behind other industries in productivity gains and especially in resources devoted to research and development. While the United States is often criticized for its low level of non-defense related R\&D investment (a rate of between 3 and 4 percent in contrast to the significantly higher levels in Western Europe and Japan), our industry, at less than 0.5 percent, is a mere one-seventh of this already low overall national average!

What these statistics do not tell us is equally important! They do not speak adequately to the enormous "value added" of our industry nor to the significant differences among the many firms in our industry.

We should, first and foremost, recognize how important we are! Is there another industry whose role has a more direct and beneficial impact on the nation's economic prosperity and quality of life? We are enablers; the constructed facilities we create enable other segments of our economy to strive for excellence and makes possible the myriad of essential societal functions! Our influence extends well beyond the 13 
percent of GDP that we contribute. Imagine life without the foundation we provide in the form of quality homes, first-rate schools and hospitals, complex industrial facilities, imposing commercial buildings and efficient public works of all types. Yet, the paradox is undeniable! All of these constructed facilities enable the quality, efficiency and productivity that has become the hallmark of many US industries. They enable a quality of life for the average American that is envied throughout the rest of the world. Yet, they are, paradoxically, the product of an industry that is perceived as low-tech. What would we achieve and contribute to the nation if our industry were only average in innovation and resource allocation for research and development, let alone a leader? The bottom line is worth pondering: even under the present circumstances no other manufacturing activity has as profound and pervasive impact on the nation's economy and quality of life as our construction industry!

One of the important reasons behind this paradox is the structure of our industry. We all recognize the enormous differences between the many members in our industry. Over 90 percent of our firms have less than ten employees; two-thirds have less than five! Is there another manufacturing sector where firms vary so greatly in capability, where the large and small are typically lumped together in one amorphous mass, where widely divergent types of construction related activity are melded as one for statistical purposes? As already noted, we do not do well as an industry when our R\&D is compared to that of other industries. Within our industry, however, the level and scope of R\&D varies widely. Most of our firms are simply too small to accomplish R\&D. Among larger firms, however, focused and productive $R \& D$ is being undertaken. The level of $R \& D$ is also a function of what type of construction activity the firm is involved in. Construction materials producers and construction equipment manufacturers, while still below the national average, are significantly higher than the industry as a whole. Structure therefore plays a key role in the ability of our industry to accomplish meaningful research and development and deliver innovation. 
This brief perspective suggests an industry that is absolutely vital to the nation yet largely "invisible" in its political and social outreach, an industry without a common message, an industry detached from the public eye, an industry seldom painted in the media, an industry seemingly lacking a central purpose or a common direction. Contrast this with the effective, coordinated agendas pieced together by other industries/professions, for example the health sector, the insurance industry or the legal profession! This is perhaps why the seeds and impetus for national construction goals have, heretofore, not captured the necessary recognition and momentum from within our industry. This workshop is therefore a unique opportunity to redefine and refocus our industry in its most fundamental aspects. Our common purpose then, must be to objectively assess the validity, desirability and attainability of construction goals, considering as a model, the goals articulated by the Construction \& Building (C\&B) sub-committee of the National Science and Technology Council (NSTC). The excellent work of this sub-committee, provided to you as the Rationale and Preliminary Plan for Federal Research for Construction and Building, provides an invaluable initial platform for the second workshop objective, the framing of a template for eventual development of a construction industry implementation plan, should such a plan be deemed appropriate.

\section{Proposed National Construction Goals}

The Subcommittee on Construction and Building (C\&B) has studied research priorities expressed by the construction industry in industry forums and in proposals for the Advanced Technology Program of the Department of Commerce. Two priority thrusts; better constructed facilities and health and safety of the construction workforce, were defined for focus of research, development and deployment (RD\&D) in the construction and building area for the FY 1996 budget. In each of these priorities the goals for the $\mathrm{C} \& \mathrm{~B}$ Program were defined as: 
Better Constructed Facilities (by 2003)

- $50 \%$ reduction in delivery time.

- $50 \%$ reduction in operation, maintenance and energy costs

- $30 \%$ increase in productivity and comfort

- $\quad 50 \%$ fewer occupant related illnesses and injuries

- $\quad 50 \%$ less waste and pollution

- $50 \%$ more durability and flexibility

Health and Safety of Construction Workforce (by 2003)

- $\quad 50 \%$ reduction in construction work illnesses and injuries

Although many of the C\&B goals appear to apply only to buildings, all infrastructure constructed projects are and should be included.

The motivation for such goals is rooted in the desire to enhance the competitiveness of U.S. industry, improve environmental quality, and ensure the safety and quality of life of our citizens.

The construction industry is the nation's largest manufacturing industry. In 1993 new construction put in place amounted to $\$ 470$ billion, $8 \%$ of the GDP, and provided 6 million jobs; renovation and retrofit adds another $5 \%$ of the GDP and approximately four million jobs.. There is little doubt, however, that much needed infrastructure improvements are still not being addressed. For instance, the Federal Office of Technology Assessment reviewed the results of the 1982 to 1987 traffic congestion study performed by FHWA and estimated that delays due to highway congestion in major urban regions costs the nation $\$ 30$ billion annually (see Table 1 ). This is almost one half of the $\$ 65$ billion total spent by the federal, state and local governments for highways. Overcrowding has increased every year since, rendering the $\$ 30$ billion estimate conservative and probably obsolete. 
TABLE 1

\begin{tabular}{|c|c|c|}
\hline \multicolumn{3}{|c|}{$\begin{array}{c}\text { TABIE I - TRAFFIC CONGESTION INCREASES IN } 15 \text { MAJOR CITIES } \\
\text { Amual Cost of Congestion a }\end{array}$} \\
\hline & Iotal & Per Capicas \\
\hline Cities & (in billions of 1987 dollars) & (in dollars) \\
\hline Los Angeles & $\$ 7.9$ & $\$ 730$ \\
\hline San Francisco-Oakland & 2.4 & 670 \\
\hline Washington DC & 2.2 & 740 \\
\hline Phoenix & 0.9 & 510 \\
\hline Houston & 1.5 & 550 \\
\hline Ailanta & 1.1 & 650 \\
\hline Seattle & 0.9 & 580 \\
\hline New York & 6.8 & 430 \\
\hline Chicago & 2.5 & 340 \\
\hline Detroit & 1.9 & 480 \\
\hline San Diego & 0.6 & 280 \\
\hline Philadelphia & 2.1 & 520 \\
\hline Dallas & 1.0 & 530 \\
\hline Minneapolis-St. Paul & 0.5 & 240 \\
\hline Milwaukee & 0.2 & 190 \\
\hline
\end{tabular}

SOURCE: Office of Technology Assessment, based on Texas Transportarion Instinure, "Roadwry Congestion in Major Urban Areas, 1982 to 1987," Research Reporn 1131-2, 1989 
The C\&B's vision of the construction and building industries is that:

- High quality constructed facilities will support the competitiveness of U.S. industry and everyone's quality of life.

- U.S. industry will continue to provide leadership in quality and economy in the global market for construction products and services.

- The construction industry and will provide constructed facilities that are energy efficient, environmentally benign, safe and healthful and sustainable in use of resources.

- Natural and manmade hazards will not cause disasters.

- Produces intelligent renewal of our built environment and cost effectively manages the use of economic, material and human resources in rebuilding America.

To achieve progress toward this vision, there must be a coordinated plan that balances economic, political and social objectives. The articulation of specific goals is a significant and necessary step in the development of such a plan. The construction industry is not a single entity - not functionally economically, not politically and not socially. The industry members are, however, the experts on the present practices and the needs for improvement, both in methods and technology. An implementation plan must therefore create a viable and accepted industry mechanism for the development and execution of the plan. It is with this perspective that the construction goals should be viewed.

The $C \& B$ goals are to improve certain components of the overall life cycle of each constructed project. Achievement of the goals requires that the entire construction industry be viewed as a multifunctional system, whereby the owner, architect, engineer, constructor, operator, user/maintainer and the government as regulator all accept their role in optimizing the 'system', even though the component in which they are most directly responsible may not, be individually optimized. This view is quite 
contrary to present day realities wherein each participant typically seeks to optimize their component, without much concern about the impact on other elements in the life cycle of the facility.

The desire to view the constructed project from a life cycle perspective is noble, but must be approached with caution and realism. Is it reasonable to expect the architect, the engineer or the constructor to make all material selections and design decisions based on a life cycle cost model of the facility, even if such decisions increase the capital costs and/or adversely affect the owner's cash flow? Should the government add more regulations and inspection to ensure that life cycle costs are considered? Moreover, much uncertainty and many variables influence the 25 year to 50 year or greater lifespan of the typical constructed project. Agreement on the method to calculate the costs is therefore extremely difficult. For example, how long would it take to get all parties to agree on whose cost we are talking about. Is it the owner's? The public's? These and many other 'process' related questions must be resolved prior to the establishment of mandated down life-cycle costing. We can however, rigorously seek improvements in technology and present construction practices so that design, construction and operating processes are more efficient, less expensive and more environmentally sustainable that the present state of the practice.

Research to improve construction technologies, education to bring the technologies to practice, and the removal of non-technical barriers to implementation of advanced technologies are needed to achieve the $\mathrm{C} \& \mathrm{~B}$ goals.

Eight areas of technology will need to be fully developed to achieve the goals:

\section{Information and Decision Technologies}

Integrated data bases and information systems

Knowledge systems as successors to standards and books 
Integrated project information systems

Construction management technologies

Collaborative decision making environments

Post-occupancy evaluation systems

2. Automation in Design, Construction and Operation

Simulation and visualization

Computer-aided design

Computer-integrated construction

Advanced sensors

Construction robotics

Building automation systems

Computer-aided facilities management

3. High Performance Materials, Components, and Systems Advanced materials

Advanced components

Entire building systems

Connections

Mechanisms, models and data for life cycle performance

Assessment and quality assurance technologies

Renewal engineering

Recycling and reuse

Functional flexibility

4. Environmental Quality

Energy conservation

Indoor environmental quality

Remediation of contaminated construction sites 
Sustainable development (ecological quality, conservation of raw materials, etc.

5. Risk Reduction Technologies

Fire protection

Toxic exposures

Earthquake risk reduction

Wind risk reduction

Other hazards

6. Performance Standards System

Performance standards for products and processes

Test methods and data for life cycle performance

Conformance assessment system

Certification system

7. Condition Assessment and Monitoring Technologies

NDT technologies

Expert systems

Adaptive controls systems

Smart materials

8. Human Factors

Cognitive processes and uses of information

Physiology

Ergonomics

Environmental and person-machine interactions

Team building and workforce efficiency

Education and training are required for implementers of the technologies (designers, 
manufacturers and fabricators, regulators, construction workforce, operators and maintainers, and users). Educational materials and curricula will be required for each area of technology and each category of users. In some instances, research on educational methods may be needed for selected technologies and users.

Improved technologies alone are not sufficient for improvement of the life cycle quality of constructed facilities and enhancement of the competitiveness of U.S. industry. The improved products and services must be successful in the marketplace and become the ruling technologies in construction practices.

Finding practical solutions to complex construction and building problems and challenges is hard enough when the technologies are well characterized. Developing and applying new technologies is extraordinarily difficult because so little is known about how they will actually perform. As the Office of Technology Assessment (OTA) has stated, only the Federal Government can channel resources necessary to support large scale, applied research and development programs. At present in the area of public works infrastructure, no significant, comprehensive federal technology research and support programs exist for state and local governments seeking solutions to long-range problems. Until appropriate new technology choices are obvious, such governments will tend to focus on rehabilitating and repairing existing facilities to keep them functional, while hoping that someone will be successful in the search for better answers.

\section{Role of the Federal Government}

The Federal Government is also the only party with a vested interest in every step of a domestic facility's life cycle and in the global competitiveness of U.S. industry. It would seem therefore that the Federal Government's role should include the 
following:

- Conduct technology policy analyses to improve United States industrial productivity, technology, and innovation, and cooperate with the construction industry in the improvement of its productivity, technology, and ability to compete successfully in world markets;

- Identify technological needs, problems, and opportunities within and across industrial sectors that, if addressed, could make a significant contribution to the economy of the United States;

- Assess whether the capital, technical and other resources being allocated to domestic industrial sectors which are likely to generate new technologies are adequate to meet private and social demands for goods and services and to promote productivity and economic growth.

- Encourage and assist the creation of centers and other joint initiatives by state or local governments, regional organizations, private businesses, institutions of higher education, nonprofit organizations, or federal laboratories to encourage technology transfer, to stimulate innovation, and to promote an appropriate climate for investment in technology-related industries;

- Serve as a focal point for discussions among United States companies on topics of interest to industry and labor; including discussions regarding manufacturing and discussions regarding emerging technologies;

- Provide adequate and stable funding for applied research and demonstration projects.

You may recognize the first five issues. They are excerpted from the existing law (Chapter 63, USCA Title 15, Commerce and Trade) that established the Technology Administration in the Commerce Department and created the position of Under Secretary of Commerce for Technology. The final issue is the fuel necessary to achieve the first five! 


\section{Role of Industry}

Industry has an enormous stake in the improvement of construction technologies and for improving the policies, procedures and methods used to deliver the constructed project. For many reasons, however, the industry dedicates precious few resources to the pursuit or development of innovative ideas. CERF estimates that the total construction industry investment is $0.5 \%$ of revenue, one seventh of the average for all U.S. industry.

The construction industry's fragmentation is well known! Over 90 percent of firms are very small with less than 10 employees; two-thirds have fewer than five. This factor may be partly responsible for the relative difficulty in the past of introducing technological innovations into practice in construction; this is now being addressed by the Civil Engineering Research Foundation (CERF) which is filling the role as the industry's "facilitator/coordinator/integrator" for R\&D and innovative technologies. Much more can and should be done by industry to be more innovative and to assist in overcoming the existing barriers to innovations. Some specific areas where industry can make significant contributions are:

1. Assist the policy-makers in making informed decisions. For instance, provide data for benchmarking construction processes, methods, systems, etc.

2. Identify the most promising applications or processes for innovation. Communicate these priorities to appropriate funding agencies.

3. Help identify the most significant barriers to innovation.

4. Assist in developing improvements to project delivery policies that are barriers to innovation.

5. In the conduct of your business seek to innovate.

6. Support and guide research at universities, and professional organizations, like 


\section{CERF.}

7. Seek cooperative research and development agreements with the national laboratories.

8. Set improvement goals for your firm -- like the national construction goals -- and development implementation plans, in conjunction with the owners.

\section{Barriers}

Barriers of many types pose significant problems for our industry; they are therefore the topic of a separate white paper. Nevertheless, a brief discussion of at least one barrier is in order, inasmuch as the elimination of barriers loom as an essential and primary component of the industry strategy that will be proposed later in this paper. Elimination of many barriers will require the coordinated efforts of both the public sector and our industry. One barrier, however, is clearly our responsibility! Industry leadership is essential if national construction goals are to be promulgated and attained! The proposed goals cannot and will not be achieved by the public sector alone, no matter how excellent the focus and leadership that emanates from our Federal agencies, the Congress and the Administration. The focus outlined in the Rationale and Preliminary Plan for Federal Research for Construction and Building is a major departure from current Federal practices. Federal research and development will now be coordinated between agencies and will be prioritized in accordance with such national construction goals as are mutually identified and agreed upon with industry. Federal agencies expect to play a key role in the attainment of the proposed national goals through development and demonstration of new technologies. However, they cannot lead our industry in the adoption and implementation of those actions necessary for goal achievement. That challenge is ours and ours alone. A template for this leadership is outlined later in this paper. 
E. Analy'sis of Specific Goals

The $\mathrm{C} \& \mathrm{~B}$ goals are broad, embracing public and private infrastructure construction and residential housing. The assessment of these goals needs to be performed on the constituent parts of the broadly stated goal. Once broken into identifiable parts the efficacy of the (sub) goal can be judged and benchmarks can be established against which improvements can be measured. To illustrate this point, a comparison of the value of public and private construction put in place is shown in Figure 1. As seen in the figure they are roughly comparable. The residential housing put in place, however, is significantly greater than either. For instance, in 1993 new construction put in place amounted to $\$ 470$ billion, of which $44 \%$ was residential, $28 \%$ private non-residential and $28 \%$ public works. This, along with the fact that there are practices and barriers unique to each group, suggests that such goals might be apportioned, among these three categories, or else into the five sector framework of this workshop. 


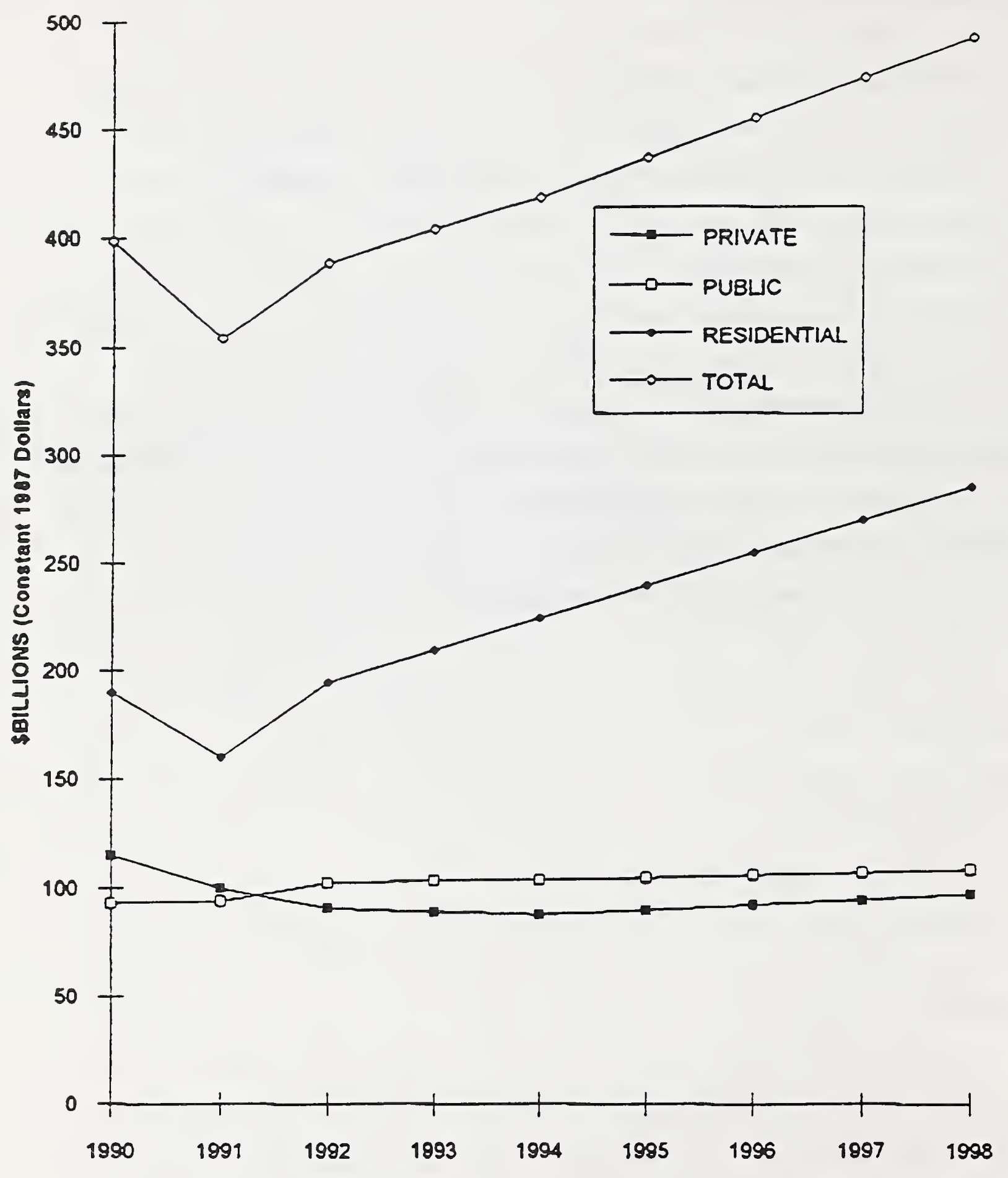

Source : AE Business Review, Jan 1994 
In the following sections the importance of technology in achieving each of the $\mathrm{C} \& \mathrm{~B}$ goals to each of these three broader categories is assessed and some of the barriers are highlighted.

Goal Number $1-50 \%$ Reduction in Delivery Time

For non-residential construction, delivery times vary greatly, depending on the use, ownership, funding source, provider and location. Typically, the process takes many years and is characterized by seemingly endless permits, legal wrangling, reviews and inspections.

Residential construction, on the other hand, has a much shorter delivery time and has significantly less variability, although most constructors would point out that there are many exceptions to this and that there is plenty of room for improvement. Reduction in delivery cost, including the cost of money, would be a more relevant goal to the residential constructor. These cost reductions have a higher probability of being passed directly to the consumer and of making housing more affordable.

The technologies that could make significant contributions in the near term toward this goal are:

Information systems

Engineering software

Construction methods appropriate databases available to and shared by all stakeholders; electronic filing of building permit applications

user friendly CASE programs; CADD (especially 3D) automated positioning and surveying, material management; computer based construction simulation systems

Materials 
Construction equipment

Project delivery system e.g. Design-Build, BOT

Standardization of designs and of codes

Barriers: $\quad$ The major barriers are institutional - excessive regulations, complex risk management, lack of financial incentives for innovation.

Feasibility: It is clear that significant improvements can be made if the funding for $R \& D$ and the political will to address the regulatory and liability barriers appear soon. Otherwise the target date of 2003 is overly optimistic.

Goal Number $2-50 \%$ Reduction in Operation, Maintenance Costs and Energy Use

This goal is equally applicable to residential and non-residential construction. There are two observations regarding the elements of this goal. First, the costs for O\&M and for energy vary significantly, even within regions, as can be seen in Table 2. The goals should be geographically adjusted. Secondly, for existing facilities significant reductions in energy consumption may come at the expense of increased life cycle and maintenance costs - because older, existing facilities need to be extensively refurbished to achieve significant energy savings, and their useful life may no be long enough to recover this investment at a reasonable rate of return. 
TABLE 2

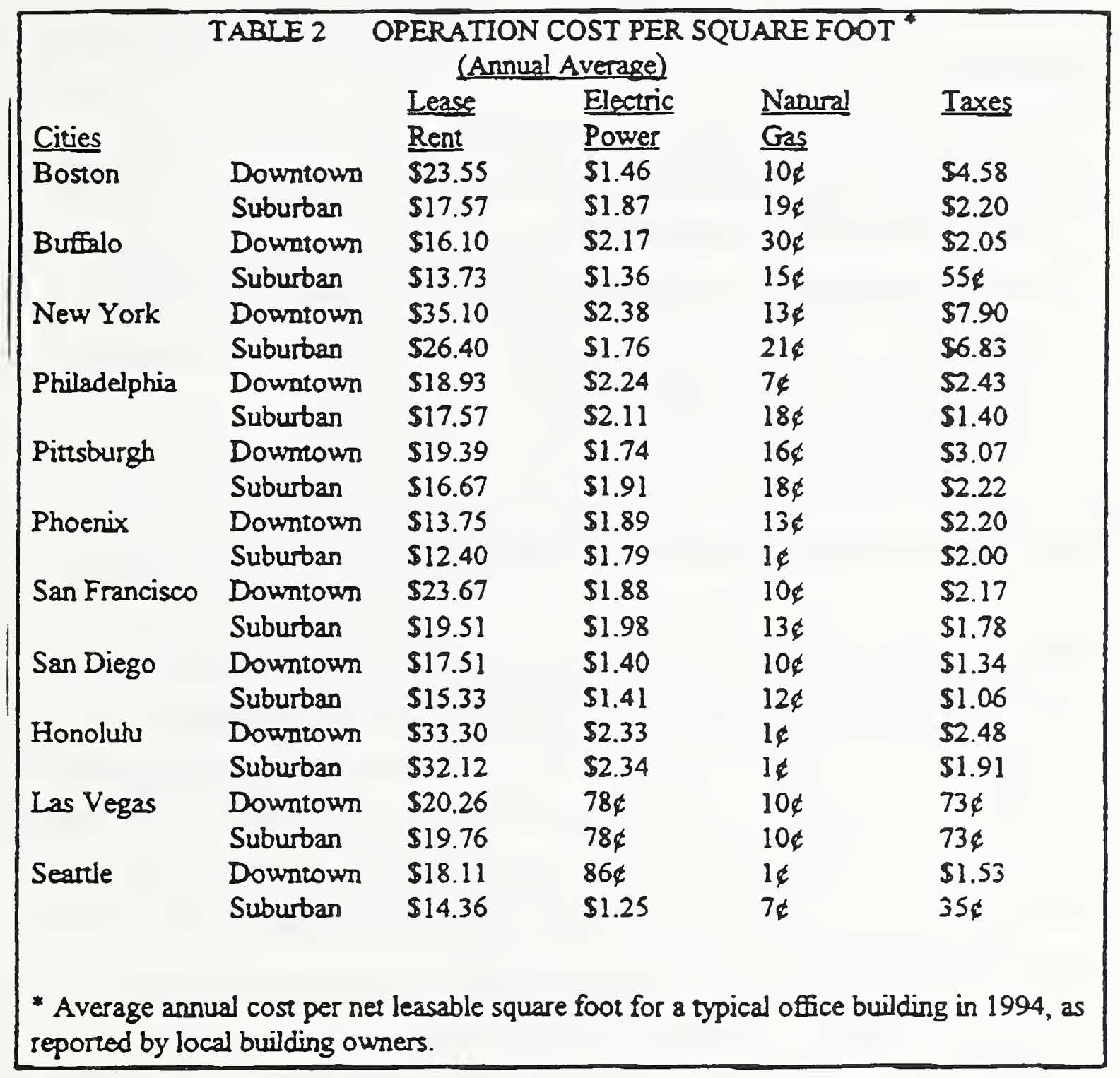

SOURCE: ENERGY USER NEWS, October and November, 1994 
This goal is best divided into the two parts stated below, both of which are achievable by the year 2003;

- for new construction no change in goal

- for existing facilities "50\% reduction in energy use"

\section{$\underline{\text { Technologies }}$}

- Information and real time control systems

- $\quad$ high performance construction materials

- energy conservation technologies, e.g. solar, insulation, efficient appliances, lighting,etc.

- Expert systems for maintenance and PM

- $\quad$ Condition assessment systems

Goal Number $3-30 \%$ Increase in Comfort and Productivity

The appropriateness of this goal will require more detailed analysis. Comfort is a characteristic that has many shades; measuring improvement will therefore be problematic. Also, it is intuitively obvious that a person who is uncomfortable in his or her working environment will not be at peak productivity, but the corollary is not clear at all - i.e. an individual may be quite comfortable and quite non-productive. There is no clear relationship between comfort and productivity in today's facilities, thereby making an incremental improvement a measurement challenge.

It is not at all apparent how progress toward the vision discussed in Section $\mathrm{C}$ regarding the U.S. construction industry's competitiveness would be achieved by adopting this goal.

It is noted that this goal is intended to address the productivity of the users or inhabitants 
of the constructed facility. The achievement of goal number one $-50 \%$ reduction in delivery time -- will require substantial improvement in construction productivity. These improvements will certainly enhance the U.S. industry's competitiveness.

\section{Goal Number 4 - 50\% Fewer Occupant Related Illness and Injuries.}

Most of these occurrences are avoidable, suggesting that the goal is not sufficiently ambitious. For instance, the number of fire related death in residential homes in 1993 comprised eighty percent of all such deaths in structures in the U.S. Many certainly could be avoided, if the residence were fully outfitted with an effective and properly maintained sprinkler system and the residents behaved intelligently.

Indoor air pollution is alleged to be a significant cause of occupational illnesses. Although causal relationships have not been articulated and accepted, it is certainly true that there is a direct relationship between complaints of IAP and occupant illness.

Perhaps the largest class of occupant related illnesses is the cold or flu transmitted by fellow occupants. How this is to be reduced or eliminated is not clear from a construction perspective.

\section{Technologies}

1. Provide technologies for heating, cooling, ventilation, humidity control, lighting, acoustics, etc. that provide a healthy and safe work, residential or recreational, environment.

2. Provide technologies and practices to reduce risks to user's safety and health from hazards such as fire, earthquake, wind, flood and release of toxic substances.

3. Provide an internationally recognized performance standards system that reflect user's health and safety in initial design and construction of the facility, promotes 
acceptance of innovations capable of improving safety and health, and provides for operation and maintenance for safety and health.

\section{Goal Number $5-50 \%$ Less Waste and Pollution}

Because they shelter and support most human activities, improvement of the performance of constructed facilities provides major opportunities to reduce waste and pollution at every step of the delivery process, from raw material extraction to final demolition and recycling of the shelter and its contents. Examples are reduced energy use and greenhouse gas emissions and reduced water consumption and waste water production. Wastes and pollution also can be reduced in the construction process: construction wastes are currently estimated to require $20-30 \%$ of the volume of landfills.

\section{Technologies}

1. Provide information systems and decision support systems to provide real-time information on the waste and pollution implications of alternative materials, components, systems and practices for construction, operation, maintenance, renovation, demolition and waste recycling.

2. Provide construction materials, components and systems that conserve resources over the life cycle, are adaptable to changes over time in users' needs and activities, and are suitable for recycling or re-use.

3. Provide technologies for heating, cooling, ventilation, humidity control, lighting, communication, water supply and waste handling and treatment, etc., that reduce production of wastes and pollutants.

4. Provide technologies and practices to reduce damages to and harmful discharges from constructed facilities as a result of natural and manmade hazards such as fire, earthquake, wind, and flood.

Goal Number 6. - $50 \%$ More Durability and Flexibility 
Durability denotes the capability of the constructed facility to maintain (given appropriate maintenance) its initial performance characteristics over the intended service life, and flexibility denotes the capability to adapt the constructed facilities to changes in use or users' needs. High durability and flexibility contribute strongly to the life cycle quality of constructed facilities since they usually must serve for many decades. However, they also contribute greatly to the first cost of the facility.

\title{
Technologies
}

1. Provide automation in techniques for design, construction, operation and maintenance to improve durability, sense needs for maintenance or repair, and adapt the system for changed users' needs.

2. Provide construction materials, components and systems that are durable and adaptable to changes over time in users' needs and activities.

3. Provide technologies for durable and flexible environmental systems for constructed facilities.

4. Provide technologies and practices to reduce damages from natural and manmade hazards.

Drug abuse control.

Goal Number 7 - 50\% Reduction in Construction Workers' Illnesses and Injuries

\begin{abstract}
Although the construction workforce represents about 10 percent of the nation's workforce, it is estimated that the construction industry pays for about one-third of the nation's Workers' Compensation. Worker's Compensation insurance premiums range from 7 to 100 percent of payroll in the construction industry.
\end{abstract}

Construction workers die as a result of work-related trauma at a rate that is 3 times the 
annual rate for workers in all other industry sectors (24.1 deaths per 100,000 construction workers, as compared to 7.9 deaths per 100,000 workers in all other industry sectors). Construction workers also experience a higher incidence of non-fatal injuries of varying severity than workers in other industries.

\section{$\underline{\text { Technologies }}$}

1. Provide management practices, information systems and decision support systems characterizing workplace safety and health hazards and safe work practices.

2. Provide automation to make equipment safer to operate and to reduce workforce exposure to hazardous environments and tasks.

3. Reduce vulnerability of incomplete and temporary structures to natural and manmade hazards such as wind, earthquake, fire and toxic substances.

4. Develop and implement standards providing explicit attention to workforce safety performance for construction activities and equipment and for incomplete and temporary structures and equipment.

\section{F. An Implementation Process}

As the foregoing analysis suggests, national construction goals not only make sense, but will be essential for the nation and our industry as we prepare for the unprecedented challenges of the 21 st Century! But, if so, how do we proceed? Let us look at a notional process that may serve as the initial template for the more rigorous discussions that will ensue during the workshop.

This notional process is anchored on the following set of premises:

$\checkmark$ process success requires a unified industry;

$\checkmark$ process implementation will be on a sectoral basis; 
$\checkmark$ "life-cycle", when adequately defined, should become a fundamental operational parameter;

$\checkmark$ barrier reduction/removal is the most critical first step;

$\checkmark \quad \mathrm{R} \& \mathrm{D}$ is essential and requires coordination between the public sector, academe and industry

$\checkmark$ the process is continuous, rather than a one-time "fix";

$\checkmark$ the process demands a cultural shift, and;

$\checkmark$ process coordination will require a national "council".

Establishing appropriate goals is by no means an easy task. Is one set of goals reasonable for the entire industry or will distinct goals be required for each sector? Are different timelines appropriate/necessary for each sector? These are but two of the many issues that will require resolution. The important issues, however, pale in comparison to more fundamental challenges that our industry must face and resolve.

Success will require a united industry, a fundamental change from today's environment in which the five sectors we have identified operate in relative independence, focused on, for example, the particular issues that may impact the residential sector, or industrial construction or public works. The fragmentation that is so characteristic today is unlikely to enable the set of coordinated industry actions required for goal attainment. The many industry and professional associations that exist today provide essential "value added" to their respective constituencies and will continue to be essential components in the accomplishment of the proposed national construction goals. Our industry will, in all likelihood, require a strong, focused, effective central coordinating body, one that is representative of the industry sectors, entrusted with the authority to act for the industry as a whole and accountable to our industry as a whole and to our respective sectors. Defining and sculpting such a "council" is an appropriate consideration for this workshop; the emerging national council for the attainment of high-performance construction materials and systems may prove a valuable template. Out of this council 
must come the leadership that will propel our industry towards the innovation and productivity needed to achieve established goals. And, above all, this council must ensure that our industry becomes a visible force and an audible voice in promoting and adjudicating matters that are critical to our industry and our profession.

Goal attainment thus requires, as an initial sine qua non, a unified industry. But, unified to do what? Two components are essential: barrier reduction and productive research and development. While barrier reduction is an important focus for academe and the public sector, it is absolutely vital for our industry. Significant and meaningful research and development has already been accomplished by the public sector, academe and industry but languishes, either under-utilized or not utilized at all, due to seemingly insurmountable obstacles. An initial, focused industry objective to minimize or eliminate existing barriers is therefore essential! Success in doing so will enable, as a first step, the implementation of the promising R\&D that now exists and thus the advancement of the "state of the practice". The simultaneous focus and coordination among academe, industry and the public sector of always scarce R\&D assets on "cutting edge" technology, systems and processes will, advance the "state of the art". This process is captured in the attached figure (Figure 2). Note, in particular, that this process implies a long-term industry commitment! This process has no end state, but is instead, a continuous set of actions focused on continuing improvement with respect to the then current "status quo." Note also that no goal is an end to itself, but rather a transient in time, requiring redefinition and refocus as earlier goal objectives are met. 
$n Z 0-\rightarrow \cap D$

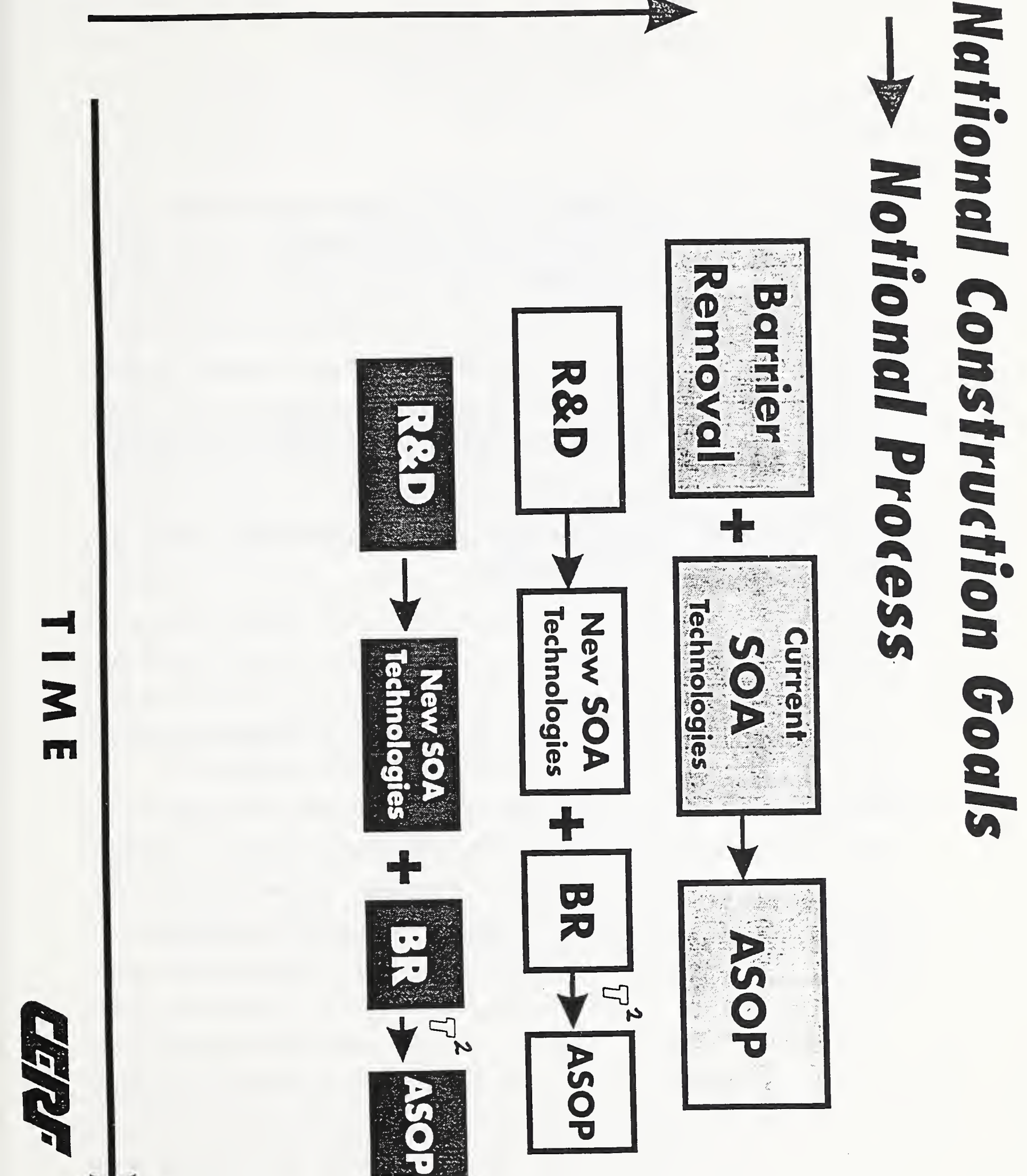




\section{G. Initial Steps}

How do we begin this journey without an end? This workshop is clearly its start. Our initial challenge is to ensure that what emerges from this workshop is a set of templates that define in scope and priority, for each sector, those goals that are relevant as well as the set of actions that are required within each sector, both in the short and long term. Equally important is an understanding of how to most effectively "benchmark" the status quo within each sector so that meaningful planning can be undertaken and, in due course, accurate measurement of progress made. Finally, a template for real industry leadership must emerge, a template that builds upon the strengths that exist in each of our industry sectors and ensures that a more united and pro-active construction industry emerges as a result of this important initial workshop effort.

\section{Conclusion}

It has been noted that our industry combines "art and science" in order to make our "world" habitable. As an industry, we have established an enduring legacy of engineering accomplishments throughout the nation's history; our "value added" goes beyond what statistics alone can portray. We now confront the opportunity to contribute in even greater measure! Let us collectively work to ensure that this workshop is the springboard for a pro-active construction industry that enters the 21st Century as one of the nation's leaders in innovation and productivity. 


\section{White House-Construction Industry Workshop \\ National Construction Goals \\ White Paper}

Untying the Gordian Knot:

Some Thoughts on Liberating the Creativity of

America's Design and Construction Industry

by

Terrence M. McDermott, Chief Executive Officer. The American Institute of Architects

A survey of the current state of America's design and construction industry recalls Lincoln's admonition that "A house divided against itself cannot stand." A house divided against itself is an apt characterization of this country's design and construction industry. Trying to get a handle on what everyone recognizes is a fragmented enterprise is like playing threedimensional chess: Only the devil himself could imagine such a complex way of doing business. The wonder is that we do as well as we do.

But at what cost to the essential process of technological innovation, and at what peril in a global economy where survival of the fittest is the new world order?

It is the contention of The American Institute of Architects (AIA) that the cost today is too high and will be intolerably so tomorrow. We are here because we are concerned that our industry may be poised to repeat the fate of America's steel industry in the 1960s and the auto industry in the decade that followed. We are here also because we believe that by working together and harnessing the enormous creativity and energy of America's design and construction industry, we will be able not only to avert a decline, but to enhance this nation's competitive edge in the critical area of technological innovation. 
Before suggesting some approaches intended to lead to a more healthy, productive, and competitive industry tomorrow, it is useful to recall why the health of the construction industry should be of great concern in the first place, not simply to those who work within our industry, but to the country as a whole.

The Shape of Today's Building Construction Industry:

If the building design and construction industry can be characterized as fragmented, it can with equal validity be described as a powerful engine driving our economy. New construction accounts for eight percent of America's gross domestic product (GDP). Add renovation to the equation and the figure looks more like 13 percent. ${ }^{1}$ Reverse the thrust of this great engine, however, and the ripple effects create an extraordinary drag on our standard of living, as the 1990-93 recession surely made clear.

So it matters very much to the people outside this room how well the industry functions, which is the implicit assumption behind a conference devoted to an assessment of technological innovation. We are talking about our international competitiveness as a nation, our future, our jobs. In considering these critical issues, we would like to focus on that segment of the industry that we know best: namely, buildings.

Like the construction industry as a whole, the building industry is diverse in terms of what it builds. It is also diverse from the standpoint of its many different players, each with their own objectives and needs. We could run the alphabet from acoustical engineers to the producers of zinc-coated products. But for our purposes it is enough to group all the players into three broad categories: project deliverers, project users, and project designers. That is, (1) the producer/suppliers and the constructor/assemblers, (2) the owners and occupants, and (3) the architects and engineers. Within each of these large abstractions-deliverers, users, and designers-is a dense thicket of individuals, entities, processes, and interests. 
Now, let us imagine throwing a large net of dis-incentives over this not-so-small army that comprises the building industry. The strands of this tangled net are well known and have been looked at before. ${ }^{2}$ One particularly interesting study of building materials technology R\&D undertaken for the U.S. Department of Energy laboratory at Oak Ridge identified 27 barriers. ${ }^{3}$ Barriers cited included product liability and tort law uncertainty, the lack of a fundamental science base, the conservative nature of the construction industry, the low level of information exchange between suppliers and fabricators, inadequate coordination between universities and industry, and cyclical market uncertainty.

If the design and construction industry were relatively monolithic in nature, it could possibly break through such a constricting net by its own sheer weight. But the process of shaping America's built environment is carried out by an extraordinary number of small entities, none of which on its own can break through the dis-incentives that are a drag on the entire enterprise. To put this another way, there does not yet exist the critical mass for focus. Nor is there sufficient leadership. Without leadership, rational forward motion of the kind the country needs is not likely to occur.

This unsettling assessment is reflected in the conclusions reached by the Oak Ridge study, which focused on that part of the industry serviced by the building material producer/suppliers: "New commercial buildings, that typically require services from over 50 separate industries, illustrate why focused R\&D efforts (e.g., whole building testing) are virtually impossible to achieve within the private sector....Most private firms will only undertake basic R\&D activities if there are substantial and immediate monetary gains for the firm; this is seldom possible in a fragmented industry such as the building materials industry. ${ }^{n 4}$

\section{The Design Team and Innovation:}

The design team (i.e., the architect/engineer team) suffers from the same disaggregation and dis-incentives to innovation as the building materials community. 
Innovation does take place on a regular basis within the design community as it indeed does throughout the industry. However, it is also true that the pace and breadth of innovation in this country are not proceeding in an optimal fashion. We should regard as a warning and take seriously the fact that the level of R\&D in the design community and the construction industry as a whole is significantly below that of other industries in this country ${ }^{5}$ and well below the level of investment some of our international competitors are making in their design and construction industries. ${ }^{6}$

This, what might be called, suboptimization concerns the AIA not only because we have a responsibility to promote the welfare of our members, but also because the A\&E design team plays a unique role in the process of innovation. It is the strategic link between the project deliverers, on the one hand, and the project users, on the other. As such, the team is in a critical position to take an integrated approach to buildings as systems and to optimize their total performance. ${ }^{?}$

The importance of this position and responsibility, which includes an extraordinary opportunity for innovation, cannot be overstated. The project designers quite literally have a 360-degree field of vision that takes in the entire construction process because they approach innovation from the point of view of both the individual product and the whole building. They are, therefore, an essential link between the project delivery and project use communities. The designers are responsible for selecting the products and systems available in the market to create building designs, for shepherding these designs through the construction process, and for delivering constructed facilities to owners. To do their job, the $\mathrm{A} / \mathrm{E}$ team must understand and coordinate the activities of the producer/suppliers and the constructor/assemblers on behalf of the owners and occupants.

This description of the design team's role identifies it as a central "gatekeeper" to innovation within the entire industry. The A\&E team is, one might say, like the neck of an hourglass, either facilitating the momentum of technological innovation between project delivery and project use or, because the team itself has been constricted, shutting it off. 
Barriers to Technological Innovation:

The question before us now is, "What constricts or inhibits the design team from acting as effective gatekeepers to technological innovation?"

Five critical, nontechnical barriers to innovation have been identified and summarized in the Subcommittee on Construction and Building's document: "Rationale and Preliminary Plan for Federal Research for Construction and Buildings." They are (1) lack of leadership, (2) an inhospitable regulatory climate, (3) the chilling effect of liability, (4) adversarial relationships among the parties, and (5) financial dis-incentives. The AIA believes the Subcommittee's findings are an accurate and useful identification of barriers that inhibit innovation in the design and construction industry as a whole; further, we believe that several of these barriers have particular meaning for the design team.

The ground covered so far by this paper has no doubt offered few if any surprises to the attendees of this conference. There is broad agreement that, for all its creativity and energy, the A\&E team and the industry in which it functions as a "gatekeeper" are not living up to their potential in the area of technological innovation. Moreover, there is likely to be little disagreement with the proposition that we-the industry as a whole, its individual components, and the public all of us serve-cannot afford to continue to conduct business as usual if we are to maintain and sharpen our technological edge in an unforgiving global economy.

The AIA sees this conference as an important opportunity to go beyond an enumeration of the problems we face. With all the talent assembled in this place, we are challenged to engage in creative and informed discussion over the next two days that will lead to recommendations for specific actions. In the course of going from where we are now to where we can and should be, the AIA would like to pose several "what if" questions and then make a recommendation for action that the Federal government can take in the near 
term to help untie the knots that are currently holding back the industry. Again, our perspective will be that of the design team dealing with buildings because this is what we know best.

Breaching the Barriers:

\section{Codes and Regulations}

The category of barriers upon which everyone seems to readily agree is the building codes and regulations environment. A building regulatory process that protects the health and safety of the public is of course a necessary and desirable thing. But a process that is so labyrinthine, contradictory, and confusing that it chokes innovation is a problem. Indeed, many in the industry put regulatory barriers on the top of their list of the obstacles to overcome.

Over 44,000 code-enforcing entities exist in the U.S. alone, and together they form the maze through which the industry has to pass when it delivers its product. Although states have the authority to administer building codes, the actual administration of these codes tends to occur at the level of the local municipality. Not surprisingly there are often different positions taken on the same issue from one jurisdiction to the next. ${ }^{8}$ For the industry, it the world's biggest crapshoot.

Working in an environment where local, state, and federal regulations overlap can entail wasteful expenditures of time and money; it can also lead to costly over design. Time is also lost if one chooses to go through the process of seeking a variance. Even the task of getting a clear interpretation or technical assistance can be complicated by the fact that building officials are not required to have professional training as architects or engineers. 
One consequence of confusing and contradictory regulations that are unevenly applied is a chilling effect on innovation. It can be unduly difficult to specify innovative, one-of-a-kind products that have no equivalent in the marketplace or products that have gotten stuck in an unreasonably protracted process of testing and approval. Rather than specify innovative products, designers are put in a position of having to call for an old, familiar product or approach, even when they know that something else will perform better.

- What if mutually-contradictory regulations could be harmonized?

- What if we had one, consensus-based, national building code?

- What if we required licensing, including continuing education requirements, for all building officials?

\section{Liability and Adversarial Relations}

The barriers represented by liability issues and adversarial relations have become major, industry-wide problems in the last several decades. In former times, the threat of liability, for example, was never the threat to technological innovation it is today. We have come a long way from the friendly handshake or even the occasional duel, which could at least be counted on to resolve conflicts among disputants in relatively short order.

The construction industry has always been a fertile ground for disputes, but never more so than at present. Today, the atmosphere in which we work is heavy with an adversarial smog that hangs over a cycle of mistrust among the parties involved in a building project, and this in turn stifles a willingness to take reasonable risks on behalf of innovation. What we see is a conservative, risk-averse climate that inhibits innovation by all but the most tenacious and well-capitalized. ${ }^{9}$

Interestingly, a statistical overview of legal claims brought against the design community in the last 30 years points on the face of it to a situation that appears to be improving. ${ }^{10}$ The overview shows that legal claims against architects and engineers grew markedly after 1972, 
reaching a high of 42.1 claims per 100 firms in 1983. In the next ten years from 1983 to 1993, there was a 35 percent decline to 26 claims per 100 firms. In 1992, over 50 percent of the claims were brought by project owners, and 11 percent were brought by contractors and subcontractors. And in the overwhelming majority of cases, the design professionals are exonerated from liability.

What these statistics do not tell us, however, is how much it cost to defend even those cases that the design professionals win. Nor do they tell us the extent to which the commonplace perception of the legal liability issue is characterized by deep and widespread concern. The threat of liability has caused owners, architects, engineers, contractors, and others to react defensively. Risk shifting and risk avoidance by all players on construction projects became epidemic in the 1980s, nor has this pattem has by any means gone away. Caught between the hammer and the anvil of deteriorating relationships, on the one hand, and the threat of legal liability, on the other, many design teams have withdrawn from the innovative to more conservative and seemingly safe ground. Some innovation still takes place despite this situation, but one can argue that many more ideas vanish untested because of the fear engendered by liability concerns.

- What if joint and several liability were eliminated on building projects?

- What if workman's compensation laws were reformed?

- What if "wrap-up insurance," paid for by building owners and covering all members of the project team were applied to construction projects?

- What if an integrated, whole building design did not need to be subject to a piecemeal and adversarial approach to procurement and construction?

- What if true partnering could be achieved, from preliminary design through commissioning and use? 


\section{Financial Dis-incentives}

If creativity is the engine that drives the $A \& E$ team, there is no question that compensation is the lubricant. Any discussion of the barriers to innovation must inevitably reckon with the hard fact of financial dis-incentives."

The standard set of basic architectural services consists of five things: schematic design, design development, construction documents, bidding/negotiation, and construction administration. These basic services begin when the architect is handed a program statement; they terminate when a building official signs off on a certificate of occupancy.

It is important to note that the basic services do not speak explicitly to questions of building performance in terms of overall life cycle costs or conditions for the user. Nor do the basic services entail long-term responsibilities for maintenance or for post-occupancy evaluation.

In order to receive more than what can be provided in basic services alone, one needs to contract for "additional services." These are services that typically take place at the predesign stage (e.g., feasibility studies, site selection studies, planning, programming, and so forth), or after construction is complete. Additional services may also run concurrent with basic services when, for example, special tests of materials or systems are conducted for the purpose of evaluating a new design approach.

So far so good, at least in theory. Unfortunately, however, the realities of the design and construction marketplace, as well as some standard procurement practices, are constraining and cutting back, not extending, the A\&E services that could be provided, but that are increasingly remaining untapped.

The key obstacles to overcome here are the "lowest first cost" mentality and a prevailing tendency among many building owners to think in short range, quick pay-back terms. The "lowest first cost" approach often precludes any consideration of additional services and it 
can hamstring the A\&E team's ability to perform so severely that it amounts to a financial dis-incentive to the successful provision of even basic services. The design team can only do so much with less and less.

Different types of building owners have different investment "profiles" or "horizons," to be sure. The institutional or public sector owner may be more inclined to think in long-range, full life cycle terms than the developer of a commercial building who requires a certain rate of return within five years. As a general rule, however, the near-term, short-range way of thinking prevails as a factor that undermines the design and construction practices that would lead to better, more innovative building.

The net results are serious. The A\&E team is not able to develop qualitative improvements that can increase the durability and flexibility of a building; there is no encouragement to experiment with the kinds of materials, systems, or techniques that can facilitate upgrading or recycling at a later stage; and there is certainly no consideration of approaches that might entail higher capital costs at the front end, even though such an investment would lead to real savings over the long term.

- What if life cycle analysis completely replaced first cost analysis for all design and construction decisions?

- What if building performance became the key metric, not building cost; in other words, what if our approach to project delivery were value-based, rather than first cost based?

- What if A\&E fees were performance based, rather than first cost based?

The Role of the Federal Government:

At this point, we have reviewed the state of today's construction industry and its relation to technological innovation; we have limited the discussion to buildings; and we have narrowed the focus further by concentrating on the A\&E design team. Along the way, we have 
advanced the proposition that the design team is a key gatekeeper to technological innovation by virtue of its unique role relative to all of the other parties in the process of delivering and using a building. We then noted in a brief overview that various barriers to technological innovation have an especially negative impact upon the gatekeepers. We also asked a number of "what if" questions that we hope will be considered in the next two days with the goal of arriving at specific recommendations that we, in partnership with the Federal government, can work to advance.

The recommendation that we favor is the full development and implementation of an idea which, although it is not original to us, strikes us as a very promising beginning. It is the idea that calls for using the Federal building stock as a "laboratory" for innovation.

The Federal Government controls an enormous stock of buildings that should be regarded as an extraordinarily valuable resource. If the Federal Government is truly committed to spurring technological innovation, what better way to do it than to utilize this resource to test promising technological developments? What more obvious route to explore methods of overcoming the regulatory hurdles, liability concerns, and adversarial relationships that currently constrain the industry?

The vast inventory of buildings owned or leased by the Federal Government should serve as a source of "test beds" where "real world, " project-specific research into innovative products, design, or construction methods can be undertaken. The research would pertain directly to the building in question, but would ultimately be broadly applicable to other buildings. Where applicable, innovations resulting from the research would be incorporated directly into that particular "test bed" site. If no feasible innovations are found after conducting the research, the reasons why would be documented in a report to the sponsoring agency.

These field-based, project-specific research efforts would constitute a working "laboratory" where it would be possible to monitor the performance over time of an experimental or 
prototypical material, system, or process, and where one could go to "kick the tires" before deciding to take the same approach with one's own building. Indeed, the inventory of existing building stock requiring rehabilitative or retrofit work of some kind may present special opportunities for research on behalf of innovation, if only because the amount of money involved is likely to be far less than that required for the new construction of an entire building.

This recommendation that "test beds" be developed is consistent with Executive Order 12902 issued on March 8, 1994. ${ }^{12}$ Entitled "Energy Efficiency and Water Conservation at Federal Facilities, "this Executive Order has potentially far-reaching provisions that deserve to be noted in detail. Both the letter and the spirit are significant.

The Order aims at achieving a 30 percent reduction in energy consumption over the next ten years, and an implementation program designed "to speed the introduction of cost-effective, energy-efficient technologies into federal facilities." By March 1995, each agency is to have identified its "high priority" facilities and have completed "comprehensive facility audits" for the first ten percent of its inventory. Thereafter, ten percent of its inventory is to be audited each year.

Part Three of the Executive Order goes on to state that the "goal of the Federal Government is to significantly increase the use of solar and other renewable energy sources," and that each agency shall "design and construct new facilities to minimize life cycle cost" and "ensure that design and construction...meet or exceed energy performance standards." New leases for existing facilities are required to incorporate provisions "that minimize energy costs under a life cycle analysis."

In addition, "New Building Showcases" are to be developed: "When an agency constructs at least five buildings in a year, it shall designate at least one building, at the earliest stage of development, to be a showcase highlighting advanced technologies and practices for energy efficiency, water conservation, or use of solar and other renewable energy." Regarding the 
existing building stock, each agency is obliged as well to "designate one of its major buildings to become a showcase...."

Part Four of the Order is especially noteworthy. Under the heading, "Use of Innovative Financing and Contractual Mechanisms," agency heads are instructed to "utilize innovative financing" and contracting, to eliminate "unnecessary regulatory and procedural barriers that slow the utilization of such audit, financing and contractual mechanisms or complicate their use," and to "work with their procurement officials" to carry out the mandate. They are to "develop procurement techniques, methods, and contracts to speed the purchase and installation of energy, water and renewable technologies."

Part Five of the Order includes a directive to the DOE and others to "issue a Federal Procurement Challenge inviting each Federal Agency to commit a specified fraction of their purchases within a given time period to advanced, high-efficiency models of products."

We applaud these initiatives as real and significant movement in the right direction. We also believe they should be carried one critical step farther: We would like to broaden the thrust of the initiatives beyond energy-related issues and apply the same mandates in pursuit of innovative products, design, or construction methods in other areas. We believe that the improved financing and procurement techniques should include dedicated set-asides to underwrite research, and that there should be requirements to pursue commercial applications of successful innovations in a manner similar to those stipulated in the National Aeronautics and Space Administration (NASA) contracts of some years ago.

These Federal initiatives should recognize the key role played by the design team in fostering innovation by providing the team with the financial and contractual latitude necessary to explore and implement technological innovations in new or existing Federal building projects. The funds needed to accomplish this could be earmarked in the manner of the one percentfor-art set-aside, or in the form of a subsidy, or in the form of an additional quarter-point or half-point on the A\&E team's fee for the work. 
Whatever specific mechanism were chosen, the critical question of financial incentives for research and development would be addressed.

\section{Leadership and Partnership}

Still missing is the leadership needed to make these initiatives truly effective. Here the Federal Government has a vital role to play - a role undertaken in active partnership with the professional societies and associations that represent the building industry. Indeed, whether the "testbed" concept or some other pilot project is launched, such a partnership will be essential to its success. Without it, the crucial leadership question and the focus that such leadership needs to provide will remain unresolved.

The partnership we have in mind will work to accomplish at least two things: First, it would coordinate the program and the activities in the field, specifically including the recording and archiving of the results at the individual testbed buildings. The information generated will be extremely valuable, not only to the Federal Government and the nation as a whole, but specifically to the various members of the professional societies and industry associations involved.

Second, the partnership will play an active role in setting the overall agenda for the program, that is, guiding the goals and the objectives of the innovations pursued in the field. This does not mean getting involved in the specific innovations themselves, but rather keeping a clear eye on the larger goals to be achieved by the buildings that incorporate innovations. For potential goals in this area, we can begin with the recommendations identified in the course of this symposium.

As the Federal Government prepares to play its leadership role, we at the AIA are ready to do our part. We are committed to work over the long term with our public and private partners in government and industry to build a program that strives for the day when we are no longer a house divided. 
1. Civil Engineering Research Foundation (CERF), "Innovation in the U.S. Construction Industry: An Essential Component for America's Economic Prosperity and Well-Being. A Construction Industry White Paper", April, 1994, p. 36.

2. See especially two volumes from the Studies in Management of Building Technology series of the Building Research Board, National Research Council, The Role of Public Agencies in Fostering New Technology and Innovation in Building, edited by David R. Dibner and Andrew C. Lemer, 1992, and The Fourth Dimension in Building: Strategies for Minimizing Obsolescence, edited by David G. Iselin and Andrew C. Lemer, 1993. See also the earlier study, "Building for Tomorrow: Global Enterprise and the U.S. Construction Industry", National Academy Press, Wash., D.C., 1988, pps. 85-104.

3. Oak Ridge National Laboratory, "U.S. Building Materials Industry: R\&D Barriers Assessment", prepared for the U.S. Department of Energy, Conservation and Renewable Energy, Office of Buildings and Community Systems, Building Systems Division, ORNL/Sub/88-SB964/1, September, 1989, Section III and passim.

4. Ibid, p. II-17.

5. CERF, "White Paper", p. 37.

6. Dibner and Lemer (Eds.), Role of Public Agencies, p. 37.

7. A striking example of how the design team can function as a catalyst and conduit for innovation by all members of the project team, from building product manufacturers to constructors, is the role played by Burt Hill Kosar Rittelmann Associates (BHKRA), an architecture, engineering, interior design, and research firm. The firm works with four other core partners (USG, Ryland, GE Plastics, and Masco) in a Pittsburgh-based consortium, 
IBACoS. Associate members are Honeywell, Inc., Molex, and GE Appliances. With ideas stimulated by designers, IBACoS is pioneering new products, services and processes designed to produce significant energy efficiencies and construction savings for housing.

8. Dibner and Lemer (Eds.), Role of Public Agencies, pps. 25-7. See also the collection of 26 papers compiled under the heading, "Research and Innovation in the Building Regulatory Process", proceedings of the first national conference, September, 1976, sponsored by the National Conference of States on Building Codes and Standards (NCSBCS) and the National Bureau of Standards (NBS), NBS Special Publication 473, Wash., D.C., 1977. The AIA has officially endorsed the development of a single, consensus-based, national building code since 1991. For a look at the single code issue as it has developed since the 1930s, see the discussion prepared by the Institute's Building Performance and Regulations Committee, "Evolution Towards a Single Building Code for the United States", April 12, 1994.

9. There are some noteworthy efforts underway now to break the cycle of adversarial relations and liability, and to reduce both as barriers. Those efforts include "partnering", a new and formalized method originated by the U.S. Army Corps of Engineers for establishing good working relationships among the principal participants on the construction project. There is also the use of ADR, or "alternative dispute resolution", in lieu of litigation. Today, we are using a variety of methods, including mediation, dispute review boards, and mini-trials. We are encouraged to hear that the Federal agencies are now considering ADR, although not all of them as aggressively as the Corps of Engineers has adopted partnering. For more on the subject, see Technical Reports 118 and 126 of the Federal Construction Council, "The Use of Partnering in the Facilities Design Process. Summary of a Symposium", 1994, and "New Tools to Achieve Client Satisfaction in Building Design. Summary of a Symposium", 1992, National Academy Press, Wash., D.C. 
10. These data are compiled by the AIA's commended Professional Liability Insurance Program available from Continental Casualty Company, a CNA Insurance Company program administered by Victor O. Schinnerer \& Company, Chevy Chase, Maryland.

11. For a more full discussion of the impact of financial disincentives on design services, see the "Background Paper" prepared by Donald Watson, FAIA for the AIA/Energy Foundation Roundtable, "Performance-based A\&E Compensation and Other Energy Efficient Design Practice Options", January, 1994.

12. The full text of the Order appears in the Federal Register. For a concise survey of a variety of relevant legislative and regulatory actions over the last several decades, see Appendix D, "Federal Laws and Regulations Related to Technological Innovation in Building", in Dibner and Lemers (Eds.), Role of Public Agencies, pps. 87-90. 


\title{
National Construction Building Goals:
}

Housing Industry Sector Perspective

\author{
by \\ Liza K. Bowles. President \\ Burton Goldberg. Program Manager, Advanced Housing Technical Programs \\ NAHB National Research Center
}

\section{Background}

Research-based advances in building technology combined with a program that aggressively addresses selected economic, management, social, and institutional issues can reduce the physical costs associated with housing production.

For home builders, the increased cost of housing, particularly starter homes, constrains the market for new homes as builder margins are threatened. The lack of affordable housing means that consumers with extremely limited income cannot obtain decent housing without hardship and that prospective homebuyers with modest income and middle-class aspirations may not be able to achieve the American dream of homeownership. In fact, the nation's rate of homeownership declined in the decade between 1980 and 1990, providing dramatic evidence of the increasing difficulty experienced by consumers in meeting the cost and expense of homeownership.

If the housing industry in the United States is committed to reducing costs and improving affordability, then it must markedly increase its level of investment in research and development (R\&D) to improve productivity. When productivity increases, more homes can be produced from a given set of factors of production (labor, materials, equipment, and land). Entrepreneurs such as builders, the trades, manufacturers, material producers, wholesalers, and retailers then reap the rewards of higher net returns. A National Research Council study found that the lack of increase in construction productivity was related to the low rate of investment in R\&D. 
Moreover, technological innovation, by reducing time spent on the construction site, limiting the effects of seasonality, and improving management and scheduling, can have a significant effect on the "soft" costs related to construction interest rates and administrative overhead, which now account for almost 50 percent of total housing costs.

\section{National Construction Building Goals for the Housing Industry}

\section{Goal 1 -- 50 Percent Reduction in Delivery Time}

Given the state of current technology, an ideal but achievable construction cycle-time goal for onsite builders is 63 work days ( 88 calendar days) for a 2,000 square foot house from foundation excavation through finishing work and presettlement. This goal is derived from a pilot benchmarking study of best-practice construction cycle times of innovative, on-site home builders and modular housing manufacturers. A recommended ideal but realistic construction cycle-time goal for modular builders is 28 work days ( 42 calendar days), a 56 percent reduction in the number of work days required to site build the house under the most favorable conditions.

According to the benchmarking study, innovative builders combined a variety of new processoriented management techniques with innovative technology to overcome barriers to rapid construction. Best practice ranged from 58 to 88 work days depending on the size of the house. For complex operations with multiple sites, innovative builders expedited operations by tracking operations, solving problems, and adjusting schedules daily instead of weekly. Expedited operations took advantage of computers and telephone and facsimile interconnection services, which automatically and instantaneously updated project status. Other innovative practices included concurrent scheduling of activities; reduced "wasted time" or gaps between subcontractor activities; use of precoded purchase order system and just-in-time procedures; and reliance on variance purchase orders to speed budgeting and purchase of materials for correcting variances.

Shorter cycle times were associated with improved quality and increased customer satisfaction, which led to more customer referrals, an improved builder reputation, and greater profitability. 
Two of the most innovative builders found that the number of units sold and their respective market shares increased over a two-year period, placing them number one and two in the Atlanta metropolitan market.

Best practice of innovative modular manufacturers ranged from nine to 38 days. Impressive throughput speeds in the controlled factory production environment that ranged from 2 to 10 days and averaged 6.5 days were the main factors that contributed to modular manufacturers' short cycle times. Manufacturers achieved these times by performing construction tasks concurrently, accomplishing all possible cutting and assembly work off line, and focusing production line activities on making connections.

Despite such improvements in the construction process, delays due to zoning approval, code inspections, problem site conditions, supplier tardiness in fulfilling orders, and inclement weather are examples of activities and events that do not add value to the construction process. Instead, they pose significant barriers to speedy and efficient production. Delays related to weather and site problems may be avoided by technological innovation, but other delays and occurrences are extremely variable and dependent on external factors beyond the control of the builder.

The complicated distribution system for housing materials and components as well as the cumbersome, complex regulatory procedures associated with land development and building code approval merit further study for their impact on cycle time and construction costs. Protracted and duplicative state and local administrative reviews and approvals, particularly environmental reviews, lack predictability and certainty and provide for excessive administrative discretion. Consequently, substantial and measurable costs are added to projects and, ultimately, are passed on to the homebuyer. It is not uncommon for many subdivisions to experience three- to four-year delays because of these factors.

Innovative firms selected for the benchmarking study were chosen for their scrupulousness in tracking and recording data related to scheduling. Preliminary reconnaissance in the benchmarking study indicated that scheduling data were not systematically tracked or maintained 
by most builders, a necessary first step in improving delivery time. Data on planned versus actual time of construction would be ideal for measuring cycle time, but no builder maintained such data. It is anticipated that lack of metrics in the home building segment of the construction industry will be a major barrier to improvement of cycle time. Small, entrepreneurial firms that produce less than 11 units a year account for 61 percent of all production and are notoriously poor data collectors. On an encouraging note, computer usage among builders, however, has increased markedly in the last five years to 81 percent in 1994 . Yet, there is no indication that builders use computers for scheduling activities associated with delivery time.

\section{Goal 2 -- 50 Percent Reduction in Operations, Maintenance, and Energy Costs}

Operating costs are consistently higher as house age increases. Data from the Census Bureau's 1991 American Housing Survey indicate that during 1990 the annual average operating cost for new homes was $\$ 2,874$, about 21 percent less than homes built in the 1960 s. For the most part, major components of operating cost for new homes fare well in comparison to older homes. Components include utility costs (fuel, water/sewer/trash), maintenance costs (routine maintenance, repairs/replacement), and property insurance. Utility and maintenance costs steadily decline with newer housing while the cost of property insurance increases slightly.

More detailed components of cost generally mirror the decline in the operating cost of newer homes. Relative declines for routine maintenance and repair/replacements are substantial compared to relatively small declines for fuel. The one exception to general trends is the cost of sewer/water/trash, which is consistently higher in newer homes except for a slight decline for homes built in 1990. When costs are related to the square footage of living space or to each $\$ 100,000$ value of housing, greater decreases in operating costs occur despite the increased size and value associated with newer housing.

The data clearly show that a new home with improved technology may be less expensive to operate than an older home and that conversely, homes become more costly to operate as they age. Certainly, the level of required maintenance and number of repairs are likely to increase 
with the age of the house. That these trends occur despite the increase in the size, complexity, and value of newer houses suggests that some independent variables associated with changes in use patterns may also be at work to produce declines in new home operating costs. For example, efforts to conserve resources, particularly energy, may result in declining use in larger, more expensive, and newer homes occupied by higher-income residents. The factors of innovation and use, however, do not appear to have led to reductions in the cost of water/sewage/trash services.

Data indicate that the decline in fuel costs are not due to a particular energy source or location in a particular region but rather support other information that points to the increasing energy efficiency of homes. Energy consumption per square foot depends on a unit's size, structural insulation, quality of windows, air leakage, and heating and cooling equipment. Improvements have occurred in all these factors, and, although newer units tend to be larger, the exterior surface area responsible for heat and air-conditioning losses has increased proportionately less than interior floor area.

A study of energy conservation trends by the Office of Conservation and Renewable Energy of the U.S. Department of Energy indicates that in 1986 the residential sector, which accounted for 21 percent of total U.S. energy use, contributed 34 percent to energy savings, conserving proportionally more energy than any other sector of the economy. Another study of energy use by the U.S. Congress Office of Technology Assessment indicates that although energy use increased between 1970 and 1989, energy intensity or energy consumption per household per year actually decreased by 15 percent in the same period. The primary reason is improved technology and building practices. Specifically, older houses were retrofitted to improve energy efficiency, newer houses made increased use of energy-efficient building practices, and the energy efficiency of equipment used in homes improved dramatically. Yet, the improvements in the existing stock of older homes have yet to equal the efficiencies of new homes. Evidence indicates that lower-income residents in older housing units have the most to gain from lower heating and cooling costs but are often the least likely to adopt energy conservation measures. 
The high first cost of more efficient, energy saving equipment often contributes to longer-thanacceptable payback periods for the consumer and thus represents the principal barrier to further energy conservation in the housing industry. Further, given that energy costs have remained relatively stable in recent years, incentives to conserve energy have diminished. Moreover, home builders see their market for new homes shrink as the costs of compliance with increasingly stringent energy codes contribute to higher housing production costs.

In contrast to energy costs and consumption, trends in the cost of residential water use have not been as favorable. Residential water service is costly. It must be supplied from a reliable source; treated to standards of potable quality; and often heated, pumped, and treated again as wastewater. The large infrastructure of reservoirs, treatment plants, and distribution systems necessary to provide quality water to urban and suburban users is expensive to build and maintain. Many of the older distribution systems are severely deteriorated and contain lead service mains that are extremely durable but increase lead levels in the public water supply.

In summary, although data indicate that new homes compare favorably with older homes for most components of operating and maintenance costs, particularly energy, more potential for improvement exists in utility costs such as trash and sewers, particularly water.

\section{Goal 3 -- 30 Percent Increase in Comfort and Productivity}

Comfort, according to a 1981 American Society of Heating, Refrigerating, and Air Conditioning Engineers (ASHRAE) definition, is "the state-of-mind that expresses satisfaction with the environment." The ability of a house's indoor environment to provide satisfaction depends on the physical factors of temperature, humidity, ventilation, air velocity, odor, lighting, and noise, all of which can have an important effect on productivity. The factors that define thermal comfort depend on the thermal characteristics of building materials such as thermal conductance, thermal resistance, and thermal mass as well as on the capacity of the heating, ventilation, and airconditioning (HVAC) system. Visual comfort is dependent on the location and photopic intensity of artificial and natural light sources in the building envelope and the spectral reflectance of 
various paints and materials. Acoustical comfort depends on absorption, reflection, uniformity, and reverberation characteristics of building materials and structure.

Comfort is measured by asking occupants to rate their satisfaction with a specific environmental factor over a range of settings while controlling other variables. Satisfaction, then, is commonly expressed as the percent of people satisfied at a given setting of that variable. Perception of comfort varies depending on individual physiological and social factors. Given differences in preferences, it is impossible to create an environment that satisfies everyone at the same time. For example, dissatisfaction, at a minimum, typically equals 5 percent and may never fall below 20 percent. Satisfaction with various combinations of factors associated with thermal comfort has been expressed in a single equation (Fanger) in terms of Predicted Mean Vote (PMV) or the Predicted Percentage of Dissatisfied (PPD). Little research has been conducted into ways of using these measurements on a scale that has statistical significance for the residential sector.

Productivity of the occupant of a house or household, on the other hand, is difficult to define and almost impossible to quantify. The house supports the productivity of inhabitants by contributing to their social and psychological well being with respect to child-rearing activities, food preparation, privacy, recreation and, increasingly, occupation-related as well as personal business needs. For example, according to the U.S. Bureau of Labor Statistics, of 21.8 million people who performed all or some of their work at home in 1991, a little less than 20 percent performed all their work at home. Housing innovation and/or increased comfort cannot only increase household productivity by decreasing the cost of inputs of equipment, labor, and material related to child care, recreation, privacy, and/or business needs, it can also decrease time and convenience costs associated with those activities. Indeed, the increase in the number of two-wage-earner households means that occupants place a greater value on time for various home activities, including leisure pursuits. Automation can increase household productivity by either increasing convenience or reducing the time required for productive activities, thereby increasing the household's available leisure time. Measurement of most of these forms of productivity in the residential sector is, however, difficult. 


\section{Goal 4 -- 50 Percent Fewer Occupant-Related Illnesses and Injuries}

Fire in residential homes is a significant cause of occupant deaths, injuries, and property loss, but the overall number of fires, fire-related deaths, and injuries declined from 1984 to 1993. In 1993, fires in residential structures accounted for about three-quarters of all structural fires, representing a 0.4 percent decrease from 1992. The number of fire-related deaths in homes in 1993 accounted for 80.2 percent of all such deaths in structures but still remains well below the plateau achieved between 1982 and 1988. Residential properties were the site of 74.1 percent of all fire-related injuries in 1993. Moreover, 65 percent of all fire-related property losses were residential, a significant portion of which were attributable to wild fires in California.

Given that the residential sector appears at high risk for fire, several prevention strategies have been posed by the National Fire Prevention Association: stepped-up fire safety education, programs to encourage use of smoke detectors, improving the fire safety of home products, and promoting the wider use of residential sprinklers. The high cost of residential fire sprinklers, about $\$ 2,000$ per dwelling unit, is one more factor that threatens the affordability of homes and is a principal obstacle to home builders' or owners' specification of sprinklers in both new and existing construction. In addition, the high first cost of housing components such as sprinkler systems may actually have the unintended effect of keeping people in older, less safe housing.

The controversy over the nature, extent, and causes of health complaints associated with indoor air pollution and the difficulty of assigning responsibility and means of administering any indoor air quality (IAQ) regulation in private homes mean that it is unlikely that mandatory IAQ standards for residences will be implemented in the near future. Major contributors to residential indoor air pollution are combustion sources such as defective or unvented fuel-burning appliances or space heaters and tobacco products such as cigarettes; volatile organic compounds (benzene, formaldehyde) found in some particleboard, cabinets, floor coverings, solvents, and adhesives; particulate matter from microorganisms, spores, fungi, and dust; radiation in the form of radon gas from soil underlying the home; and contaminants from the outdoor air. 
The principal combustion sources of pollution in the home produce carbon monoxide, nitrogen dioxide, and particles from smoke. Carbon dioxide and water vapor, byproducts of combustion are not considered indoor air hazards. Pollutant emission rates vary by age, brand, and model of combustion appliances and are determined by source strength, air exchange rate, house volume and rate of mixing, and concentration of pollutants in outdoor air. Reasonable residential pollutant levels from combustion sources are usually one-tenth that of occupational standards, although soil radon gas levels can be highly variable between measurement points, even within a few feet of each other. Variation in radon levels occurs with depth, differences in geology and soil moisture, and climatic factors such as temperature and barometric pressure. For example, a geological formation extending from Reading, Pennsylvania, to Newburgh, New York, the socalled Reading Prong has produced elevated radon levels in a large proportion of homes not found in homes in adjacent areas.

Exposure to oxides of nitrogen above $25 \mathrm{ppm}$ can be dangerous, but typical nitrogen dioxide concentrations in homes fall well below $25 \mathrm{ppm}$, and are rarely greater than $1.0 \mathrm{ppm}$. Ratios of indoor level of carbon monoxide $(\mathrm{CO})$ that are four times that of outdoor levels $(\mathrm{I} / \mathrm{O}$ ratio $=4)$ can be harmful. Although concentrations of $50 \mathrm{ppm}$ have been found in some kitchens, I/O ratios of $\mathrm{CO}$ for houses are usually closer to 1 . Suspended particles range from 0.01 to 20 micrometers, but respirable suspended particles (RSP) less than 10 micrometers, particularly those less than 2.5 micrometers, can damage health. RSP concentrations in residences are usually close to the outdoor concentration.

Technology offers opportunities for cost-effective abatement of the harmful effects of indoor air pollution by finding substitute materials, adopting physical methods of mitigation such as filtration or electrostatic precipitation, using mechanical systems such as ventilation for dilution or exhaust, and developing cost-effective sensing systems for measurement and detection. In extremely tight houses, natural ventilation rates which are dependent on outdoor temperature and vary over time may not sustain minimum ASHRAE guidelines for ventilation. Mechanical ventilation is a costly alternative that imposes high energy penalties. Although adding heat recovery lessens energy losses, high first cost is a barrier to adoption by home builders and owners. Currently, however, 
there are no inexpensive or readily available methods for use by homeowners to measure precisely or estimate accurately the levels of most combustion-generated pollutants in their homes. It is not surprising, therefore, that the distribution of combustion-generated and other indoor air pollutants in the U.S. housing stock, except possibly radon, is not well known. Even less information is available on the illnesses that result.

\section{Goal 5 -- 50 Percent Less Waste and Pollution}

Innovation can play an important role in a number of strategies for dealing with the environmental impact of residential waste disposal practices and other forms of pollution. Construction and demolition (C\&D) waste accounts for more than 20 percent of the 225 million tons of waste generated annually in the United States. Further, it is estimated that construction of an average single-family house can yield over seven tons of debris. In addition, the housing industry may soon be confronted with the task of preventing the continued emission and accumulation of such greenhouse gases as carbon dioxide, methane, chlorofluorocarbons (CFCs), nitrous oxide, and ozone, all of which are said to contribute to global climate change.

One strategy for waste disposal is prevention, which calls for reducing the construction waste stream by extending the useful life of building products (see Goal No. 6 related to durability). Another approach emphasizes innovation in the construction process to avoid errors and the improper dimensioning of materials that results in waste. Other measures reduce the amount of packaging for housing components and materials. An entirely different strategy focuses on waste recovery rather than waste reduction. It encourages the use of materials that can be recycled and reused for other productive purposes and therefore do not contribute to adverse environmental impacts or disposal problems. Technology can change the composition and type of materials used in housing so that such materials become suitable for recycling and application in other products. Given that residential buildings consume a large volume of materials, they represent an important outlet for the nation's recycled products. With the aid of technology, byproducts such as fly ash, which poses a serious disposal problem for the electric power industry, may well find productive and economic uses in the housing industry. 
While considerable debate persists as to the seriousness and timing of global climate change, the destructive effects of CFCs and hydrochlorofluorocarbons (HCFCs) in the stratospheric zone are well documented. Controls on CFCs, fossil fuels, and the burning of wood will force the development of new forms of CFC-free insulation and air-conditioning systems, gas-fired heat pumps, and on-site generators. Benign distributed sources of power for housing that use renewable resource, in the form of passive and active solar energy systems and photovoltaics can also reduce dependence on polluting and expensive fossil fuels. The commercialization of these new technologies, however, often requires their production at a premium to cover development costs. The resulting high first costs could prove a barrier to adoption by home builders and owners. Moreover, a ban on CFCs and HCFCs could eliminate some of the most energy-efficient and cost-effective building insulation materials. Buildings are a major market for products using CFCs; foam plastic insulation accounted for 15 to 17 percent of the estimated 1.6 billion pounds of CFC production in the United States in 1986.

As the population increases, the demands for fresh water for a variety of uses will likewise increase. At the same time, currently available resources may become more limited owing to the widespread adoption of land use, growth, and siting controls that deal with dispersed sources of pollution such as urban and agricultural runoff, the protection of major sources of groundwater from contamination, and the maintenance or protection of entire watersheds, including wetlands and forested areas. As a result of such restrictions, almost every region of the country could become susceptible to the prospect of periodic drought. Regulation may therefore shift to controlling the consumption of water through mandatory water conservation measures.

Traditional efforts to conserve water in the residential sector have been associated with inconvenience, poor service, and substantial changes in lifestyle such as half-flushed toilets, brown lawns, and reduced shower water pressure. As a result, these efforts have met with stiff resistance from consumers. Moreover, using recycled "grey water" for nonpotable purposes in the home remains controversial. Despite these barriers, the residential sector of the economy compared to other sectors of the economy is more concentrated, generally accessible, and relatively uniform due to the imposition of plumbing codes. Further, technological advances in 
the development of low-flow toilets, showerheads, and faucets now offer improved performance without compromising comfort. Although residential water efficiency projects have proved that they have the potential to pay for themselves, the new technologies have yet to be adopted on a massive scale.

The 1990 Census indicates that 25 percent of existing housing is located in areas without public sewers. Moreover, census figures show a nationwide 15 percent increase in unsewered units between 1980 and 1990. A substantial unsewered population exists in states where most homes are sewered. For example, although 80 percent of the homes in New York and California are sewered, these states have 1.51 and 1.16 million unsewered homes, respectively. Builders and homeowners in these areas rely mainly on conventional septic tank/soil absorption systems for sewage disposal, although only about 32 percent of the total U.S. land area is suitable for such systems. Large areas of unsuitable soil conditions combined with the extent and growth of unsewered housing merit the investigation and development of improved on-site wastewater treatment and disposal technologies.

\section{Goal 6 -- 50 Percent More Durability and Flexibility}

It is noteworthy that despite the low level of technological advancement in houses built 50 or more years ago, such houses constituted 23 percent of the existing housing stock in 1990. Although many components in these homes have since been added or replaced, the original foundation or frame largely remains in place. In addition, the average life of some housing components has increased during the past 20 years because of innovation and the introduction of new products even as the life of other components has declined.

Some observers say that life expectancy is the result of technological factors, the economics of production, or the willingness of customers to pay for quality, while others assert that durability is the conscious choice of the material producer or manufacturer and can be the result of planned obsolescence. Certainly, some products remain functional but become obsolete due to changing styles, tastes, or new technology. Manufacturers or material producers, on the other hand, often 
claim that durability depends largely on how a material or product is installed, used, or maintained.

The durability of a material or product is defined by its ability to withstand weathering action, chemical attack, abrasion, and a long period of use that results, for example, from human and mechanical traffic. Whatever contributes to durability, durability is known to be closely related to other elements of functionality such as moisture resistance, which is the ability to resist dampness, water, vapor penetration and related decay; reliability, which is the ability to perform consistently to certain standards; and strength, which is the ability to withstand bending through compression, tension, or shearing stresses.

In contrast, flexibility is less precise and more difficult to define or quantify. It is just as often the result of design as it is an inherent characteristic of a material. A material such as wood is robust or forgiving because it can be easily modified to suit a variety of site conditions found in the field. On the other hand, a housing component or framing member designed as part of a modular system can be easily adapted to produce a number of shapes, sizes, and functions in a structure. Balloon-frame construction, for example, facilitated the production of housing, especially the evolution of the modular 16-inch-on-center framing system, which permitted the standard sizing of panels, fasteners, and other components. Off-site fabrication of complete housing systems, including the frame and all subsystems such as found in Scandinavia, was part of a modular system capable of considerable design flexibility, however, when it came to assembly at the site, such systems were exacting and unforgiving. Recent experiments with flexibility have focused on service or utility cores or movable interior walls that allow the house to adapt better to this changing life-cycle needs of families.

For centuries, U.S. builders have found wood to be durable, readily available, inexpensive, and easy to work with: but, as privately held stands of high-quality, old-growth timber continue to diminish and environmental groups lobby to preserve old-growth timber on public land, the rising price of dimensional lumber has been accompanied by an overall decline in the quality of lumber. Moreover, as consumers become both more discerning with respect to the quality of their housing 
and increasingly concerned about environmental problems, builders seek greater assurance on the exact performance characteristics of wood and other materials particularly as the concept of reliability-based design gains prominence within the construction industry. Builders therefore are increasingly looking to alternative technology related to materials to develop more durable, feasible, economic substitutes for lumber. With a shifting economic context, technologies such as engineered wood products (EWPs), steel, foamed-core panels, plastics, light-weight concretes, and composites that were formerly under development may eventually prove commercially feasible as substitutes for lumber.

Innovative materials such as EWPs and steel first appeared in the more technologically complex, commercial, industrial, and institutional segments of the construction industry, where sufficiently high product specifications tend to spur the development of better materials despite high initial costs. In the housing industry, however, costs ultimately determine both the rate and degree of substitution. As with other innovations that must cover high initial costs investment of R\&D, EWPs and steel are priced higher than the traditional materials they supplant, thus posing a barrier to entry into the residential market.

EWPs are not only durable, they also demonstrate high strength. Precut to specifications, EWPs reduce the labor usually required to cut and join two conventional wood beams on site. Similarly, steel's light weight may reduce labor costs. Steel's durability, strength, fire performance, and consistent quality are superior to conventional wood, but its superior strength has yet to be reflected in the more cost-effective spacing of framing members. While EWPs are in the family of familiar wood products, framers and builders have generally resisted steel framing because of high switching costs, i.e., the time and expense necessary to retrain crews to adapt to steel. Moreover, steel has yet to establish a performance record. Producers will have to work closely with other segments of the production chain such as fabricators and builders to develop a competitive product that buyers will purchase and users will install. 


\section{Goal 7 -- 50 Percent Reduction in Construction Work Illnesses and Injuries}

As a matter of principle, safety in the workplace is understandably a concern of all businesses. With rising medical costs and increased attorneys' fees, the total cost of workplace injuries reached over $\$ 63$ billion in 1991 , leading to increased regulation by all levels of government. As a major cost issue, workplace safety will therefore have a major influence on home building costs, adding to the problems of building affordable housing. The average cost of worker's compensation insurance in residential construction is more than 17 percent of on-site wage costs and adds about $\$ 4,370$ to the cost of the average new home. One example of an approach to this problem is the proposed Occupational Safety and Health Administration (OSHA) legislation in 1991 that could add an estimated $\$ 4,500$ to the cost of an average home by requiring an on-site safety coordinator at every construction site, a "competent" person on site to represent every subcontractor, additional training costs, and costly notices and filings.

Compared to other major sectors of the economy, construction in general claims the highest annual worker injury rate: 12.8 workers injured per 100 full-time workers and 6.0 lost workdays per 100 full-time workers. Although overall injury rates have declined between 1980 and 1991, the lost workday rate, as an indicator of more serious injuries, declined only slightly.

Comparisons between construction in general and with the residential sector in particular are at best indirect because no comprehensive studies have distinguished residential injuries from those incurred in commercial construction. In any case, injury rates for components of the construction industry that cater primarily to the residential sector are substantially lower than for construction in general and for most construction trades. They are therefore also lower than for the nonresidential portion of the construction industry. Residential general contractors who often build for others for a fee registered an overall injury rate of 9.6 percent and a lost workday rate of 4.8. Operative builders, on the other hand, who build homes for sale exhibited an overall injury rate of only 7.5 percent and a lost workday rate of 3.7 percent. By far, the largest portion of workers in residential construction work are subcontractors. Employees in the trades who work in either residential or nonresidential construction have an overall injury rate of 13.3 and 
a lost workday rate of 6.2. Injury rates for carpentry, which accounts for the largest proportion of workers employed in the residential sector, were about comparable to rates for all trades.

According to OSHA, the principal causes of injury to construction workers are overexertion, being struck by an object, and falls. The more serious injuries such as fractures and multiple injuries are the result of falls. Home builders have safety concerns unique to residential construction. Given that home construction involves more labor time per square foot in framing and interiors work than light commercial construction and relatively less labor time in foundation, exterior wall, roofing, and electrical work, it easy to understand why the largest share of workers in home building are carpenters. Carpenters, for example, accounted 17 percent of all injuries for all construction but 49 and 32 percent, respectively, for residential general contractors and operative builders. The rank order of causes of injuries in carpentry is being struck by an object, falls, and overexertion, which differs from that of construction in general. Since 1970, builders have erected an increasing number of two-story new homes and, in the 1980s, built more new homes with partial or full basements. These trends have contributed to increased risk of injury from falls. For construction laborers, on the other hand, overexertion resulting in injury mainly to the back during heavy lifting is the principal cause of injury.

Clearly, more direct and comprehensive information is needed on the nature and causes of injury in the residential sector. It is difficult to implement an education program or enforce guidelines in the residential portion of the construction industry where so much of the production is accomplished on dispersed sites by small builders who produce less than 11 units a year. Given the fragmented structure of the home building industry, one option could be to emphasize innovative methods of reaching this sector through prevention and education programs rather than after-the-fact inspection and enforcement.

\section{Implementation}

Limited resources are devoted to residential construction research in the United States. In fact, much residential construction research is privately sponsored and thus is proprietary and oriented 
to functional improvements of high-value products for high-end markets. A substantial portion of research sponsored by public organizations focuses only on housing problems related to the organizations' individual missions and on developing and responding to regulations that may actually increase housing costs and decrease the productivity of the housing industry. At present, no agency has overall responsibility for developing guiding principles for a housing research agenda.

The implementation of the seven goals proposed above is in danger of succumbing to some of these same problems. At present, there is no cross-cutting core vision, focus, or philosophy that can serve to galvanize the leadership and coordination necessary to implement these goals and integrate institutional issues with issues related to technology and the quality of housing. As explained in the background to this paper, the theme of increased productivity provides one muchneeded focus. It offers an economic incentive and reward for those in the housing production chain who have to buy into the construction goals program. At the same time, it can bestow on the end customer--the homebuyer--the benefits of reduced cost and increased quality.

The goal of reduced delivery time most closely approximates this theme. In the housing industry, benchmarking studies of cycle time have shown that adopting the principle of time-based competition or just-in-time production allows early detection of small flaws in construction. Detection is made possible because just-in-time production processes leave little margin for error and expose quality problems as they occur, thereby fostering immediate solutions.

Innovation in management processes spurred by new techniques in quality improvement is often a prerequisite before technological innovation can advance. Such improvement often requires complex computer-supported scheduling, changes in the layout of material and information flows, and adaptive skills in the labor force whereby one person performs multiple tasks. This management approach fosters decentralization of decision-making authority and responsibility, encourages team work in the handling of complex information flows and multifunctional tasks, and requires the participation of suppliers and subcontractors as part of the team. In the end, the homeowner's interest is served by rapid delivery of the house as product. 
Some of these goals, particularly those related to occupant- and worker-related injuries and illnesses and occupant comfort, could easily become the province of one or two agencies with particular narrow interests. Framing these goals at their present level of generality is relatively simple in that the goals represent the proverbial "motherhood and apple pie" and offend no one. The more difficult task is to define the detailed objectives that support each goal in such a way that goal achievement can be measured. It is at this stage that the conflicts among the various goals emerge necessitating tradeoffs between goals. The system impact of the goals on housing structure and construction cost must be objectively examined and evaluated. Accordingly, the risks, tradeoffs, and conflicts among the goals can be reconciled.

Coupled with the emphasis on productivity, the housing industry must address the financial and institutional barriers to innovation that would otherwise provide the impetus necessary for achieving the seven construction goals. The financial barriers are the limited financial capacity of the typical small home builder, the premium cost of innovations that are necessary to cover development costs and ensure early monopoly returns, and the initial costs usually incurred when switching to an innovation. The principal institutional problems are the expense and delay associated with a complex product approval system and fear of potential liability.

The following are actions that support a general strategy based on increased productivity and institutional reform in the housing industry:

1. Develop a Residential Construction Industry Research Agenda. A lead federal agency, in cooperation with other agencies and stakeholders, should assume responsibility for a systematic, consensus-based approach for research funding that would culminate in the development of a research agenda oriented to achieving the seven construction goals.

2. Foster Government-Industry Partnerships. A lead agency, with the cooperation and participation of other agencies, should provide funds to the private sector on a cost-sharing basis to assist in commercializing the technologies essential for achieving the seven goals. The assumption is that many already existing technologies could facilitate implementation of 
the goals, but they require assistance in the complex and expensive commercialization process.

3. National Evaluation and Testing System. Establish a uniform national system for developing benchmark standards, test procedures, and evaluations for housing industry innovations for which no standards currently exist.

4. Technology Transfer: Expansion of NIST's Manufacturing Extension Partnership and Computer Technology in Construction. Expand the function, scope, and significance of NIST's initiative for a Housing Manufacturing Extension Center, which is intended to provide technology transfer to the small businesses that predominate in the home building industry. Through this vehicle, the Center could initiate a technology transfer program to facilitate the introduction of computers and systems-related software oriented to the residential construction industry.

5. Production Time Reduction Awards Program. Sponsor an annual competition and awards program for proven, innovative methods and products that reduce production time in conventional housing construction and publicize the results to the industry.

6. Exemplary Program for Speeding Development Reviews and Approvals. Provide grants for exemplary demonstrations to show how administration of development controls can be "reinvented" so that average development review and approval time can be reduced by 50 percent without any commensurate loss in quality of development, environmental protection, or public welfare.

7. National Affordable Housing Demonstration Program. With the lead from a federal agency but executed by private industry, sponsor a housing program that demonstrates innovative products and methods for affordable housing. 
8. HUD ExTech 233 Program. Modify and extend the HUD ExTech 233 program that insures lenders and property owners against the failure of advanced technologies or untried construction concepts for homes. The program would provide long-term relief from potential liability for homes that use a range of innovative products or construction methods reviewed and approved by HUD.

9. Quality Improvement Program. Expand efforts to improve the quality of construction in new homes through a Total Quality Construction (TQC) program that provides pilot improvement projects to educate and train home building firms and their employees in identifying and solving quality problems.

10. National Building Code. Under the auspices of NIST, develop a national performance-based housing code that would supersede the current model building codes, thereby fostering innovations in building materials and components. The Canadian Building Code, administered by the Institute for Research in Construction of the National Research Council in Canada, is an example of such a system.

11. Safety and Training Program. Initiate a "dual track" safety and training program. This could begin by conducting a self-assessment on safety, incorporating the results into a residential construction safety database that would pinpoint priority areas for correction and focus on training for safety rather than rate compliance with OSHA regulations. In developing a simple, proactive safety program, efforts with OSHA should focus on fair regulation based on data and uniform enforcement. 


\section{National Construction and Building Goals \\ Bringing Tomorrow Into Today's Commercial Buildings \\ by: \\ H. J Parmelee. President \\ E. E. DiTomas. Chief Engineer \\ Turner Construction Company}

With the approach of the $21^{\text {st }}$ century acting as a catalyst, a surge of new ideas and increased efforts to improve the many facets of the construction industry has gained significant interest and support. The needs are many and the resources are finite, if not limited, therefore we must focus on those issues and potential solutions that will gain us the most long-term benefit.

When focusing on the challenges facing the construction industry, it is important to understand a unique characteristic that sets the industry apart from many others-each project has a life cycle of one. Work people, who may number into the hundreds, are assembled on and off the job site to accomplish a task of building a facility. At the end of this task, the project organization, in essence, is disassembled only to become players on different projects. It is totally unlikely that the same team of players will build a second project. Even the manufacturing facilities have a life cycle of one for a specific project. The product is made once-then, like the project job site team, the project manufacturing facility is disassembled and is prepared for the next project with a different manufacturing cycle and different team members.

The Subcommittee on Construction and Building has provided specific goals that are a welcome challenge to an industry that all too often does not set meaningful goals for itself. These goals are:

- Better Buildings

- $50 \%$ reduction in delivery time

- $50 \%$ reduction in operations and maintenance 
- $30 \%$ increase in comfort and productivity

- $50 \%$ fewer occupant related illnesses and injuries

- $50 \%$ less waste and pollution

- $50 \%$ more durability and flexibility

- Health and Safety of Construction Workforce

- $50 \%$ reduction in job related illnesses and injuries

There are many definitions of the construction industry's commercial sector. For the purpose of this discussion, we will define it as that portion of the industry that constructs facilities for use by the many areas of commerce-merchandising, hotels, financial institutions, conventions, corporate and company offices, manufacturing, research, sports and medical are some of the traditional elements of this sector. Using this definition let's explore how the commercial sector of the construction industry can better utilize the R \& D resources available to meet these goals. Again, the Subcommittee on Construction and Building has provided a plan for us to work with-a road map defining the technology areas that need to be explored to bring about the much need improvements. These areas include:

- information and decision technologies

- automation in design, construction and operation

- high performance construction materials, components and systems

- environmental quality

- risk reduction

- performance standards system

- human factors 


\section{An industry fragmented}

We have stated that the industry's manufacturing facilities have a life cycle of one-this attribute is made even more challenging by the construction industry's significant fragmentation. Unlike Japan's construction industry which is dominated by a relatively few major participants, the U. S. construction industry is comprised of thousands of small, often regional or local entities. The combined U. S. market share of the construction industry's major domestic firms is less than $10 \%$ !

$\mathrm{R}$ \& $\mathrm{D}$ in this fragmented industry must not be a reflection of the industry's structure, but must address the industry's needs. The $\mathrm{R} \& \mathrm{D}$ efforts put forth by the multitude of industry elements must be coordinated to ensure complete synergism while eliminating duplication of effort. Most importantly, the fruits of R \& D must be relevant to the needs of the construction industry and be shared with one another, raising the standard bar with each shared experience.

\section{Providing direct power}

Time, money and quality, in the final analysis, are made or lost by measurements of what happens at the construction site. Certainly management plays a large and often decisive role in how the time, money and quality resources are defined and allocated, but the bottom line is the performance at the job site and use of the constructed facility. Giving more power to the workers, providing clear and complete instructions and Just-In-Time delivery of the right materials are all crucial parts of a formula for success. Give well trained work people clear instructions, equipment and material in a timely fashion and they will build. Provide these resources and the experienced leadership of the construction process, and the results will be fulfilling. This overly simplified vision is the challenge facing our industry. 


\section{An Agenda for R \& D Focus: The Removal of Existing Barriers}

Finding challenging barriers against the implementation of new ideas and technologies in the construction industry is an easy task. Focusing on the most formidable barriers, establishing priorities and developing strategies to overcome them is quite a bit more difficult. Major barriers include, but certainly are not limited to:

- Parochialism

- Financial

- Labor

- Insurance

- Safety

- Industry rules
- Disputes

- Contract type

- Product liability

- Environment

- Education

- New products and systems

\section{Barriers and their removal}

The 80's and 90's have produced new concepts and approaches to the construction and contracting processes, including partnering, TQM, team building, etc. These approaches need maturing and expansion so they become the rule rather than the exception in the next decade. In addition, these concepts need to be nurtured in the $\mathrm{R} \& \mathrm{D}$ efforts of the construction industry. While sociologists might look at the tenets of labor, psychologists investigate the ways of human behavior, engineers examine materials and processes, lawyers study the governing laws, but where are the studies that bring all these elements together and analyze their interaction? As we present the identified barriers and possible solutions, let's keep in mind that the best solutions will come from teams with a knowledge base consisting of the input of all vested parties. 


\section{Parochialism:}

We are an industry obsessed with keeping our best ideas close to our vest-we are an industry whose numerous participants share nothing of value with their competitors. This results in a substantial stretching out of the time it takes for good new ideas to become common tools of the industry, and it assures substantial duplication of effort put forth to solve common problems.

\section{Disputes:}

Staying out of court must be the goal of all participants in the construction process and attendant disputes. While team building efforts should reduce the number of disputes that could lead to legal actions, greater effort and new approaches must be used to resolve those disputes that do arise. $\mathrm{ADR}$ is a big step in the right direction, but even more efficient means of preventing litigation and resolving disputes out of court are needed.

\section{Financial:}

No one wants to be an industry laboratory, risking time and money-new ideas take time to implement, often requiring the allocation of more resources than narrow margins allow. Governments, project developers, owners and contractors need new and better ways of providing adequate funding for financing new products and processes, and covering the possible associated risks.

While many of the risks faced by the construction industry are related to the constructed project and the activities that take place on the site and in the structure, substantial risk also lies in the area of project financing. The old methods of financing and the distribution of the funds among 
the participants are in dire need of modernization. The builder must be taken out of the position of having work performed, thereby becoming liable for payment, and yet be at the mercy of the client for the distribution of the funds for the work, particularly at the end of the project. Assurance that the cash will be available when due is equally important. Greater use of payment guarantees and escrowed funds are a must, with a strong focus on the assurance that funds are available at the end of the project to compensate all participants for work performed.

\section{Contract Type:}

The acceptance of new technologies and procedures can be significantly improved by selecting the proper type of contract. New forms of contracting should be developed to improve the environment and the contract type selected should meet the needs and abilities of all parties to administer it. It should also provide mechanisms for the sharing of the benefits and risks in using new technologies. The proper contract form should be a vehicle for encouraging free interchange of information relating to the project at hand and should provide a value added result for all participants.

When the University of Cincinnati found an immediate need for 400,000 square feet of office and parking space, it was obvious that the traditional approach of legislative approvals, conceptual development, design, budget, budget preliminary design, legislative approvals, bid award and build would fall far short of meeting their need for occupancy. Using the design-build-leaseback approach, the $\$ 25,000,000$ Edwards Center was completed in 16 months-a savings of over 44 months! Not only did the process save time, it also virtually eliminated the University's normal project risks for budget, schedule, programming and quality-translating to a savings in cost as well as time. The design team, Turner Construction Co. and the subcontractors also benefited from more efficient operations, better productivity and improved cash flows. The approach used by the 
University of Cincinnati provided the right environment for financing and managing the project so all participants came away winners!

Traditional approach, including the required legislative processes.

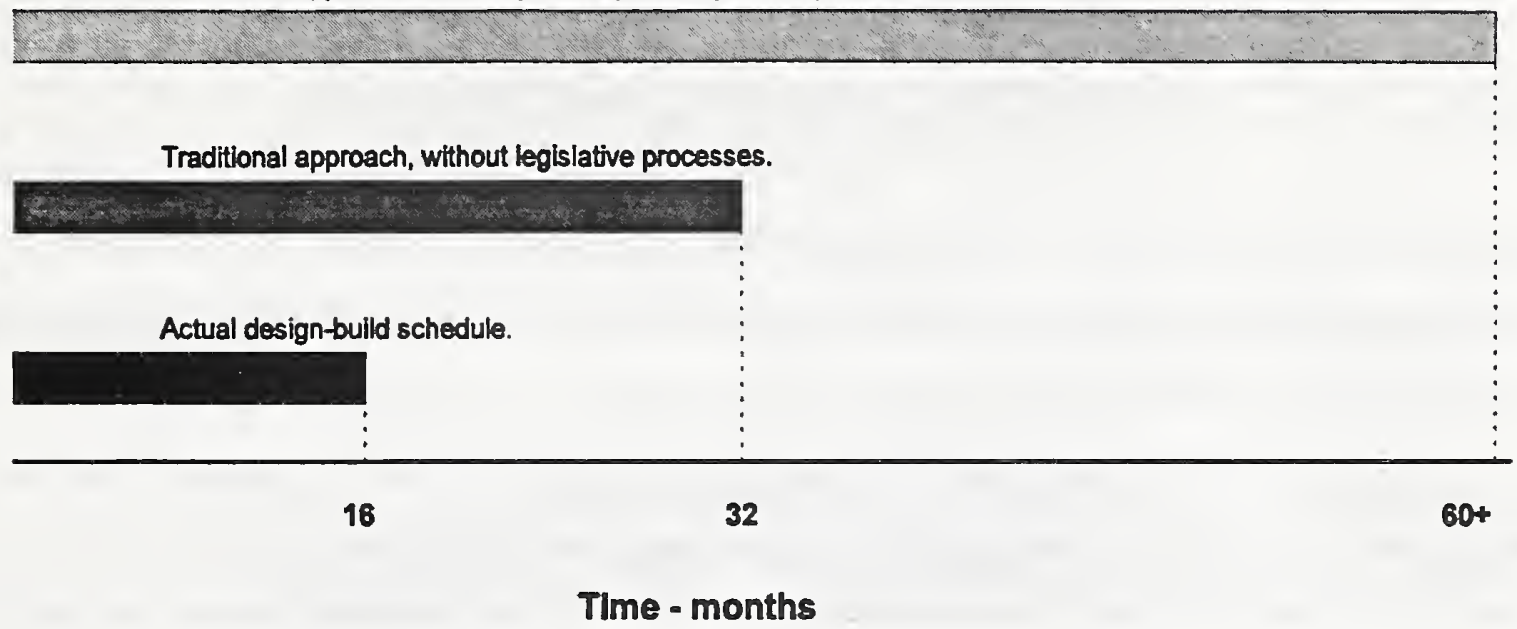

University of Cincinnati Edwards Center Schedule

Not only should a broader use of the design-build process be encouraged, it should also be combined with the concepts associated with privatization. The shedding of the old paradigms about the bid and award process is most important. The Middletown Courthouse, a State of Connecticut project, is an excellent example of successfully using the design-build process in a traditional lump sum bidding environment. The highly finished seven story, 131,000 square foot facility housing courtrooms, judicial support areas, a 22 cell prisoner holding block and a 365 space parking garage was completed in 28 months-from land acquisition to final punch list. 
Approval to use the design-build-leaseback method required an act by the state legislature, but in the end the State of Connecticut received a litigious free project well under budget and in one half the time required to build a similar project using traditional methods. Again, such approaches to project implementation prove to save time and money, and reduce risk for all team members.

\section{Labor:}

Must become more involved in modernizing the work place and the attitudes related thereto. More trade flexibility, quicker acceptance of new processes and materials, changed rules for around the clock work shifts are but a few of the areas to investigate.

While the focus of this paper is on how to improve the construction industry's R \& D effort, some industry improvements need cultural, instead of technological, changes. Immediately after the Gulf War, the Kuwaiti government retained Turner Construction Co. to rebuild the war ravaged Bayan Palace. The Kuwaiti needs were clear and formidable-take the significantly damaged 750,000 square foot guest residence for royalty and government officials and restore it to its former opulence-in three months! Combining the American penchant for getting things done when faced with the impossible, the American ability to schedule and manage multiple simultaneous activities on a construction site and the American talent to plan and control worldwide logistics for procuring and delivering materials-with a cooperative labor atmosphere that allowed the use of foreign and local labor around the clock-the challenge was met.

\section{Product liability:}

As we explore ways to set aside funds for $R \& D$, we should also determine the feasibility of establishing a pool of funds for coverage of risk associated with the implementation of new 
technologies. Examples of past new technologies that left untold risk at the feet of some, but not all, of the participants include asbestos, Sarabond masonry admixture and fire retardant treated (FRT) wood. In addition, the risk of using new products or finding new applications for existing products should be based on the knowledge available at the time of the implementation of the new idea and not come under the scrutiny of a judicial system based on 20/20 hindsight.

\section{Insurance:}

While much attention is given to the need to insure short and long-term risks, more attention needs to be given to the means of insuring the constructed project and all involved parties. Wrapup insurance, while not a new concept, is gaining recognition and acceptance for:

providing adequate coverage and minimizing risks

eliminating duplication and potentially saving money reduction in insurance administration time and cost reduction in claims and counter-claims, and the associated haggling among insurers for responsibility and cost

While wrap-up insurance brings many benefits to the project, it also has its own unique set of short-comings. Usually written as loss sensitive programs, numerous and large unfavorable claims can drive the cost up higher than a traditional program. Enhancement of the wrap-up concept to reduce the negative issues is needed.

\section{Environment:}

While much focus is on the physical aspects of environmental remediation, additional consideration needs to be given to the management side of the problems we face. We must 
develop a more equitable assignment of responsibility for today's problems, establish better ways to resolve tomorrow's problems and improve our investment of our resources in long-term solutions. As an example, when dealing with contaminated sites should the penalty for contaminated materials be borne by the contractor or the owner of the property containing them? The current process has all the appearances of a big net being used to find the deepest pockets, with little or no consideration of guilt in causing the problem. When searching for big game in the environmental arena, the targets should be perpetrators, not scapegoats!

Safety:

While the introduction of new processes and products to the construction environment mandates $\mathrm{R} \& \mathrm{D}$, we must also address the potential risks to workers and other users of the new processes and products. The examination of these risks defines the need for another type of $R \& D$-the investigation of the sociological changes needed to bring about a team effort between designers, builders, labor and trades people working towards the goal of a safer industry.

A careful comparison of safety in the construction industries of the United States and Japan reveals interesting insights worthy of further investigation by interested parties. The fact that the building on a Japanese construction site is enclosed with full-height scaffolding and plastic mesh is immediately obvious. The daily morning exercise and safety pep talk establishes a tone for safety and management's expectations. Even the greater expenditure for protection equipment soon shows itself. Return to the entrance gate of the job site and take another look-a sign proudly proclaims the number of man-hours worked since the last accident-and not a worker on the job would want to bring upon himself the tremendous loss of face by being the subject of the accident to end that string. 
While legislation and training hold important positions in the safety environment on any construction site, culturally-driven changes will have an even greater impact.

\section{Education:}

This category covers not only the formal education of the participants-engineers, trades people, designers, managers, etc.-but also the informative, informal teaching of the team members on the needs for and proper application of new technologies. Funding for research efforts should include determining means for training designers, construction management and trades people on the use of new products and processes.

Society's and the industry's attitudes toward education must change-a greater focus must be placed on vocational and on-the-job training. A substantial effort must be made to improve the training and therefore the overall image of the trades person. Involvement and pride in work produced must again be part of the culture of the industry.

At the same time, there needs to be a rethinking of how and what is delivered to the technical university student. Establishing the fact that industry is one of any university's main customers, more consumer input is needed in the development of university curricula. When a university is measured for success, more emphasis needs to be given to the quality of its main end product-the graduates-as opposed to the quality and prestige of its research programs. While graduates steeped in the wisdom of theory add to the prestige of the university, common sense and knowledge of the practical are the resources needed by industry. In short, research is important, but so is good teaching and learning.

\section{Industry rules:}


As in many industries, the construction industry is controlled by a variety of rules and regulations, including state and local codes; federal, state and local regulations and statutes; and standards such as ACI, ASTM and ANSI. The codes, rules and regulations vary significantly from place to place as does their interpretation. Research into ways to provide greater uniformity and more meaningful standardization in all of these areas will provide a more receptive environment for the introduction of new ideas, processes and technologies. The up-dating and broadening of standards is sorely needed. Up-dating must be done with something more than glacial speed, and there must be more uniform implementation of the standards developed.

New products and systems:

Innovations in technology bring with them their own special barriers to implementation-awareness of the innovations and training for their proper implementation. $R \& D$ to advance technology in the new areas should have high priority; however, it is equally important to study means and methods of better implementing current technologies, giving them broader acceptance and greater use. Such existing technologies include:

Prefab of structures, modular, sub-assemblies

Electronic data transfer

- CAD and CAM

- E-mail and electronic data transfer

- Video conferencing

The barriers to fully realizing the power of CAD systems is a notable example. Product details should freely flow electronically to designers, while the designers' efforts should likewise stream on to the general contractors and subcontractors, eventually finding their way to the CAM processes in the industries' fabrication facilities. Every time information is recreated in a project team member's engineering or drafting department via out-dated methods, time and money are 
wasted and opportunities are provided for making mistakes. Researchers must investigate not only the technical aspects of such barriers, but the legal ramifications as well.

The industry would substantially benefit by advances in the technologies associated with vapor transmission through exterior walls, thermal barriers in roofs and walls, replacing and/or enhancing current fire resistance treatments and new longer life coatings for metals and woods. One area that has received a lot of $\mathrm{R} \& \mathrm{D}$ focus, but demands to be studied further, is the issue of corrosion-corrosion of metals in concrete, corrosion of all materials in infrastructure and corrosion of all surfaces exposed to normal and hostile environments.

Other areas for further research include those products that require the proper combination at the job site of components to create the end product-paints; synthetic acrylic plasters; cements and stuccos; epoxy adhesives; epoxy coatings and sealants, just to name a few. Elimination or at least the reduction of the VOC's; greater tolerance to variations in the storage conditions, mixing times and mixing ratios; longer shelf life, as well as a better understanding to the long range performance of these products outside the laboratory and in the real conditions of the construction environment is greatly needed.

The Department of Defense is putting forth a commendable effort by encouraging its R \& D partners at various academic institutions to take the wraps of secrecy off of their new technologies, and work with industry to find profitable ways to transform the knowledge into new products and processes for non-military uses. A specific example of this effort is the initiative taken to introduce composite materials in the construction industry, with a specific focus on uses to renew our deteriorating infrastructure.

Many of us have a perception that the American construction industry lags its counterparts in 
other countries-in technology, competitiveness and quality of product. Some go so far as to espouse abandoning our way of doing things and adopting the ways of the others. Certainly the barriers presented here represent significant challenges, and identify many areas for improvement. But do we really want to emulate those whose results-perceived and actual-we envy?

We have already discussed how some of the American construction industry's skills have been used to overcome obstacles unapproached by others. These are not the only areas where the United States excels on the constructed project. While inexpensive labor can often successfully complete a foreign project, there are times when highly skilled management and labor combined with technical expertise is the only way to get the job done. These are skill areas where we often stand tall among the others. Echelon Square, a twin tower, 39-story office building in Colombo, Sri Lanka, is a case in point. While there was an abundant supply of low-cost labor, it took American forming systems and precasting knowledge to produce the architectural precast concrete in sufficient quantities and of acceptable quality to meet the project's needs.

Having looked at an agenda for R \& D focus, we must not lose sight of what we do well and improve on it. At the same time, we should investigate those means and products that have succeeded elsewhere, examine them against the fabric of our industry and culture, and adopt or adapt as appropriate.

\section{A Plan for Positive Action}

$\mathrm{R} \& \mathrm{D}$ for the construction industry must be done by the industry as a whole, with all elements working in concert with each other. The cohesiveness of such an effort might come from a controlling body with representation from the major elements of the industry-users, owners, designers, builders, labor, academia and the appropriate government agencies-a clearing house for construction industry R \& D.

Too many opportunities to benefit from forward thinking people developing leading edge projects 
have been missed. In the late 1970's CIGNA (then Connecticut General) established their need for additional office space on their campus north of Hartford, Connecticut. A plan was conceived and developed, a building was built and a few words were written about its success. Except for the few that were fortunate to be participants in the project, or those that read what little was published, or those that enjoyed the opportunity to occupy the new facility, little is known of its success. While the project stood out because of the new technologies, processes and material used in its design and construction, the real achievements of the CIGNA project went beyond the construction issues. The April 1983 and March 1985 issues of Architectural Record gave the reader a good sense of what had been accomplished from a design and construction perspective, but it was a publication by the CIGNA Corporation Employee Communications group, From The Ground Up, The Inside Story, that showed how unique and innovative the entire process had been. It was a clear demonstration that every thought, every brick, every hour of effort was focused on the end user's needs-at the time it was built and well into the future. Unfortunate parochial attitudes and failure to communicate the new ideas meant that much of what was accomplished went unrecognized by an industry starving for new ideas.

Knowledge gained must be captured so it can be shared throughout the industry for the benefit of all parties that have a vested interest in the constructed project.

\section{Government}

All levels of government need to become more proactive. They must become team players as opposed to being the inspector general of the team. Governments should be more aggressive in giving tax incentives-recognizing they are investments made for long-term returns. Abandoning the bankrupt concept of down-and-dirty lump-sum bidding, lowest bid price gets all, would be a major step forward. However, when using contract award processes that are commonplace in the private sector, government agencies must learn the culture of these processes. When asking 
approved qualified bidders for their Best And Final Offer, they must avoid revisiting bidders for better pricing-a best and final number is just that, Best And Final!

All levels of government need to become more consistent and should consider themselves members of the same team. As a team member, government agencies must learn to be good listeners and less dictatorial. Too often contractors and the construction industry suffer the results of conflicts between different levels of government or different agencies within a governing body. Within the construction industry, government is often looked upon as dictatorial and punitive. Efforts to change this perception would be welcome and rewarding. As an example, wouldn't many attitudes change if OSHA were to issue positive citations extolling exemplary safety performance by a contractor?

\section{Academia}

Our colleges and universities must foster greater interaction with industry, and encourage industry to be more proactive in the relationship. The concept of government and industry handing colleges and universities resources such as time and money for R \& D, and sitting back waiting for a document giving the results must be numbered. Government and industry must be part of the process-they must become involved in the research while it is happening, become involved in the education process as an active participant, giving academia a better insight as to what is needed and what is important.

\section{Industry}

In addition to being involved in the academic $\mathrm{R} \& \mathrm{D}$ efforts, industry needs to become more proactive in its own $\mathrm{R} \& \mathrm{D}$ arena. Industry members must dedicate in-house staff resources to their own research efforts. This will assure them opportunities to participate with academia and 
governments on $\mathrm{R} \& \mathrm{D}$ issues, communicate with other industry members and collaborate on research efforts, network with the manufacturing segment of the industry and assure ample opportunities for new products and processes to reach the market place.

Owners, users, designers, builders, labor and trades people must join together to develop a program with government-federal, state, local-that will allocate funds to R \& D. A tax on the cost of a project and a dollar matching program going into an $\mathrm{R} \& \mathrm{D}$ escrow fund should be evaluated. These funds should be made available for any worthy R \& D effort in industry, government, academia or labor. In addition, all appropriate research efforts should include funds for the training of the management, installation and use of the new products and processes.

Parochialism should be looked on with the same favor as negative cash flow. Like negative cash flow, you can survive parochialism for the short term, but in the longer view, it hurts all participants and bankrupts the industry. The sharing of knowledge for the mutual benefit of all is key to the U. S. construction industry's survival in the global market place.

\section{The construction industry user}

Let's not lose sight of the fact that the current construction environment is substantially driven by all parties on the economic chain wanting to maximize short-term returns on their investments. Our present system allows for relatively cheap construction because part of the bill has been invoiced to succeeding generations. If the real cost of safety, environmental protection, durable products and efficient operating structures were included in the initial bill, we would achieve sustainable growth, have an environment we can live with and maximize the long-term returns on our investments. Such a shift in the industry's culture would greatly improve the environment for meaningful and creative $\mathrm{R} \& \mathrm{D}$.

\section{A First Step}


Establish a project category where $\mathrm{R} \& \mathrm{D}$ funds are used in a model environment and the project would benefit from special consideration such as tax incentives. All vested parties would participate in the $\mathrm{R} \& \mathrm{D}$ activities-all parties would share in the knowledge gained. The benchmarked results along with any new products and/or processes would be made available to the entire industry, either as public domain knowledge or through the profitable marketing of new products. Such a project would provide open and free transfer of information to and from all parties. Clearly defined responsibilities and authorities for all phases of the project, including project oversight would encourage a cooperative team atmosphere. Clear definition of the penalties and rewards for different levels of performance and meeting of goals would provide the necessary incentives to maximize performance.

By focusing America's R \& D resources on the challenges described above, we will find the answers to bring about the goals set forth by the Subcommittee on Construction and Buildingbetter buildings, and a healthier and safer construction work force.

\author{
H. J Parmelee. President \\ E. E. DiTomas, Chief Engineer \\ Turner Construction Co.
}


National Construction and Building Goals

An Industry Sector Perspective -- Industrial

by

Philip J, Richter, Senior Technical Director, Fluor Daniel, Inc. Irvine, California Ramzi G. Saaty Director. Fluor Daniel, Inc. Irvine. California

\section{INTRODUCTION}

CERF (Civil Engineering Research Foundation) is convening a national workshop in order to explore the national goals for constructed facilities as presented in the draft report, "Rationale and Preliminary Plan for Federal Research for Construction and Building". This document and the goals it presents were developed by the Subcommittee on Construction and Building (C\&B). C\&B is a subcommittee of the Committee on Civilian Industrial Technology of the National Science and Technology Council. The overall purpose of the workshop is to develop a construction industry response which will complement the ongoing efforts of the subcommittee and help define a plan of action toward implementation of the national goals.

A number of white papers have been commissioned for use in the workshop, including those with perspectives from the five major sectors of the construction industry: housing, institutional, commercial, public works, and industrial. Each of the sector white papers is intended to stimulate discussion and act as a catalyst for workshop working groups in their sector. The working group discussions are a key element in the process leading to fulfillment of the workshop goals.

Key workshop topics listed below are for all sectors. In this paper these topics are discussed in light of the industrial sector:

- National construction and building goals

- Unique barriers to implementation

- Technologies that can have an impact

- International comparisons

- Case studies where barriers were overcome

- Implementation issues and recommendations 
These topics form the substance of the remaining sections of this paper in which a perspective from the industrial sector of the construction industry is examined.

Before proceeding, however, it is necessary to provide a definition of what comprises the industrial sector of the construction industry. Industrial facilities are defined as those primary and ancillary buildings, structures, systems and their equipment, components, and furnishings which are involved in the production and/or processing of:

- Materials, including but not limited to, areas of mining and production and processing of raw and synthesized materials -- for example, gas processing, oil refining, and production of metals, cements, plastics, glass, metals, pharmaceuticals, and foodstuffs.

- Electric power by mechanical means, including but not limited to, nuclear, coal, oil, gas, solar, wind, geothermal or wood-fired plants and cogeneration plants which burn otherwise waste materials.

- Machinery, equipment, and components used for but not limited to -- systems and items employed in the above processes and production, furnishing and equipping of buildings and other facilities, transportation (e.g. automotive, rail, aerospace, shipping), communications, electric power transmission, pipelines, and construction.

Within a few written pages attempting to discuss the goals and related issues for this sector with its enormity of size and great breadth and diversity, is an extremely challenging task. In speaking to the whole sector the discussion is limited by necessity to be quite general. However, some specificity is provided by relating some issues and examples from the industrial segment most familiar to the authors.

2. NATIONAL CONSTRUCTION GOALS IN THE CONTEXT OF THE INDUSTRIAL SECTOR

In this section each of the national goals are examined. Key issues and the significance of the goals from the perspective of the industrial sector are discussed. Issues related to benchmarking the current state of construction of industrial facilities relative to each of the goals are also discussed. In order to properly define the goals, it is necessary to assume that the improvement (as measured in percent for each goal) occurs with no increase in cost and over a predetermined period of time (e.g. ten years). The first six goals listed below relate to better facilities while the seventh relates to construction workers.

- $\mathbf{5 0 \%}$ reduction in delivery time: 
In the industrial sector requirements for constructed facilities are more rapidly changing than those for other sectors. This occurs because production technologies for processes and manufacturing are changing almost continuously and additionally because new products and processes are continuously appearing for which new facilities are required. Delivery time is greatly impacted by all of the above factors, as well as by two of barriers: regulatory and adversarial. With respect to the impact of technology, the biggest problem is lack of ability to standardize due to the changeability of requirements. Thus, improvement can likely be made through increased use of automated engineering design and layout using modular approaches and robotics in construction, for example. Because of breadth of the constructed facility types and changeability of requirements, benchmarking of delivery time for current new constructed facilities is extremely difficult to provide in a quantitative way. In order to provide benchmarking in the industrial sector, benchmark projects should be identified from various areas of the sector and appropriate parameters studied and recorded. Perhaps some of this data can be obtained from recent/current projects.

\section{- $\mathbf{5 0 \%}$ reduction in operation/maintenance cost:}

Operations and maintenance, on a global basis, are fundamentally more important for industrial facilities than facilities in any of the other sectors. This is true because with continuous or steady production which is generally required, interruption and/or breakdown will have major economic impacts. Benchmarking of a measure for the level of operations and maintenance should be somewhat more direct than the benchmarking of facility construction time. One appropriate measure, cost, can likely be quantified from existing figures for selected facilities. Also it is likely some of the data is already available for a number of facilities in various areas of the industrial sector. However, a study effort which identifies baseline facilities in selected industrial areas and collects appropriate cost data on an annualized basis, should be initiated. This should be done in the context of a program to develop benchmarks for all sectors and to measure progress with consistent parameters in conjunction with a unified program for fulfillment of the national goals. Though collecting appropriate data and establishing benchmarks may be difficult in many cases, this effort must be made. Often the successful collection of data will depend a great deal on the particular area of technology and the owner involved.

\section{- $30 \%$ increase in comfort and productivity:}

Comfort and productivity of workers is probably less of a factor in many respects for industrial facilities. Though these factors are very important for individual operators, the overall impact as measured by cost is likely low. This is because of the generally smaller number of people needed in industrial facilities than in the facilities in other sectors. In the industrial sector, productivity is gained more by improvement in 
processes and changes in technology. Productivity is not significantly enhanced by improvement in worker comfort. Again a study effort, for benchmarking and measuring progress in this and the other sectors would be needed in conjunction with a united national improvements program.

- $\mathbf{5 0 \%}$ fewer occupant related illnesses and injuries:

Reduction of occupationally related illnesses and injuries are a very important factor for industrial facilities because of ongoing production processes. Benchmarking data on incidents and related lost time accidents are currently available from a number of sources.

- $\mathbf{5 0 \%}$ less waste and pollution:

Waste and pollution are major issues for industrial facilities. Waste and pollution also are important factors in the construction and construction process for industrial facilities. The amount of waste and pollution are heavily impacted by technologies used in industrial processes and production. Data on waste is probably more difficult to obtain and benchmark than that for pollution because of difficulties in quantifying waste. Remarks made in the context of studies for benchmarking and measuring progress under the previous goals are generally applicable.

- $50 \%$ more durability and flexibility:

In our judgement durability and flexibility are two unrelated goals. Flexibility must be built into industrial facilities based on planned prospects for changes in a given plant's industrial processes. Flexibility may be built into service-oriented facilities in more generic ways: e.g. open spaces with changeable partitions. Flexibility seems to be less of an issue in industrial than other sectors. Flexibility may be provided in either case by potential modular or non modular additions. Durability, on the other hand, is likely more of a key factor in industrial facilities than in more serviceoriented facilities. Often special materials and components are specified to achieve durability in particular environment. By observation, offices, general living, and other service facilities, though requiring good maintenance are more durable than the machinery, systems and components for production facilities. Benchmarking and measurement of progress are likely to be more readily quantifiable for durability than for flexibility. However, in either area, data will have to be developed and is likely to be less available than for many of the above goals.

- $\mathbf{5 0 \%}$ reduction in job related illnesses and injuries:

This goal relates to construction workers as opposed to the above goals for the constructed facilities. Differences between issues related to this goal for industrial 
facilities and those for other sectors are probably minimal. Differences, as may occur would relate to differences in safety because of complexity of construction processes for the more complex and less standardized industrial facilities. Benchmarking and measurement of progress are probably readily available because data likely already exists on job-related accidents, illnesses, and corresponding lost time.

UNIOUE BARRIERS TO IMPLEMENTATION IN THIS SEGMENT OF THE INDUSTRY - STRATEGIES TO OVERCOME

The U.S. construction industry is continuing to lose ground in its global competitiveness. We are lagging when compared to foreign competition which is employing new materials and technologies in the area of construction. In a recent survey of leading U.S. and foreign design and construction firms, nineteen areas of construction technology were considered. The U.S. led in just four areas, was even in one and trailed in fourteen. Specific instances of foreign leadership were cited in innovative materials, tunneling, underground piping, robotics and earthquake engineering. In the U.S., engineering and construction firms are fragmented and regionalized. The industry consists of thousands of small companies that are local in their mentality. The concept of working as part of a global environment is hardly considered. The losing of ground can be attributed, totally or in part, to a number of barriers which we (our industry) impose on ourselves or are caused by others. These barriers in some instances are imbedded in our culture and in our way of doing business. Such barriers discourage innovation and technological advancement in construction. They are discussed below with respect to their impact on industrial facilities:

- Lack of Leadership - Lack of leadership is herein considered to be not the unwillingness of people to take leadership roles but rather the lack of a broad vision and a longer term perspective to perceive the areas in which barriers need to be addressed and overcome. Lack of leadership in industry, government and academia is a major barrier to technological advancement and to meeting the national goals. In the industrial sector, government barriers are seen to be most significant. Often government and legislative processes do not give priority or support to certain types of industrial facilities specially those that are associated with producing higher levels of waste and pollution. Large industrial companies for example, are often forced to build needed chemical and petroleum refineries overseas. This occurs because of the adversarial posture of the government, bureaucratic requirements and political environment which many times discourage construction of such facilities. Another example is nuclear related processing facilities in the U.S. Such facilities are desperately needed to process mounting nuclear wastes. However, indecision and lack of firm direction in our political and bureaucratic processes have greatly slowed this vital and important program. This is where our government should provide 
leadership in establishing a road map and constructive programs that would facilitate the building of such facilities. The government has created a complex set of legal barriers which need to be selectively dismantled. Also, industry leaders have failed in working with their counterparts in government to overcome barriers such as these. Industry leaders in many cases have failed to adopt new technologies developed at universities and private R\&D Laboratories. Japanese companies, on the other hand, often interact with university researchers in order to obtain new ideas and innovations. U.S. companies and the academic world infrequently communicate about new technologies, and both have a more independent and less cooperative attitude towards each other. This lack of leadership and cooperation between government, industry and universities has often led to failure to incorporate new technologies.

- Regulatory Barriers - Industrial facilities are generally complex and require many sophisticated and diverse technologies for their operations and production. These types of plants are often subjected to numerous and sometimes conflicting regulatory requirements. New projects in this sector usually come under more scrutiny by federal, state and local government. Such barriers often cause major problems in carrying out industrial projects because of delays.

- Liability - The liability issue has a major impact in all of the construction sectors. Because of our litigious society, U.S. companies using new materials or technologies in their constructed projects, face potentially large liabilities. Often, the risks far exceed the potential rewards. The liability issue impacts the industrial sector deeply because innovations in building industrial plants are driven by great technological diversity and constantly changing requirements. To address this issue, government needs to provide federal, state and/or local support mechanisms when using new technologies and to defuse more of the risks when non-standard products and processes are incorporated.

- Adversarial Relations in Construction Projects - The current U.S. environment discourages partnership and cooperative approaches. Instead adversarial relationships exist between, owners, design firms, manufacturers, regulators and constructors that often lead to claims, increased costs and even project cancellation in some cases. This is particularly noticeable in the industrial sector where plants often generate waste and pollutants. Owners and their builders are constantly at odds with regulators and "public interest" groups on waste monitoring and control. Such issues, which tend to be politically sensitive, would be resolved more readily with cooperation rather than confrontation.

- Financial Disincentives - The use of new technology which encompasses issues that are related to all the other barriers are discussed in this section. All of the other barriers impose large cost burdens on the development and use of new technology. 
It is obvious that these barriers including potential liabilities, lack of leadership, regulatory and adversarial relations issues all levy a high cost on deployment of innovation in constructed projects. Perhaps the most severe of these disincentives relates to the liability matters. A more cooperative relationship between government, owners and builders would in itself provide financial incentives for research and transferring new technology into constructed projects. Tax incentives and governmental protective legislation against liabilities should be used to promote development and incorporation of new innovations. Again, the industrial sector because of its fragmentation and of its complexity and the constantly evolving facilities-requirements might benefit most from such incentives. One barrier is the reticence in many instances of industry to invest in the increased training required to deploy new technology. Another financial disincentive is competitive bidding. The construction industry is constantly faced with intense competition on projects where the lowest bidders win. The U.S. contractors are told how to build and perform the work as specified and for the least cost. In Europe and Japan however, contracts in many cases are awarded based on "best bid" and the use of "performance specifications". Both approaches permit bidders to recommend new ways to design and construct projects and provide the mechanisms for transfer of innovation from the laboratory into the field. Bidding on a low price basis alone, is especially difficult in the case of industrial plants because of their complexity and lack of standardization due to constantly changing technology. The bid process in these instances would be better served by basing awards on experience, technical strength, and the incorporation of innovative and new designs in addition to cost.

In the above discussion of barriers a number of actions for remediation are also discussed. Based on this, the following strategies are outlined to overcome barriers and to develop an environment of cooperation, partnership and trust between all key participants including designers, constructors, government, academia and industry owners.

The role of government to include:

- More directed and increased financial support for civilian R\&D.

- Promotion of partnering.

- Consider revisions of anti-trust laws which inhibit partnering and joint ventures.

- Provisions of tax incentives.

- Promotion of global competitiveness measures such as:

- Collection/distribution of commercial/political strategic information that might have a direct impact on constructed facilities. 
- Assist third world countries in obtaining financing loans to build and expand their industrial infrastructure.

- Improvement by government of international tax policy to support U.S. companies.

- Through partnering and active legislation help defuse liability issues.

- Provide more protection of proprietary data rights.

- Streamlining regulatory approval processes.

- Selective use of federal construction projects as lower risk test beds for innovation.

The role of private corporations and the construction industry to include:

- Industry leaders become more proactive in encouraging government to remove the above mentioned barriers.

- Industry leaders to work more closely with government, other firms and academia in promoting research and development.

- More often U.S. engineering and construction companies should team up and form partnerships with foreign companies. This interaction will benefit U.S. firms by exposing them to R\&D and technologies developed in foreign countries and will assist U.S. companies in global competition.

- Continuously educating, training and retraining of engineers, designers and industry workers to maintain and keep up with ever changing technology. This can be achieved through close industry interaction and support of schools, seminars, workshops, etc.

The role of academia to include:

- Finding ways to increase teamwork with industry and government

- Proactive partnering with industry when conducting research

- Soliciting advise and input from industry on school curriculum that will benefit future professionals.

4. TECHNOLOGIES THAT CAN HAVE AN IMPACT - RELATIVE IMPORTANCE 
Engineering and construction of industrial facilities are complex contain a greater variety of different components when compared to facilities from other sectors such as infrastructure and commercial. Many plants contain diverse equipment, intricate piping, intricate electrical and control systems and complex structures/foundations. To maintain a competitive position in design and construction of such facilities especially on a global basis, U.S. firms must utilize innovative technologies and state-of-the-art programs including:

- Use of high performance construction materials and composites - Engineering researchers and scientists have and are constantly developing new materials including polymer concretes, fiber reinforced concrete, advanced composites, ceramics and advanced metal alloys to cite a few. These along with recent advances made in conventional materials (e.g., high and early strength concrete), when developed to a point of economic justifications could make great contribution to performance, installation, durability and strength.

- Construction Automation - Use of robotic technologies and smart tools should be incorporated to assist workers on the construction sites. These tools can assist in positioning items with increased accuracy, inspection through remote sensing, performance of repetitive tasks and accessing of remote and difficult locations.

- Modularization Approach with Factory-Produced Systems/Components - Many plant sub-units can be modularized and shipped to the job site. This construction approach which is starting to be utilized can improve schedules and reduce labor at remote site locations.

- Integrated Computer-Aided Designs - As operations become more technical and projects become more complex, the industry increasingly needs ways to exploit and better utilize the capabilities of computers and artificial intelligence. Computer-aided plant design systems for example can:

- Integrate engineering, design and drawings functions

- Transmit construction information directly to fabricators and the field

- Provide interference checks

- Document and track materials

- Change the Design Work Process - Conduct the engineering functions to include:

- Reengineering of work processes and flows so that more engineering and design tasks can be executed concurrently. 
- Empowering employees by sharing responsibility and accountability. This will lead to increased productivity and efficiency in the work place.

- Improved safety in the office, the field and in design.

- Improved quality.

- Making design choices based on life cycle cost factors.

- Natural Phenomenal Mitigation - Improve understanding of requirements for designs to resist natural phenomena such as tornadoes, earthquakes, floods, tsunami, volcanos...etc. and their impact on plant design, society and industry.

- New Technology Applications - Two are given as examples:

- Use of seismic base isolation and energy dissipation/damping systems for earthquake effect mitigation.

- Direct electronic transfer of engineering design data to fabricators (e.g., steel fabricators) and construction sites. This would lead to significant reduction in design and construction time.

\section{INTERNATIONAL COMPARISONS}

Within the past thirty years European and Japanese construction technology has increased dramatically as more and more of the major contractors especially in Japan, have invested in their own research and development. Nearly all major Japanese contractors have an R\&D program which has become a vital tool in their development and marketing. In the U.S., however few of the major contractors have significant R\&D programs in their portfolio of activities. A CERF task force visiting Japan in 1990 found that the Japanese construction industry is reaping rewards of technological innovation and competitive strength in the global markets. Their market conditions, cultural factors and government policy combine to create an environment that encourages development and application of new technology. The following items consider innovative practices and technologies employed in Japanese and European construction which could provide models for improvement in the U.S. Many of these items may apply across the board for consideration in all U.S. construction sectors. However, in the discussions below some comparative factors which relate to the industrial sector are noted.

- In Europe and Japan government policies stress cooperation between all sectors of the industry, thus achieving effective research that can be transferred into practice. Japan has a cooperation-based system for managing liability for loss and injury from new technology. This encourages $R \& D$ and reduces the risk when new technology 
is put in to practice. A more cooperative posture between government and U.S. industry and the implementation of related measures would lead to corresponding improvement. Such measures would have a special benefit in the areas of the environment and local economies.

- Changes should be initiated in international tax policy to lessen the tax burden on U.S. companies and to provide a more level playing field in international competition. It is perceived that U.S. companies are competitive in bidding on industrial projects which require the application of changing and complex technologies in both developed and developing countries. However, it is felt that U.S. companies lag in competitiveness in other sectors of the international market. Therefore this issue of tax policy probably has a greater significance for the industrial sector.

- The Japanese use robotics with computer controlled, fully-automated construction systems in high-rise building construction. The development of this approach in the U.S. would be especially beneficial in the residential and commercial arenas. Adoption of this technology to the construction of industrial facilities holds promise in achieving the goal of reduced delivery time.

- In 1991, Shimizu Corp., a Japanese construction company invested $\$ 90$ million in R\&D which is more than the entire U.S. industry combined (about $\$ 55$ million). In the U.S., government should work with the construction industry to promote R\&D. Again the industrial sector constructed projects, because of their continuously changing requirements and complexities, will benefit more from well-directed R\&D than other sectors.

- In Japan 25 of the 30 largest construction companies have their own R\&D laboratories. In the U.S. not one construction company has an R\&D lab.

- In 1991 , the Japanese construction industry handled projects of $\$ 450$ billion which is equivalent to the U.S. construction industry total.

- The Japanese construction industry for example, uses higher grade, more weldable rebar than those used in the U.S. All splices and staggering of rebar are thus eliminated. All rebar joints are welded with portable X-ray machines examining the joints. This eliminates rebar congestion and leads to improved construction time.

- Europe approaches construction by using performance-based specifications allowing contractors/subcontractors to perform design (build) tasks using more effective and innovative approaches without interference from owners. 
- Many European countries are actively involved in education and training to upgrade the industry's ability to adopt and apply new construction technology.

- The U.S. should formally participate in international standardization activities such as the implementation of European ISO 9000 standards.

- Partnerships and joint ventures should be encouraged as in Europe and Japan.

\section{CASE STUDIES WHERE BARRIERS WERE OVERCOME}

As the European and Japanese contractors share of the foreign as well as their domestic markets have increased, U.S. design and construct firms specializing in industrial plants have still managed to win some large overseas projects using new, innovative and unique approach. To demonstrate this success, a leading U.S. engineering/construction company, which is positioned to operate on a global basis, was able to win a turnkey project in south-east Asia to build a large industrial complex. To achieve the competitive edge over other foreign and domestic contractors who were on the bidders list, this company submitted its proposal using the following approach:

- It teamed with a major European design/build contractor and formed a joint venture company. This partnership approach created a strong and broad-based experience base that was difficult to beat. Combining the two diverse experiences of both companies was well received by this Client who is based in Europe.

- Taking the client's major objective into consideration of completing and operating the plant within a specified period of time, the joint venture took an aggressive approach and bid the project reducing the scheduled time frame by over ten months. This aggressive commitment was viewed very favorably by the client.

- A well integrated project management team was formed to operate as one company rather than two.

To meet the above challenges, the joint venture incorporated the following latest available technology in executing this project:

- Implementation of CAD PDS state-of-the-art systems.

- Electronic transfer of data between vendors, fabricators and construction site.

- Computerized networking between the partners, offices, and the construction site.

- Computerized material management and tracking system. 
- Working closely with local government agencies and building authorities.

This project is still under construction. The continuing work challenges and completion milestones are carefully monitored. The project and client's objectives will be met through continued good planning and execution employing the above noted innovative practices. Though the scheduled completion is most important to the client, the project has managed to maintain quality including meeting stringent environmental standards for the design, construction and operation of the plant.

7. RECOMMENDATION'S FOR IMPLEMENTATION - ROLE FOR INDUSTRY AND GOVERNMENT

In the first six sections of this paper the whole issue of the need for improvement in productivity and quality in constructing facilities is discussed. This with the view of implementing the national construction goals and overcoming related barriers with focus on the industrial sector.

In this section, previously discussed issues and barriers related to achieving the national goals are briefly summarized. In addition some implementation measures required to accomplish these goals are also offered.

\section{- Summary of Suggestions:}

The industrial sector is the largest of the five sectors. It is estimated that on the order of half of all U.S. construction each year is comprised of new industrial facilities. A most significant factor related to trying to achieve the goals for industrial facilities is their rapidly changing requirements. This occurs because production technologies for processes and manufacturing are changing almost continuously, and additionally because new products and processes are continuously appearing for which new facilities are required. It should be noted that barriers cited are all interrelated to a large extent. For example, lack of leadership helps maintain adversarial relations in regulatory issues with attendant financial impacts on constructed projects. Liability issues generally up costs and slow processes in all sectors.

The following provides a qualitative comparison on the relative importance of the goals and barriers discussed in Sections 2 and 3 as they compare between industrial facilities and facilities of other sectors.

- Goals:

- Delivery Time: Major importance -- Achievement of goal difficult because of complexities and changing of requirements 
- Operation and Maintenance: Major importance -- Interruption and/or breakdowns have major economic impacts

- Comfort and Productivity: Lesser Importance -- Because of relatively few personnel, impact as measured by cost to achieve is low

- Occupant Related Illnesses and Injuries: Lesser importance -- Because of smaller numbers of personnel, impact to achieve fewer incidences as measured by cost is low

- Waste and Pollution: Major importance - Have high amount of waste and pollution. Even small amounts can incur major costs.

- Durability and Flexibility: Durability major importance, Flexibility less importance-- Durability relates to maintaining production in an adverse environment. Industrial plants usually have only one overall mission and flexibility is not an issue.

- Construction Related Illnesses and Injuries: This is of equal importance across all sectors.

- Barriers:

- Lack of Leadership: Major importance -- This is judged to be about same importance for all sectors and including government, industry and academia.

- Regulatory Barriers: Major importance -- This is of greater importance in the industrial sector than other sectors because of the magnitude, complexity and environmental concerns related to building industrial facilities. In this area there is perceived to be a strong adversarial posture between government and industry.

- Liability: Major importance -- Liabilities associated with third-party issues are generally less significant for industrial facilities. Those associated with owner's responsibility to the public with regard to environmental issues are greater.

- Adversarial Relations: Major importance - There may be more opportunities for teamwork and lessening of adversarial stances in industrial projects. However, adversarial relations are a major negative factor in all sectors. 
- Financial Disincentives: Major importance -- These apply in all sectors, but regulatory issues and corresponding delays have killed many large industrial projects. This relates in many instances to lack of leadership by government and industry leaders.

\section{- Proposed Implementation measures:}

This section offers a brief summary of implementation measures previously discussed. These measures are suggested for improvements in construction productivity and quality and to help drive the construction industry toward progress in reaching the national goals. The measures suggested are of necessity, qualitative statements. No details are offered as to scheduling and financing issues related to achieving the goals.

It is imperative that continuity of actions and focus are maintained on national efforts to implement improvement measures. Towards this objective a national task force should be initiated and empowered to direct implementation of appropriate measures. This task force should be comprised of members from government, industry and academia.

The suggested measures are listed below under three areas: government, industry and academia. When more than one area has major impact on implementation measures, this is noted by an asterisk.

- Government:

* - Forward ideas and attendant actions, including legislation, to provide more teamwork and unity between government, industry and academia. Promote partnering.

- Provide tax incentives to promote construction and industrial R\&D.

- Provide relief from overly restrictive requirements.

- Provide relief for anti-trust impediments.

- Streamline regulatory approval processes.

- Work with policy makers to defuse liability issues.

- Provide more directed and increased financial support for engineering and construction processes $R \& D$. 
- Selective use federally funded projects as lower risk test beds for innovation.

- Improve tax policy for U.S. companies on international projects.

- Promote and support the use of new technologies by U.S. engineering and construction companies for work on foreign projects.

- When U.S. companies are involved in the engineering and construction of industrial projects in third world countries, assist them in obtaining loans.

- Industry:

* - Change corporate culture to recognize the need for long term objectives supported by entrepreneurial $R \& D$ programs

- Provide corporate leadership to be more active and involved in implementation of improvement measures.

- Look to forming more alliances and partnerships on both $R \& D$ and construction projects.

- Push advanced technologies towards deployment in both domestic and foreign markets. This will add momentum to R\&D initiatives.

* - Become more involved in developing and using new materials and processes for constructed facilities.

- Interact with regulators to provide for streamlining of permitting processes.

- Academia:

* - Change culture to think of government, industry and academia as a team.

- Develop focus on applied research and technology transfer to more directly bring results of research to applications in constructed projects.

- Develop more partnering with industry in carrying out research.

- Develop more partnering with industry in establishing requirements for curriculum. 
* - Provide more opportunities for interaction with industrial and governmental counterparts to forward the above measures. 


\title{
National Construction and Building Workshop \\ White Paper on Institutional Buildings
}

by:

\section{Ezra D. Ehrenkrantz. FAIA}

Sponsored Chair

Architecture and Building Science Research

School of Architecture

New Jersey Institute of Technology

\author{
Principal \\ Ehrenkrantz \& Eckstut Architects
}

\section{Institutional Buildings: Focus on Health Care and Educational Facilities}

Institutional buildings represent a current market of approximately $\$ 62$ billion per year out of a total non-residential building construction value of about $\$ 148$ billion, as stated in "Construction Review." (See Appendix A) Under this category, public office and administrative buildings are included which have more in common with analogous commercial office buildings. Health and educational buildings comprise some $71 \%$ of the institutional market. If the commercial type of construction is removed from this category approximately $80 \%$ of all institutional buildings are related to health and education. The remaining $20 \%$ is divided between many diverse and specialized building types such as prisons, courthouses, libraries, police stations, postal facilities, fire stations, and passenger terminals. In this paper, health and educational facilities will be reviewed as being typical of the total institutional market.

This paper addresses issues related to educational and health facilities from both the public and private sectors. Within the educational and health arenas, there are many different building and client types which subdivide these markets into smaller units to which the design and construction industry respond. 
In education institutions, we have different building types designed to serve societal needs according to age, from early childhood learning centers and elementary schools to the full range of university facilities, as well as vocational, corporate and retraining facilities. Unlike the residential construction market in which the single family detached house dominates or the commercial market in which a generic $300 \times 300$ structural bay is typical, the design of a university residence hall, a teaching laboratory building or an elementary school in each case responds to a distinctly different building program.

The market for institutional buildings is divided into a great variety of building types. The needs for additional square footage is closely related to demographic factors. If one begins to design new products for elementary schools to meet a population bulge, by the time the products are designed, tested, approved, manufactured and distributed, the cohort has aged so that the immediate need is for middle schools. Where markets are temporal, it is more difficult to provide incentives for research and development.

In addition, funding for these different facilities is provided by local bond issues, state-aided programs, federal support, private institutions, or for-profit companies. In most cases, there is some blend of financing to design, build, and operate educational facilities. At state and local levels, criteria and requirements may differ from neighboring jurisdictions. This differentiation further divides the market in terms of space requirements, performance and/or cost.

This framework inhibits industry's ability to respond to the total aggregated market within each different building type. An elementary school in New York City is different from one in the suburbs, and both are different from a California school in a city or a suburb.

Changes in pedagogy, the use of educational technology, and distance learning, impact the establishment of a coherent market. Side-by-side suburban school districts may require the 
design and construction of totally different schools to accommodate co-operative learning and the use of educational technology as compared with a more traditional neighbor.

The relation between existing buildings, their required maintenance and the possibility of upgrading, together with demography, will determine whether the needs are for new facilities or additions and renovations of existing buildings. Between 1986 and 1992 over $50 \%$ of construction was expended on improvements other than on new buildings. This fact also contributes to a dilution of each of the individual building type markets which comprise the total educational field. When one looks at the time it takes to penetrate a market with new products, technologies, and processes, especially in a competitive bidding environment, it is not surprising to find limited funds being expended on R\&D for educational facilities.

In the area of health facilities we have a similar situation. This field encompasses a mix of clinics and medical office buildings at one end of the spectrum to tertiary care hospitals at the other end. In between there are the requirements for long-term care and many special facilities for pediatrics, laboratories, tuberculosis and hospice requirements. Together, as in the case of education, they present a market much more diverse than housing or commercial office buildings.

Within some of these health facilities, the requirements for special conditions for operating rooms, nursing wings, etc., present special and unique needs. Frequently, new space needs are met by the addition to or renovation of existing facilities. Between 1986 and 1992 approximately $65 \%$ of all new construction in the health field was for improvements rather than for totally new construction. The tieing to existing buildings, matching floor levels, providing compatible aesthetics and phasing the construction so that the institution can continue to function, all call for tailor-made attention with less opportunity for productivity and technical innovation than would be required to meet the percentage goals of this program. Contributions may be made particularly in the design, management and 
construction process areas albeit to a lesser target.

Within the health industry, the private, the religiously-affiliated facilities, the national or regional chains, the municipal, state and federal facilities and the myriad number of code and regulatory authorities, all contribute to market segmentation. Changes in care protocols, reimbursement and length of stay may change what is needed at any point in time. The aging of the population along with a changing balance of care requirements, all put an emphasis on additions and alterations that are site crafted. In the face of the high prospect for changes mandated by legislative initiatives, it is difficult for industry to set funds aside for innovation to meet evolving program requirements.

\section{Barriers to Innovation}

The building industry responds very effectively to the market it serves. If the scope of a specific market is established with regard to size, definition and continuity, companies will gear up to compete. If the market is diffuse or undefined, there is little incentive to expend R\&D resources. Predictability of projects in recent years has been undercut by the time required for regulatory approvals of all types. If one is to consider capital investment to improve productivity, there must be a market for the products at the end of the development process. Interest rates set by the Federal Reserve, ability to obtain zoning and environmental approvals together with the need for bond issue approvals and other funding uncertainties make industry investment in R\&D and the related funding of production facilities analogous to playing Russian roulette, particularly for the institutional market.

The ability to improve time, cost, and performance to the level desired depends on changing the way we obtain sites and related approvals, the manner in which we design the projects and build efficiently with factory made products. If market size and continuity is not available, coordinated, engineered, factory-made products will not be manufactured. Rather, generic products that can be made to fit any type of situation when altered and 
placed by craftsmen at the site, so that the different building components can work together, provide the more expensive and slower tailored alternative.

Productivity requires market definition and continuity so that industry can gear up to make compatible components pre-engineered to fit together and respond to the needs of the total building system. The ability to create such a framework is one of three areas where improvements in productivity have the greatest opportunity for gain. The others relate to obtaining the right to build on a specific piece of land and the financing to pay for the work. Without land and money, no matter how much is spent by industry on R\&D, nothing will be built. Without predictability of the market, we can still obtain process innovations to improve the management of an industry that has evolved to function in a discordant environment. But this will not enable us to meet the targets for improvement for which we are striving. The major opportunities for process innovation lie with the front-end issues of project initiation through obtaining a building permit.

At the onset of a project, issues of zoning, environmental approval and the total regulatory system impact the various institutional building types in terms of their ability to delay projects interminably or to stop them from proceeding at all. The administrative process is permitted to take much time and project delays are extended by opponents to try and kill any development. The tools available to stop projects frequently exceed those for development, and needed institutional projects are not built or become much more expensive because of this imbalance. When these time-consuming activities are combined with the fact that bond issues, congressional allocations, or state grants are frequently for a fixed dollar amount, we have a severe problem. Construction costs escalate during delays, requiring subsequent changes in project size and/or quality. The desired performance, which is possible at the beginning of a project, can not be afforded when construction starts.

In response to this scenario, if you are a manufacturer, do you engineer products to meet a 
program's performance requirements, or wait until they are downgraded to meet regulatory delays and then provide what can be afforded at that time? We have incentives in our system because of process delays, to wait and see what can be afforded at the end of the process and then provide ad hoc responses to a changing situation. This happens all too frequently, and the current situation does not induce the expenditure of capital for the design and manufacture of coordinated components that would go together quickly and easily at the building site.

To summarize some of the points made in the introductory section, the unique barriers to implementation of a program to improve substantial time, quality and cost of institutional construction are many and varied:

A. Regulatory processes which cause extended project delays.

B. Unpredictability of the funding stream.

C. Varied user requirements and budgets from different jurisdictions that make it difficult to define a coherent market.

D. Segmentation of the institutional construction market into many building types.

E. The difficulty of establishing a predictable market as a target for innovation.

F. The competitive bidding process requires specified alternatives which need to be available for unique new products.

G. A total design and construction environment which gives advantage to generic products and site fabrications as opposed to coordinated engineered products.

H. Liability issues require low-risk opportunities to introduce product innovations. (This item was not introduced above but it may be said that most buildings are one of a kind, in effect prototypes, so we can never test performance and then go into mass production. This leaves the design and construction industry vulnerable with respect to innovation.)

To ameliorate the context in which the industry works, actions should be taken to foster 
market aggregation based on inclusive user requirements with the development of test beds for innovation (see Section 5). Such test beds are required as incentives for industry, particularly in a complex building sector such as institutional buildings. The improvement of the regulatory context in which we work and reduction of the major program variations to which we must respond, along with better predictability with respect to both funding and interest

rates would be most helpful.

\section{Technologies}

There are many technologies that can have an impact on time, cost and quality. To achieve maximum effectiveness they should be applied in engineered, rather than generic terms. The first area must relate to complete system predictability. When a total project is constructed, we must know that it will perform as anticipated. The coordinated component systems must work together to provide the desired building performance. As this involves the products of different manufacturers, the development of compatible components is essential. As it is difficult to assure a specific acoustic environment with a new engineered flexible wall panel if the ceiling and lighting system provide an alternate path for sound transmission, compatible components must be developed to meet compatible performance requirements. The second area will deal with the components themselves; designs for function, flexibility, life-cycle cost, and environmental performance can all be improved. The responsibility to develop new components requires, in addition to meeting their own individual performance requirements, the compatible joining technologies for the components to work together. (See Appendix B.) Third, the productivity and learning activities in health and education are changing to use new developments in information technology. The mission cost and effectiveness of these and other institutional building types are going to depend on how the buildings, the users, and the information technology systems interface and evolve over time. The flexibility to optimize on these new relationships will be a driving force for technical innovations. 


\section{International Comparisons}

International comparisons are hard to make in terms of how the construction industry works. However, they are most appropriate in terms of providing precedents and setting a framework for the industry to evaluate options. Our industry has optimized itself with respect to a fragmented market, working to many different sets of standards and requirements, local approvals, and a Federal Reserve Board that steers the economic ship of state by manipulating interest rates and hence the construction industry. Under such conditions a low capital, low R\&D type of industry results. Within that framework, the building industry is very creative.

Other countries have larger school districts with counties or states acting as a single entity to control better the market and funding. Regulations are more centralized, and the ability to contract for larger volumes of work by a single entity provides leverage to maximize incentives for the development of products that are in keeping with user needs. This market aggregation has resulted in greater industry investment in R\&D and in production facilities. In some cases, extended contracts over a number of years were provided and these long term markets had a beneficial impact on promoting industrial development of building components. Where market continuity is interrupted industry falters as in the United States. Today, there is a smaller number of compatible engineered products available than there was twenty-five years ago.

These general comments are made based on detailed experience in the United Kingdom with more limited experience with respect to a number of other countries. As an example, when I worked in England at the Building Research Establishment, I noted that the Hertfordshire County Council projected a need for 175 new schools in 15 years. Bids were taken for annual programs and engineered systems developed by industry which were responsive to educational requirements and costs. The resultant construction was put in place much faster than if conventional methods were used. Numerous similar county and multi-county educational authorities were established in the United Kingdom and emulated 
in other European countries. Predictability of aggregated markets made the basic difference.

From my overseas experience, and from practice here, I believe the construction industry responds very well to incentive programs. Short term and problematic incentives, and unkept promises result in abortive efforts and the firing of industry officials who responded to the challenge, committing time and effort on an elusive and aborted opportunity.

\section{Case Studies: SCSD and VA}

Two case studies may be used to illustrate how barriers were overcome and the level of success which followed.

\section{A. The SCSD Project (1961-1967)}

This project was developed to try and meet the education requirements of California school districts which could not be satisfactorily met, within the State Aided budget for school construction. A market of 13 school districts was organized. Pioneering techniques for defining user requirements, developing performance specifications and managing the total delivery process from research to occupancy were developed for the 13 school district consortium. Investigation of the requirements of administrators, teachers, and students quickly showed that flexible classroom space was top priority. To provide this, along with high environmental standards, components of the school building were specified on a performance basis and industry was asked to respond. Manufacturers were found who were happy to meet the new critical criteria by designing new components to satisfy both the need for a high level of performance and cost savings given the promise of a mass market. Many companies checked out the criteria with other school districts and, when our directions were confirmed, they agreed to participate. These manufacturers formed teams to provide high quality compatible components. A prototype building was constructed at Stanford University as our test bed for testing the components of the selected low bid team. The 13 schools were then designed and constructed. The second and third 
low bid teams also built schools and provided the basis for competitive bidding. Additional companies soon created components to compete. (Appendix B shows our compatibility chart for coordinated engineered components as the program went from a pump-priming project to the open market.) Over 5,000 buildings were built using a total building system, or some of the components. Improved performance was coupled with a $20 \%$ reduction in the cost of the system components and construction time was typically reduced by $25-33 \%$.

\section{B. The Veterans Administration (VA) Hospital Building System}

This project was established after a feasibility study concluded it was a viable project. The original objectives of the feasibility study were to seek methods of improving VA buildings, particularly with respect to costs, performance, adaptability, construction time, and transfer of experience from building to building, or "feedback."

The original project concept was clearly that of a traditional building system, that is, an innovative design for a limited set of building components, to provide a well-engineered design vocabulary with which to build VA hospitals.

The particular subsystems selected for our study were structure, ceilings, partitions, heating and cooling, plumbing and electrical distribution. All other subsystems, such as exterior walls, communications and materials handling, were outside our scope.

Nevertheless these "non-integrated" subsystems had to be taken into account to a sufficient degree to assure their compatibility within the overall design.

We became aware in the feasibility study of the "preconceptions" with which we were working and the arbitrariness of the component categories themselves, which were constraints on system design for the VA. Other major determinants were the requirements of nationwide applicability and the need to conform to all current laws, regulations and procurement policies. Furthermore, the VA was not in a position to guarantee an ongoing 
construction market which could be used to induce manufacturers to develop new products; we were thus limited to the use of components already in production.

The essence of the VA system was a designed space module concept that would fit the overwhelming range of VA hospital design requirements. Drawings were prepared to provide for competitive bidding by alternate component technologies and designs. Innovation was required in critical areas to provide flexibility. Key innovations called for an economic walk-on ceiling and routing services so that they could be accessed as required without digging into the fabric of the building, or disturbing anyone in the occupied zone of the building. The prototype hospital was built at Loma Linda, California at a cost which was $5 \%$ below budget for a conventional VA hospital, but was $19 \%$ below the VA estimate for the facilities provided.

Because one could not commit the congress to build hospitals in advance of funding authorization, this project called for a designed system without an aggregated market. The size of the Loma Linda hospital, $(\$ 60,000,000)$ and the fact that the VA indicated it would build future projects to provide the innovations called for in the prototype hospital, engaged some companies to make new and unique products. Some of the products and concepts have found a significant market meeting hospital design requirements.

In contrast with the SCSD project, the lack of an aggregated market limited system development activity. However, the preparation of logical program requirements on the part of the VA provided for a significant level of innovation on the part of industry.

Both projects demonstrate the value of establishing test beds or prototype projects to spur innovation. The requirements for $R \& D$ must be appropriate to the market opportunity offered. The preparation of a program document to define market needs and performance requirements, to translate those needs into a form to which industry can respond, is an essential beginning. The development of new technologies and the processes to put them 
in place takes time. One must project needs from three to seven years if one is looking for significant innovation.

\section{Implementation}

Goals have been set for this program which include:

Goal 1: $50 \%$ Reduction in Delivery Time.

Goal 2: $50 \%$ Reduction in Operations, Maintenance, Energy Costs.

Goal 3: $30 \%$ Increase in Productivity and Comfort.

Goal 4: $50 \%$ Fewer Occupational Related Illness and Injuries

Goal 5: 50\% Less Waste and Pollution.

Goal 6: $50 \%$ More Durability and Flexibility.

Goal 7: $50 \%$ Reduction in Construction Work Illnesses and Injuries.

The construction industry is a very innovative and responsive industry which optimizes its performance to the framework in which it operates. Any firm that does not do so goes out of business quickly. The goals that are stated above are not achievable if the industry continues to do business as usual. Improvements in the order of magnitude of a fifth to a half of the desired levels may be achievable, built on the framework of the current industry. This is particularly true with respect to the process and regulatory issues impacting project approval activities. However, the industry is very competitive and leaves very little on the table when bidding for work. Large-scale improvements in performance, therefore, will require changes in the way we work. Contextual innovation is a precursor to any successful implementation program. This should apply to most, if not all, of the industry sectors.

To implement any substantial program for technical innovation, particularly in the institutional market, government and industry must share complementary roles. 
Government must help to set criteria related to needs, performance, and financial support for the funding and operation of the resultant buildings. The market for the products must be defined and test beds established for development which facilitate testing, reduce liability and act to introduce the innovation to the market place. An aggregated market of projects for introduction of the new components to the market place is needed so that industry can move from hand made prototypes to production. This initial pump priming of the market must be organized so that the competitive bidding requirements do not undercut the new technologies before they can be shown. Then the products must hold their own in the market place.

Industry on its part must fund the needed R\&D to create new products and work with other companies to assure compatibility of their products. Engineered products must fit together at the building site without site alterations for fit. New processes and tolerance systems may be needed to assure such compatibility.

When industry develops new products to meet the performance criteria, wide-scale testing for code approval and the construction of prototype facilities will follow. When there is assurance of the appropriateness of the new technologies, the construction of the manufacturing facilities and the marketing follows.

In short, government defines the market opportunity in an appropriate manner, and industry responds to the opportunity. We can do some work to change our current industry's comfort with its dependence on generic products. But to achieve the level of increase in productivity desired for this program calls for a new vocabulary of engineered products to be available that can provide greater efficiency and performance. In the institutional field with its many varied and disparate market requirements, government has the role to define the market and its needs. Given this target, industry has the role and the ability to develop and market the new technologies. 


\section{APPENDIX A}

Contained in this appendix are nine graphs and charts that provide an overview of the institutional construction market. The graphs establish the relationship of the institutional segment to the overall construction market and delineate a breakdown of the institutional market into its constituent parts. There are three primary categories listed under "institutional" construction: education, health, and "other public." This last category represents a compilation of at least ten significantly dissimilar types of institutional buildings including police and fire stations, courthouses, prisons, and government office buildings.

Taken together, education and health account for approximately $70 \%$ of institutional construction market. Within the categories of education and health, we see the market further fragmenting into many building types. Under education there are pre-school, elementary, middle and secondary schools. Higher education includes student centers, lecture halls, laboratories, classroom buildings, performance facilities, sports facilities, 
administration buildings, dormitories, as well as maintenance and physical plant facilities. The health segment also breaks down into a number of different building types. There are hospitals, nursing homes, rest homes, clinics, etc. Hospitals are extremely expensive, specialized facilities, and a large urban hospital presents significantly different building issues than a suburban or a rural one. Finally, new construction accounts for approximately $50 \%$ of education construction and $40 \%$ of health construction. The remainder falls under the heading of "improvements" which includes additions, renovations, and major replacements.

Far from presenting a monolithic block of building types and construction features, an analysis of the data included in this appendix indicates that the institutional market fragments into a diversity of building types and construction activities which present an array of design, construction and delivery conditions. 


\section{APPENDIX B}

The initial compatibility charts of the coordinated company products following the SCSD project are shown on the next two tables. Within 18 months the vocabulary of coordinated components had tripled. The first page shows the structure, heating, ventilating, air conditioning, and lighting-ceiling components. The second page shows how the demountable and moveable partitions interface with the lighting ceiling system. 
APPENDIX A

Ezra D, Ehrenkrantz 
FIGURE 1

NEW CONSTRUCTION PUT IN PLACE IN THE U.S.

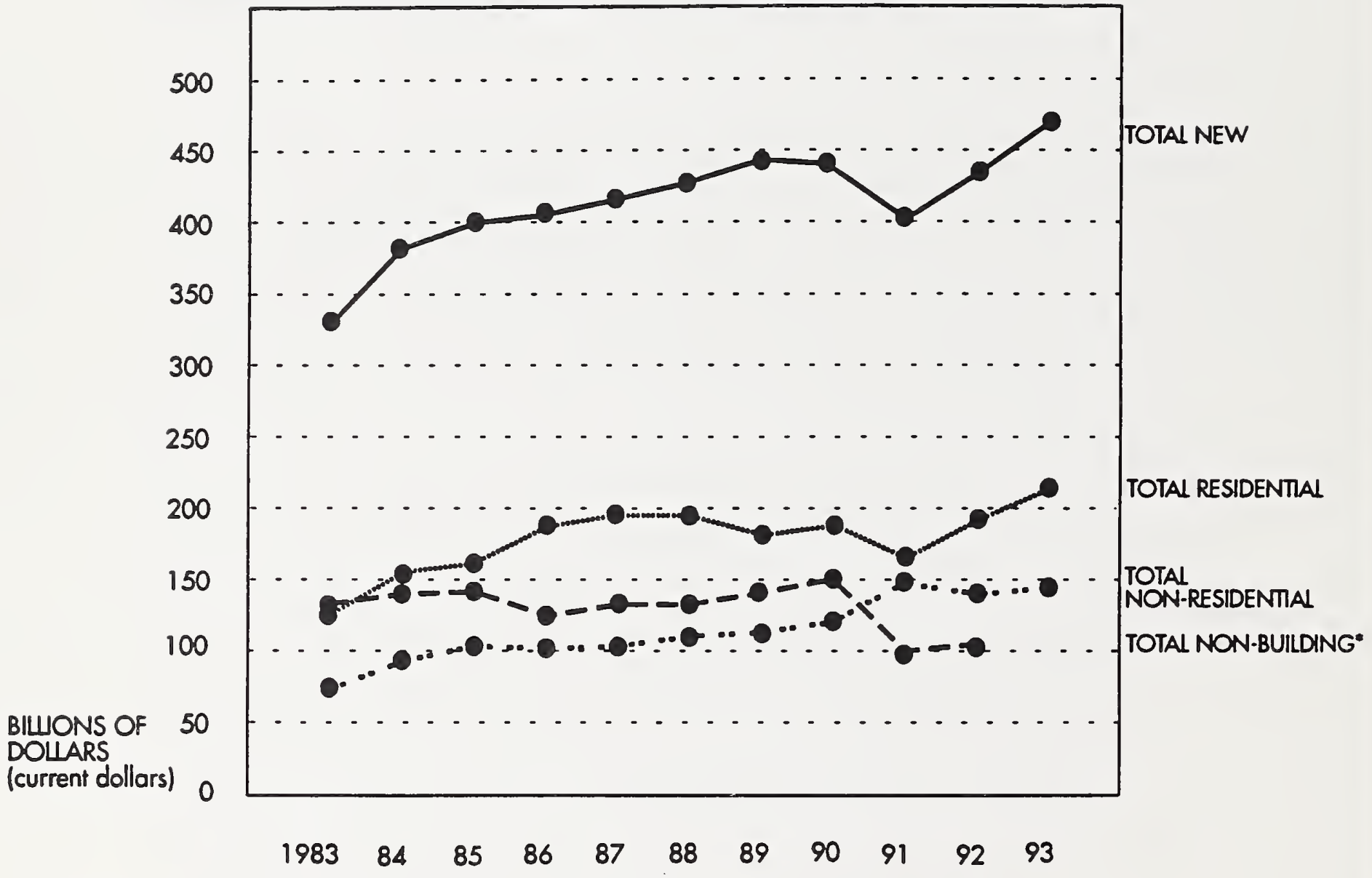

Source: Construction Review

- "Non-building" includes highways and streets, railroods, utilities (water, gas and electric, light and power), sewer systems, petroloum pipelines, consservation and dovelopment and military facilites. 
FIGURE 2

70

INSTITUTIONAL CONSTRUCTION IN THE U.S.

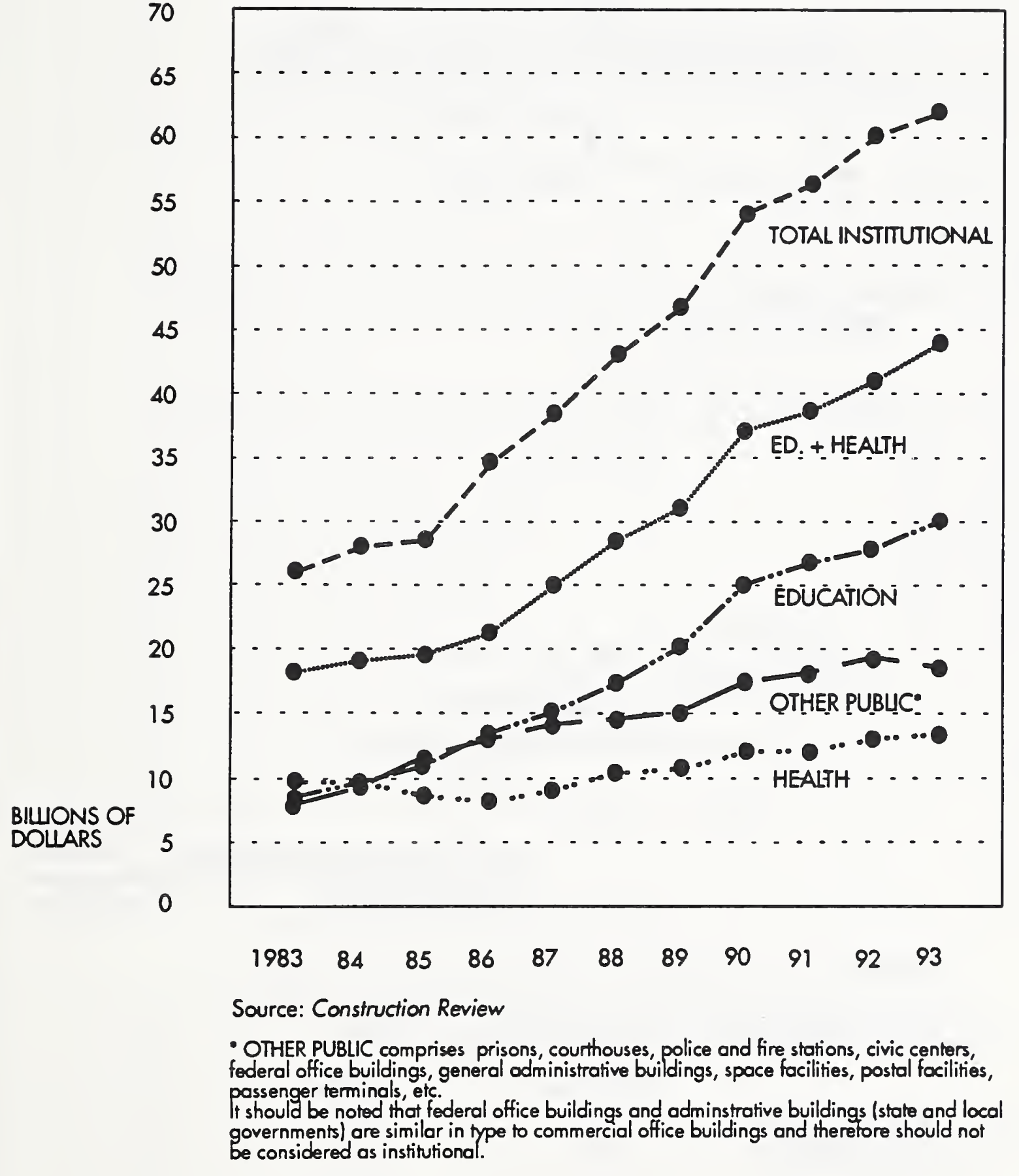


EXPENDITURES FOR NON-RESIDENTIAL

IMPROVEMENTS AND REPAIRS 1992

EDUCATION FIGURE 3

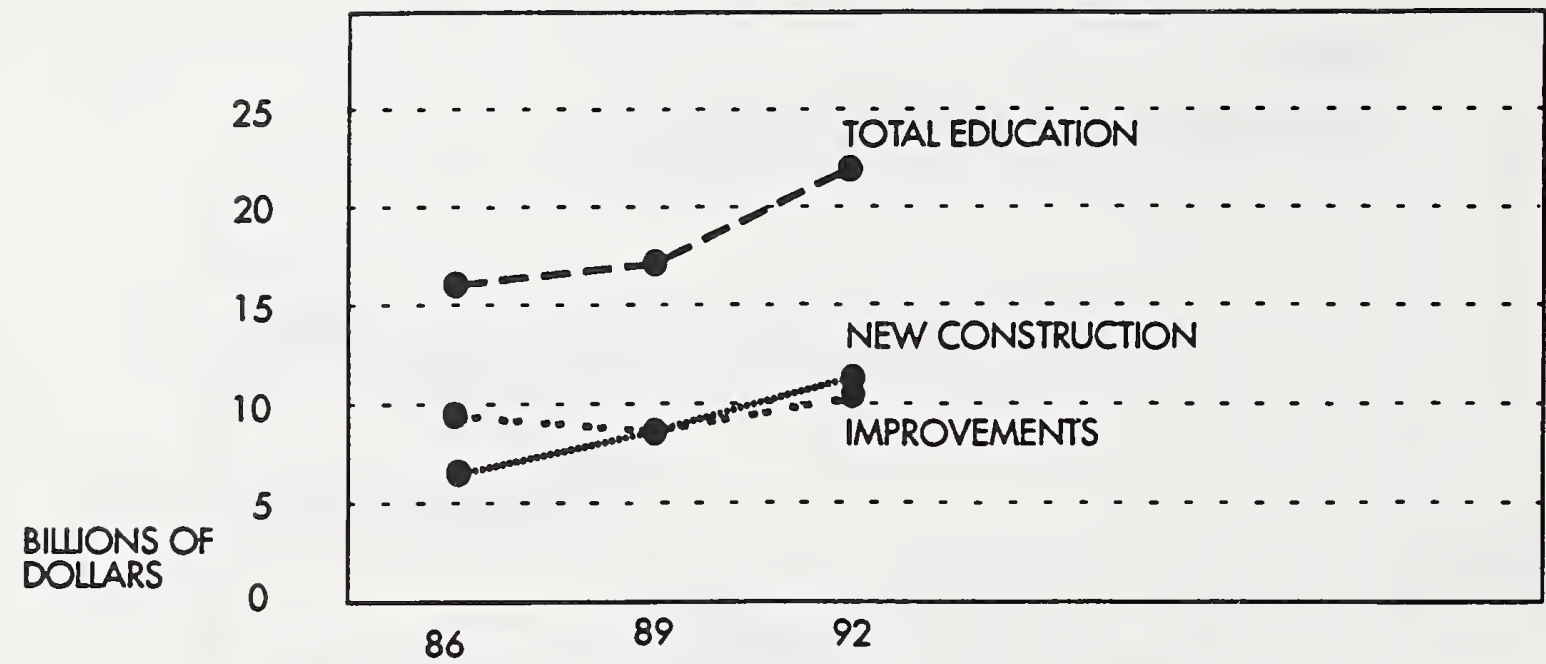

HEALTH FIGURE 4

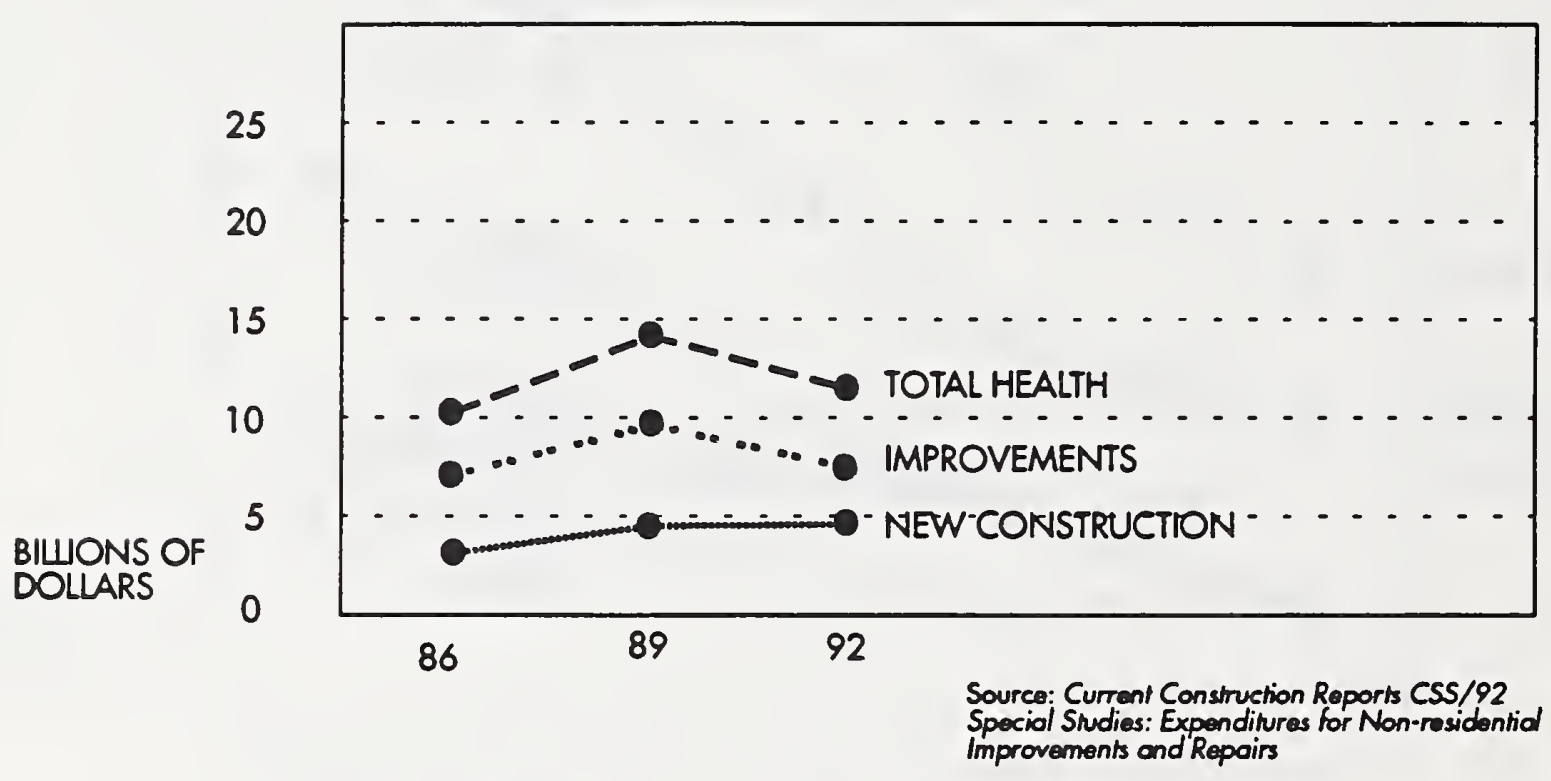

FIGURE 5

IMPROVEMENTS AS PERCENT OF TOTAL

Education Health

1986

$60 \% \quad 67 \%$

1989

$50 \% \quad 68 \%$

1992

$48 \%$

$61 \%$ 
FIGURE 6

SUMMARY OF STATE AND LOCAL GOVERNMENT

SPENDING FOR SCHOOL CONSTRUCTION IN THE U.S.

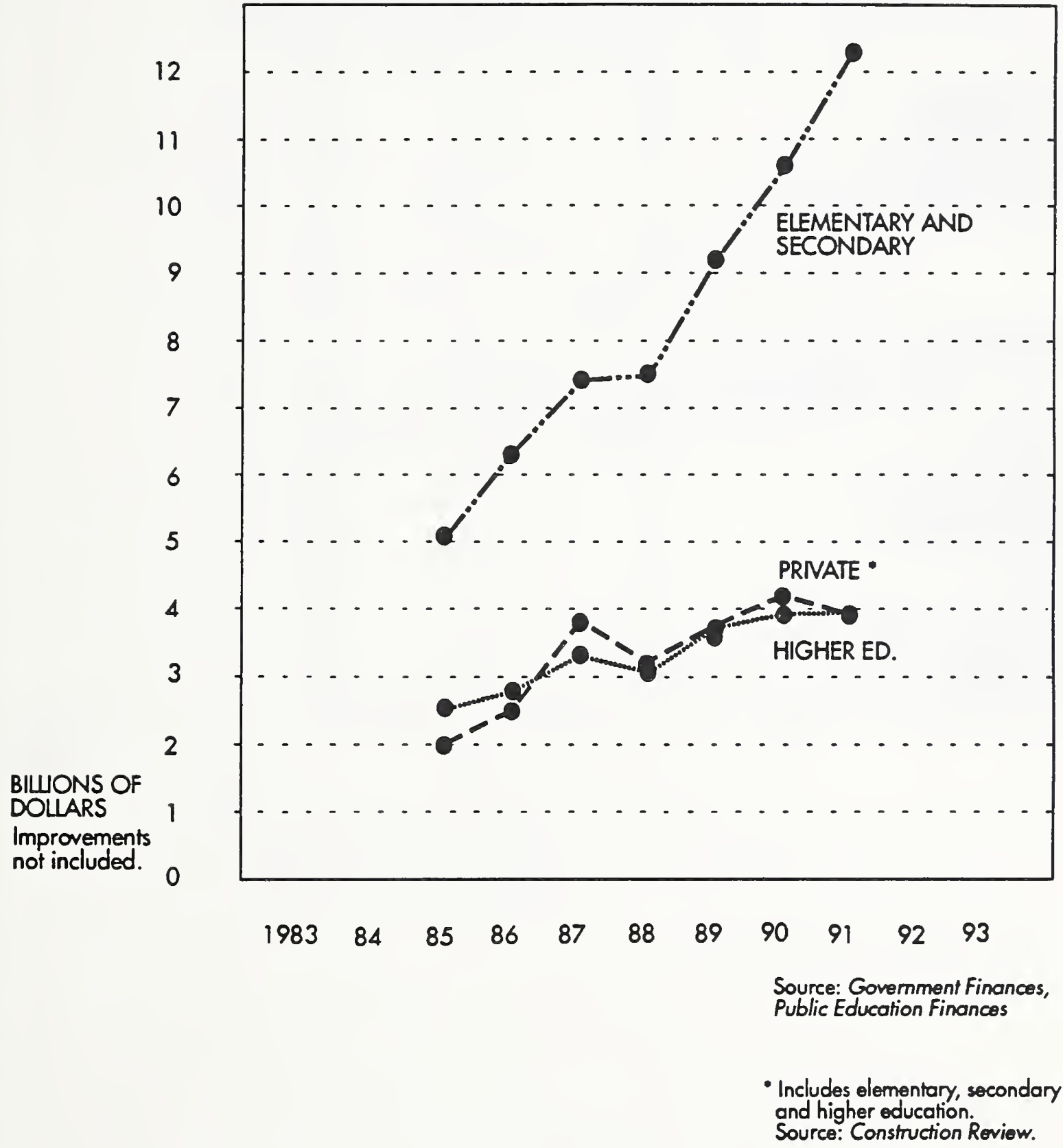


FIGURE 7

Education Sector Expenditures

\begin{tabular}{|c|c|c|c|}
\hline billions of dollars & 1986 & 89 & 92 \\
\hline \multicolumn{4}{|l|}{$\begin{array}{l}\text { NewConstruction } \\
\text { (Public) }\end{array}$} \\
\hline $\begin{array}{l}\text { Elementary and Secondary } \\
\text { Schools } \\
\text { Includes primary, middle and high } \\
\text { schools. }\end{array}$ & 6.8 & 9.9 & 11.4 \\
\hline $\begin{array}{l}\text { Higher Education } \\
\text { Includes classroom buildings, } \\
\text { laboratories, theaters, libraries, } \\
\text { dormitories, student centers, } \\
\text { adminstration buildings, sports } \\
\text { facilites, support and physical plant } \\
\text { facilities, etc. }\end{array}$ & 3.5 & 4.6 & 9.3 \\
\hline Total & 10.3 & 18.2 & 20.7 \\
\hline \multicolumn{4}{|l|}{$\begin{array}{l}\text { Source: Government Finances, } \\
\text { Public Education Finances }\end{array}$} \\
\hline $\begin{array}{l}\text { IMPROVEMENTS } \\
\text { Indicates the portion of the above } \\
\text { totals spent on improvements } \\
\text { including: additions, alterations } \\
\text { (renovation and remodeling), and } \\
\text { major replacements. }\end{array}$ & 5.7 & 8.0 & 11.5 \\
\hline $\begin{array}{l}\text { Source: Current Construction Reports } \\
\text { CSS/92 Special Studies, } \\
\text { Expenditures for Nonresidential } \\
\text { Improvements and Repairs: } 1992 .\end{array}$ & & & \\
\hline
\end{tabular}




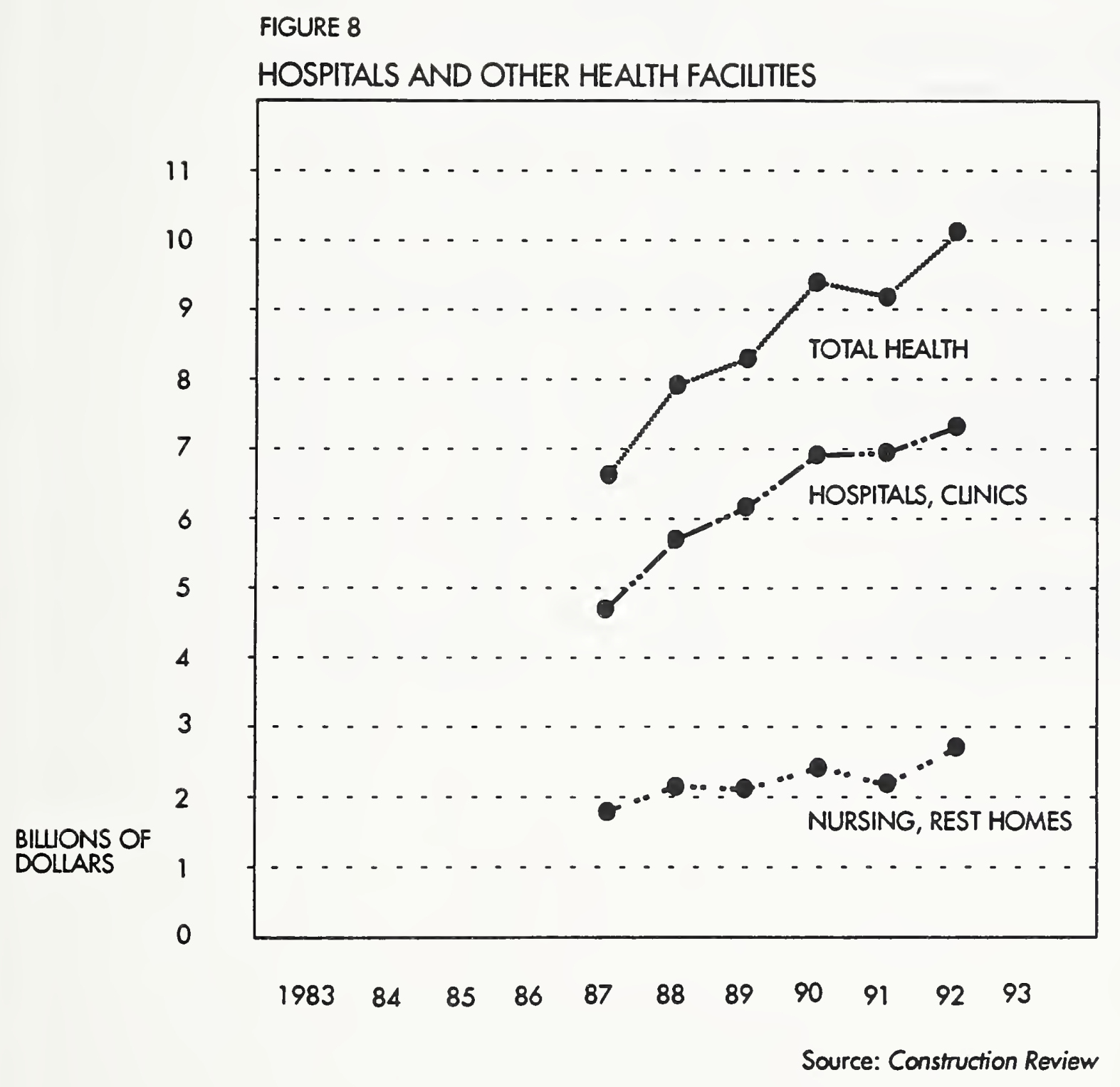


FIGURE 9

Health Sector Expenditures

\begin{tabular}{|l|l|l|l|}
\hline \multicolumn{1}{|c|}{ billions of dollars } & 1986 & 89 & 92 \\
\hline $\begin{array}{l}\text { New Construction } \\
\text { (private buildings) }\end{array}$ & & & \\
$\begin{array}{l}\text { Hospitals } \\
\text { includes: clinics, rural and suburban } \\
\text { hospitals, large urban hospitals }\end{array}$ & 4.7 & 6.2 & 7.4 \\
$\begin{array}{l}\text { Nursing Homes } \\
\text { includes: nursing homes, rest } \\
\text { homes, convalescent centers, etc. }\end{array}$ & 1.8 & 2.1 & 2.7 \\
$\begin{array}{l}\text { TOTAL } \\
\text { TOTAL }\end{array}$ & 6.5 & 8.3 & 10.1 \\
\hline $\begin{array}{l}\text { IMPROVEMENTS } \\
\text { (private buildings) } \\
\text { These numbers indicate the portion } \\
\text { of the above Lotals spent on } \\
\text { improvements including: additions, } \\
\text { alterations (renovation and } \\
\text { remodeling), and major } \\
\text { replacements. }\end{array}$ & 3 & 4.7 & 6.5 \\
$\begin{array}{l}\text { source: Current Construction Reports } \\
\text { CSS/92 Special Studies, } \\
\text { Expenditures for Nonresidential } \\
\text { Improvements and Repairs: 1992" }\end{array}$ & & & \\
\hline
\end{tabular}




\section{APPENDIX B}

\section{Ezra D. Ehrenkrantz}


Subsystem Compatibility Matrix 11

Lighting-ceiling Demountable Partitions Moveable Partitions

October 15, 1969
Lighting-ceiling

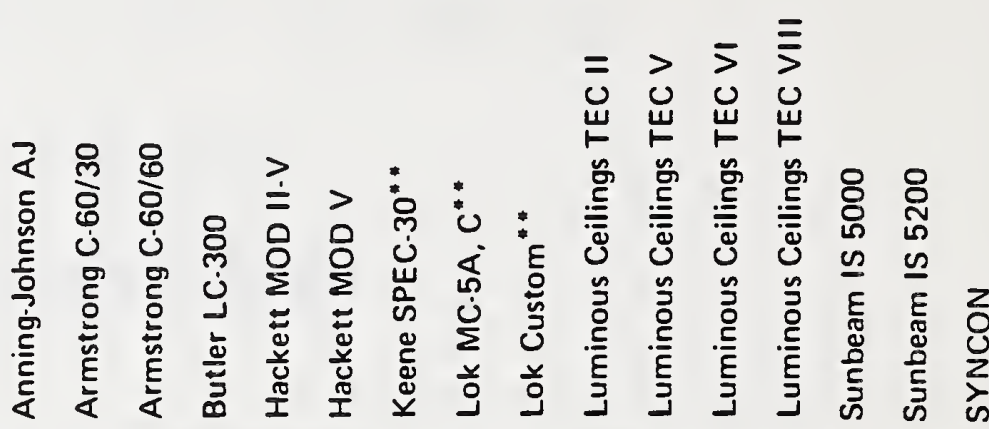

Donn CRUSADER

Hauserman DOUBLE.WALL

Mills CLASSROOM

National Gypsum CONTEMPOWALL

Penn Metal PENCRAFT

Penn Metal PENWALL

VMP CORPORATE

VMP TWINLINE

U. S. Gypsum VAUGHAN"*

Advanced TYPE 12"*

Donn UNITIZED

Hauserman READY.WALL

$\infty$ Hough SERIES 8000

글 Hough 8100

$\circlearrowleft$

Hupp MAgNAWALL 400

Hupp MAGNAWALL 600

Kwik-Wall REGULAR *

Masonite QUICK.CHANGE"*

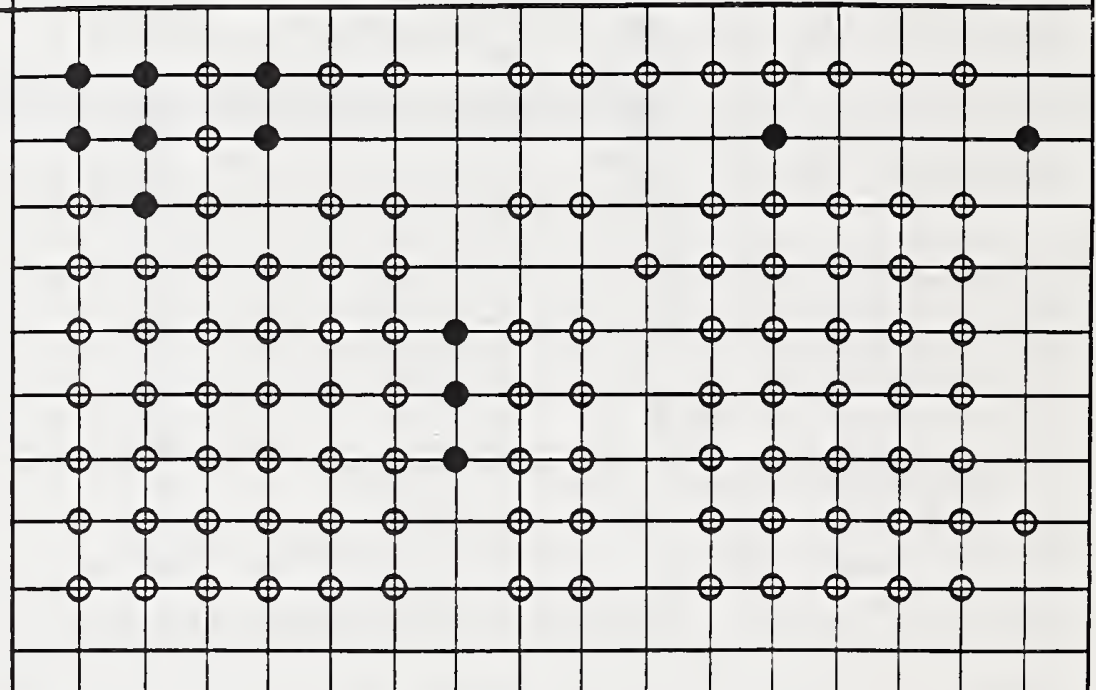


Subsystem Compatibility Matrix I

Structure

Lighting-ceiling HVAC

October 15, 1969
Heating, ventilating, air conditioning

Structure

Group A

Group B

Anning-Johnson AJ

Armstrong C-60/30

Armstrong C-60/60

Butler LC-300

Hackett MOD II.V

Hackett MOD V

Keene SPEC. $30^{*}$

异 Lok MC-5A, C*

Lok Custom "

Luminous Ceilings TEC II

Luminous Ceilings TEC V

Luminous Ceilings TEC VI

Luminous Ceilings TEC VIII

Sunbeam IS 5000

Sunbeam IS 5200

SYNCON

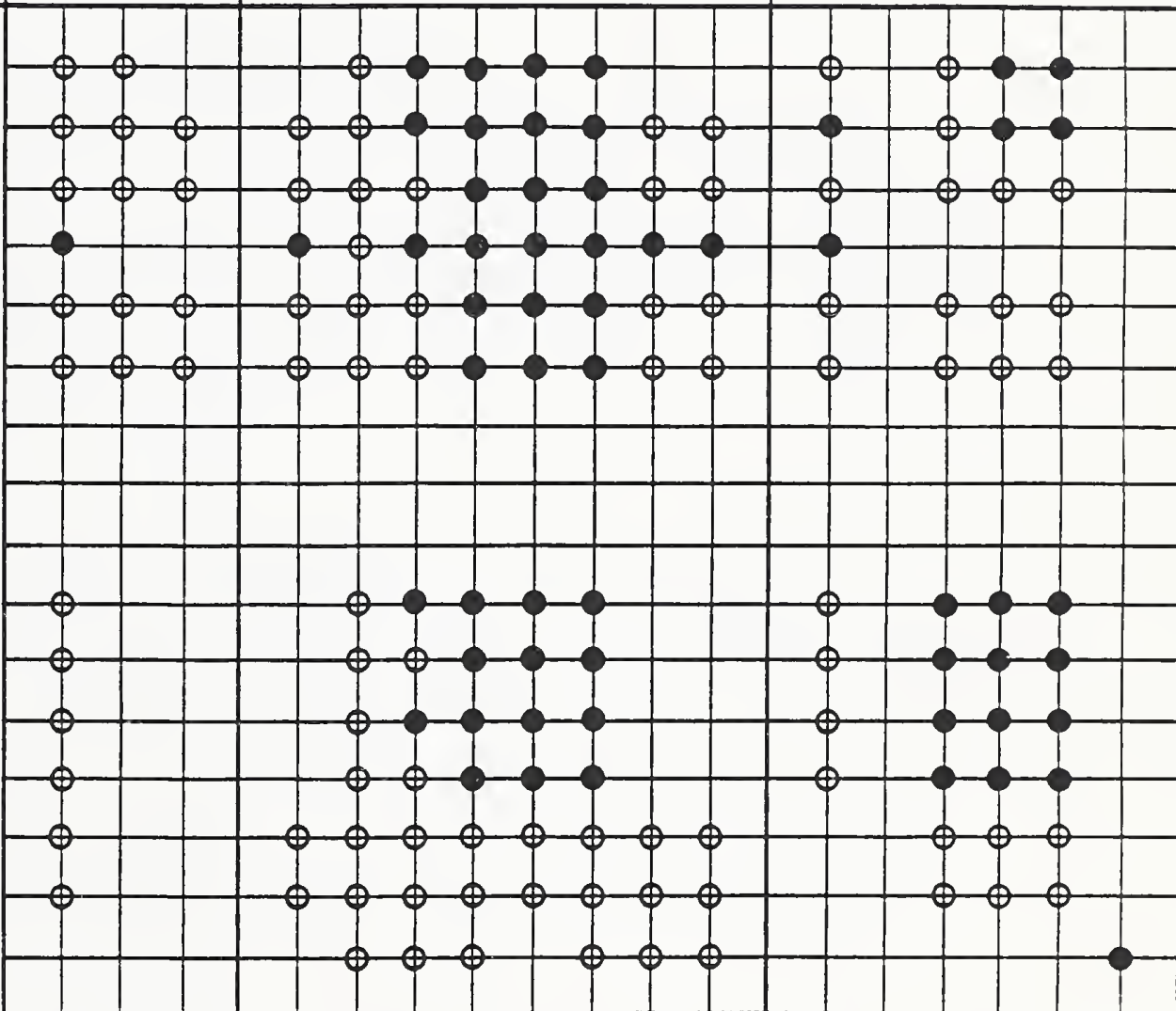

Butler SPACE GRID

Haven-Busch JOISTRUSS *

Inland-Ryerson

Macomber V.LOK

Romac MODULOC

SYNCON

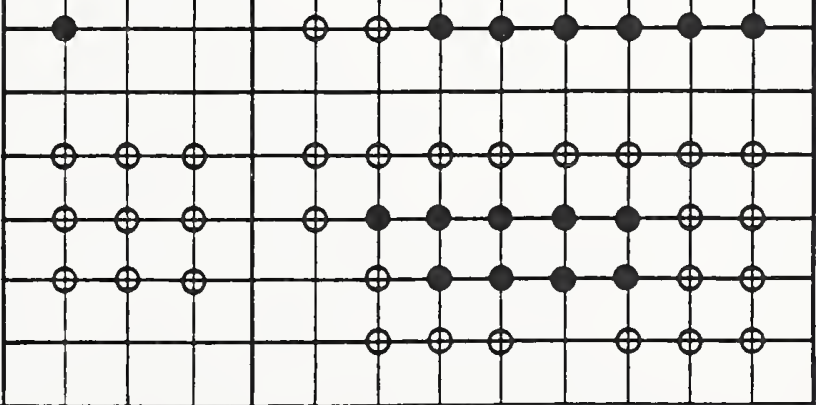

indicates details of interfacing worked out.

$O$ indicates probable compatibility but interfacing not yet detailed.

indicates product in development.

- indicates data incomplete on this product. 


\section{White Paper on \\ National Construction and Building Goals \\ A PUBLIC WORKS PERSPECTIVE \\ by: \\ Albert A. Grant. Consulting Engineer}

\section{Introduction}

Public works need to be considered in two broad categories.

The first is public building facilities that house people for a variety of functions, such as schools, libraries, and government offices. The second category includes the basic supporting infrastructure or "lifeline" networks that enable these public building facilities to operate and serve their user populations. Examples are utility and communication support systems, and transportation access and distribution networks.

Since the other four industry perspective white papers address housing, institutional, commercial and industrial facilities, all of which overlap public works building facilities in some measure, this white paper will focus primarily on the second category of public works, the support infrastructure. Further, to take advantage of recently available data, within the limits of this white paper, the support infrastructure elements to be assessed in light of the National Construction and Building Goals will be largely confined to the following for illustrative purposes:

- Transportation

- Water Resources

- Power and Energy

- Waste Water

- Solid Waste

- Hazardous Waste 
It should be noted at the outset that the application of the National Construction and Building Goals to public works support infrastructure will differ in some aspects from their application to public works building facilities. This paper will try to identify and explain those differences. Also, the achievement of the goals for public works buildings may directly impact the scale and scheduling of the support systems. For example, a 50\% reduction in waste and pollution can affect the scale and sizing of the support infrastructure needed to remove these contaminants. And a 50\% reduction in delivery time will require accelerated planning and installation of the needed support facilities.

Based on the above discussion, this white paper will review the priority public works infrastructure concerns as identified in a recent survey of local elected officials and public works professionals, and indicate how they might be impacted by the National Construction and Building Goals. This will be followed by a discussion of public works infrastructure technologies that can help to achieve the goals, the barriers to implementation of these technologies, and the strategies to overcome these barriers.

The paper will conclude with a brief summary and a set of recommendations for government and industry action designed to facilitate achievement of the National Construction and Building Goals.

\section{Priority Public Works Problems/Needs}

As part of its ongoing study of "State and Local Public Works Needs," the Civil Engineering Research Foundation (CERF), the research affiliate of the American Society of Civil Engineers (ASCE), recently published the results of a survey on the highest priority public works problems and needs (Meeting State and Local Public Works Needs, October 1994). The survey captured the views and concerns of public works directors, chief appointed officials and chief elected officials from a broad range of municipalities with differing populations and geographic locations across the country. Figure I is a matrix summary of the 
survey results.

The following is a brief description of a high priority problem and need selected from each of the public works issue categories in Figure I (except for building issues) for illustrative purposes.

TRANSPORTATION: Maintenance and Repair of Pavements

The underlying problem for pavement maintenance and repair centers around attaining appropriate pavement designs and construction.

Factors contributing to increased maintenance and repair demands include:

- Quality and management of paving methods and materials.

- Quality and management of repair methods and materials.

- Larger traffic volumes than anticipated at design.

- Greater volumes of freight truck traffic which subjects pavements to heavy payloads.

Particular challenges in repair and rehabilitation of pavements include:

- Potholes

- Reflective cracking -- older cracks in roadways propagating through new, resurfaced pavement.

- Rutting -- grooves worn in the pavement where tires meet pavement.

- Base failure -- soil foundation underneath roadway fails.

SOLID WASTE: Separation Technologies in Materials Recovery

Solid waste officials acknowledge severe, nationwide limitations of available landfill space. Recycling has been singled out as an outstanding solution because it not only reduces waste, it 
conserves resources used to manufacture new glass, paper, plastic, etc. Unfortunately, many of these recyclable items are regularly being disposed of in the waste stream. Many recycling programs have been established to collect co-mingled material (glass, paper, plastic, etc.) in hopes that easier recycling procedures will generate greater use. The recovery of recyclable materials from both solid waste and co-mingled recyclable streams is one of the most difficult technical challenges for the materials recovery industry.

Whether recyclable material is recovered from the general waste stream or a co-mingled collection, separation of specific materials remains a challenge. No singular automated process exists that can accomplish this separation. In many cases, waste separation is still performed by manually "picking" from conveyor belts. However, fully automated technologies have been introduced that remove certain types of waste items from the solid waste stream. These separation devices generally handle one certain type of waste material which produces the need for different devices for each material. These devices are often quite large. The cost of acquiring and integrating all the respective materials separation devices often makes them too expensive to be feasible to solid waste facilities. 
FIGURE I .

\section{MATRIX OF THE HIGHEST PRIORITY PUBLIC WORKS PROBLEMS AND NEEDS (Listed per infrastructure system in order of priority)}

Note: $F Q=$ Frequency, $C T=$ Criticality, and $V L=$ Value. The value is based on responses of 345 Public Works Directors to a nationwide survey on infrastructure issues. The value is the sum of the frequency that a problem was cited and its criticality, or the ranking given a problem or need.

\section{BUILDINGS ISSUES}

ADA Compliance

Maintenance of Building Systems

Construction/Demolition Worksite Safety

Excavation Safety

Flood Protection

Lighting Efficiency

Construction/Demo Scheduling \& Estimating

HVAC \& Plumbing Efficiency

\section{TRANSPORTATION ISSUES}

Maintenance and Repair of Pavements

Drainage of Highways and Roadways

Asphalt Performance for Pavements

Inspection \& Management of Pavements

Maintenance and Repair of Bridges

Roadway Markings and Signs

Roadway Snow removal and De-icing

Road Crew Safety

\section{SOLID WASTE ISSUES}

Management of Residential Collection

Source Reduction by Composting

Separation Technologies in Materials Recovery

Separation of Waste in Residential Collection

Source Reduction of Litter

Equipment Maintenance for Resid. Collection

Materials Recovery by Paper Recycling

Waste Management for RCRA Compliance

\section{HAZARDOUS WASTE ISSUES}

Recycling and Reuse of Hazardous Waste

Worker Safety in Materials Handling

Alternatives to Landfill Disposal

Management and Regulations

Residential Hazardous Waste

Spills and Clean-up Technologies

Groundwater Pollution Monitoring/Containment

Hazard Identification of Materials

$\begin{array}{rrr}F Q & C T & V L \\ 200 & 285 & 485 \\ 176 & 226 & 402 \\ 145 & 243 & 388 \\ 105 & 117 & 222 \\ 109 & 111 & 220 \\ 119 & 88 & 207 \\ 95 & 103 & 198 \\ 96 & 85 & 181\end{array}$

FQ CT VL

$293 \quad 610903$

$\begin{array}{lll}198 & 186 & 384\end{array}$

$\begin{array}{lll}211 & 154 & 365\end{array}$

$\begin{array}{lll}182 & 181 & 363\end{array}$

$\begin{array}{lll}170 & 170 \quad 340\end{array}$

$\begin{array}{lll}203 & 114 & 317\end{array}$

$\begin{array}{lll}148 & 141 & 289\end{array}$

$\begin{array}{lll}161 & 115 \quad 276\end{array}$

FQ CT VL

$\begin{array}{lll}154 & 265 & 419\end{array}$

$\begin{array}{lll}184 & 181365\end{array}$

$\begin{array}{lll}144 & 174 & 318\end{array}$

$\begin{array}{lll}129 & 127 \quad 256\end{array}$

$\begin{array}{lll}131 & 111 & 242\end{array}$

$\begin{array}{lll}112 & 130 \quad 242\end{array}$

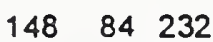

$\begin{array}{lll}95 & 113 \quad 208\end{array}$

FQ $\quad$ CT VL

$\begin{array}{lll}150 & 178 & 328\end{array}$

$\begin{array}{lll}135 & 178 & 313\end{array}$

$\begin{array}{lll}128 & 156 \quad 284\end{array}$

$\begin{array}{lll}133 & 137 \quad 270\end{array}$

$\begin{array}{lll}127 & 137 & 264\end{array}$

$\begin{array}{lll}128 & 94 & 222\end{array}$

$\begin{array}{lll}95 & 95 & 190\end{array}$

$\begin{array}{lll}99 & 77 & 176\end{array}$
POWER \& ENERGY ISSUES

Leak Detection for USTs

Leak Treatment for USTs

Leak Detection for Utility Pipelines

Above-ground Alternatives to USTs

Repair of Utility Pipelines

Clean Air Act Compliance

Efficiency of Small Generators

Waste Separation-Waste to Energy Plants

\section{WASTEWATER ISSUES}

Repair and Rehab of Collection Systems

Leak Detection in Collection Systems

Regulations for Treatment Systems

Management of Worker Health and Safety

Maintenance/Repair of Treatment Systems

Land Applications for Sludge Disposal

Composting/Recycling of Sludge

Monitoring of Treatment Systems

\section{WATER RESOURCES ISSUES}

NPDES Compliance for Stormwater

Leak Detection \& Repair of Trans. Lines

SOWA Compliance for Potable Water

Stormwater Flood Management

Stormwater Runoff Quality

Flood Control for Waterways

Groundwater Monitoring and Detection

Well Drilling and Maintenance

$\begin{array}{rrr}\text { FQ } & \text { CT } & \text { VL } \\ 101 & 154 & 255 \\ 88 & 106 & 194 \\ 86 & 92 & 178 \\ 83 & 85 & 168 \\ 54 & 51 & 105 \\ 53 & 44 & 97 \\ 52 & 40 & 92 \\ 41 & 45 & 86\end{array}$

FQ CT VL

$\begin{array}{lll}184 & 250 \quad 434\end{array}$

$\begin{array}{lll}130 & 122 \quad 252\end{array}$

$\begin{array}{lll}110 & 137 \quad 247\end{array}$

$\begin{array}{lll}117 & 114 & 231\end{array}$

$\begin{array}{lll}119 & 100 \quad 219\end{array}$

$\begin{array}{lll}114 & 74 & 188\end{array}$

$\begin{array}{llll}89 & 98 & 187\end{array}$

$\begin{array}{lll}102 & 75 \quad 177\end{array}$

FQ CT VL

$\begin{array}{lll}160 & 214 & 374\end{array}$

$\begin{array}{lll}130 & 135 \quad 265\end{array}$

$\begin{array}{lll}101 & 154 \quad 255\end{array}$

$\begin{array}{lll}114 & 113 \quad 227\end{array}$

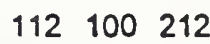

$\begin{array}{lll}100 & 105 \quad 205\end{array}$

$\begin{array}{lll}86 & 93 & 179\end{array}$

$\begin{array}{lll}85 & 87 & 172\end{array}$ 
HAZARDOUS WASTE: Worker Safety in Materials Handling

Local governments possess a vested interest in seeing advances made in the areas of health and safety for hazardous waste workers. A number of the hazards faced at hazardous waste sites are similar to those faced by municipal workers and their contractors (especially fire \& rescue and utilities workers). These hazards include chemical exposure, fire and explosion, oxygen deficiency, biologic hazards, safety hazards, electrical hazards, heat stress, cold exposure, and noise, any one of which could result in serious injury or death. In addition to technological advances, good planning, organization, training, medical programs, air monitoring, personal protective equipment, site control and decontamination measures can go a long way towards reducing the risks for hazardous waste workers.

POWER \& ENERGY: Leak Detection for Utility Pipelines

Depending on the type of piping in use, there are a few basic choices for leak detection:

- Pressurized Piping. Pressurized piping should undergo an annual tightness test and can be tested similarly to USES which includes vapor monitoring, groundwater monitoring, and interstitial (between the walls) monitoring.

- Suction Piping. Suction piping can be monitored using the methods noted under pressurized piping or by means of tightness testing.

Challenges to leak detection include:

- For metallic pipes, stress-corrosion cracking is difficult to detect until late in the process when it has grown rapidly.

For a plastic pipe, the challenge is often just finding it under the ground, since it does not contain any magnetic material.

- Once indicators point to a probable location of a leak, unearthing the pipe can cause disruption of service, property and traffic. 
WASTEWATER: Repair and Rehabilitation of Collection Systems.

Sewer pipeline stoppages and collapses are increasing at a rate of about $3 \%$ per year. Roots puncturing and growing inside the pipes cause over $50 \%$ of the stoppages, while a combination of roots, corrosion, soil movements and inadequate construction are the cause of most structural failures. Deterioration of jointing materials, pressure surges, disturbance by construction or direct tapping, and seismic activity also contribute to the collection lines being breached. In other words, about $75 \%$ of the nation's piping systems today are performing at $50 \%$ of capacity or less.

In addition to stoppages and collapses precipitating repair and rehabilitation of collection systems, wastewater treatment plants must deal with the problem of infiltration (water seepage through the collection system pipes and vaults), which can greatly increase flows and cause unnecessary burdens on the treatment plant. Infiltration tends to be a function of regional groundwater tables and will vary seasonably and annually. Old sewer systems, constructed before 1970 using mortar or mastic jointing materials, can substantially contribute to infiltration. As a standard, EPA guidelines consider infiltration to be excessive if the plant flow for nonrunoff conditions and adjusted for nondomestic use is greater than $120 \mathrm{gpd} / \mathrm{cap}$.

WATER RESOURCES: Safe Drinking Water Act Compliance for Potable Water

The most severe and acute public health effects from contaminated drinking water, such as cholera and typhoid, have been eliminated; however, some less acute and immediate hazards remain in the Nation's tap water. To maintain and increase the drinking water quality and protect drinking water resources, Congress enacted the Safe Drinking Water Act (SDWA) of 1974 and amended it in 1986. The SDWA sets standards which are Maximum Contaminant Levels for specific contaminants, along with requirements for periodic monitoring and reporting on these contaminants. 
Local water supply systems must comply with the following provisions of SDWA:

- Coliform Monitoring

- Disinfection and Disinfection By-Products Monitoring

- Inorganic Chemicals Monitoring

- Non-Volatile Synthetic Organic Chemicals and Volatile Organic Chemicals Monitoring

- Fluoride Monitoring

- Radionuclides Monitoring

- Asbestos Monitoring

- Lead Material Ran

. Lead and Copper Rule

Municipalities face compliance difficulties such as:

. The funding needed to support the manpower hours and additional laboratory testing for the monitoring that the Act requires (especially as amended in 1986).

. The requirements to monitor for 84 different contaminants are inflexible. They cannot be tailored based on occurrence data and system vulnerability, nor can compliance monitoring be eliminated for contaminants that no longer occur in the drinking water at levels that pose a risk to public health. Additionally, not all of the contaminants have been scientifically determined to be of "public health concern."

. Small systems are required to use the Best Available Technology to comply with the act. It does not recognize that the Best Available Technology may not be affordable, nor does it recognize watershed protection and pollution prevention as Best Available Technologies.

\section{Applicability and Potential Impact of Goals}

This section discusses the general applicability and potential impact of the National Construction and Building Goals to public works support infrastructure.

The National Construction and Building Goals have been summarized as follows: 
$50 \%$ reduction in delivery time

$50 \%$ reduction in operation, maintenance and energy costs

$30 \%$ increase in productivity and comfort

$50 \%$ fewer occupant related illnesses and injuries

$50 \%$ less waste and pollution

$50 \%$ more durability and flexibility

$50 \%$ reduction in construction work illnesses and injuries

50\% REDUCTION IN DELIVERY TIME

This goal offers perhaps the greatest challenge and potential impact in terms of public works support infrastructure. Major public works facilities, systems and networks in the areas of transportation, solid and hazardous waste, power and energy, and wastewater and water resources have been increasingly subject to a maze of regulatory, liability, budgetary, and procurement barriers and constraints, most of which have increased delivery times. Reversing this trend and moving toward this goal will require major breakthroughs in regulatory coordination/simplification, reductions in traditional planning/design schedules, liability/risk reduction/sharing, use of performance standards, alternative procurement strategies, incentives for innovation, and a host of other potential techniques and strategies.

\section{$50 \%$ REDUCTION IN OPERATION, MAINTENANCE AND ENERGY COSTS}

The operation and maintenance portion of this goal has significant applicability and potential impact on all types of public works infrastructure. The energy portion, while also significant, will vary with the type of public works facility. The application of accurate life cycle costing procedures is essential in addressing this goal. More importantly, investment decisions based on life cycle analysis are essential to achieve this goal, and will require encouragement and incentives to public works infrastructure owners. High quality, cost effective and energy 
efficient public works operation and maintenance equipment, processes and technologies will also contribute to this goal.

\section{0\% INCREASE IN PRODUCTIVITY AND COMFORT}

This goal applies primarily to the occupants of buildings and would be applicable only to public works infrastructure buildings, such as a water treatment plant or pumping facility.

\section{0\% FEWER OCCUPANT RELATED ILLNESSES AND INJURIES}

This goal also has limited applicability, primarily to public works infrastructure buildings.

\section{$50 \%$ LESS WASTE AND POLLUTION}

This goal has important applicability to public works infrastructure because of the increasing awareness of and concern over the environmental impact of major facilities such as freeways and regional water systems. Issues of quality, sustainability, and secondary impacts of public works infrastructure investment all need to be addressed in pursuing this goal at all stages, including planning, design, construction, operation and maintenance.

\section{0\% MORE DURABILITY AND FLEXIBILITY}

To the extent that durability denotes maintaining the initial performance characteristics of a constructed facility over its intended service life, and flexibility denotes the adaptability of constructed facilities to changes in use or user needs, this goal has important applicability and potential impact on public works infrastructures. New materials and improved operation and maintenance practices will contribute to durability, and visionary long range planning needs to incorporate flexibility as this goal is addressed. 
While construction workplace environments differ somewhat for building and non-building (public works) facilities, this goal has equally high applicability and potential impact for both in terms of costs, liability and international competitiveness.

\section{Illustrative Problems/Needs. Technologies, and Barriers}

This section discusses each of the six selected high priority problems and needs described earlier in terms of applicable high impact technologies, and barriers to their implementation. The purpose is to illustrate through specific examples the options and issues related to achievement of the National Construction and Building Goals as they relate to public works infrastructure.

TRANSPORTATION: Maintenance and Repair of Pavements

The major goals related to this problem/need area are the reduction in operation, maintenance and energy costs; and more durability and flexibility. (Underlining added) Reductions in delivery time are also important in terms of delays and inconvenience to motorists during maintenance and repair operations.

Composites, ceramics, plastics and higher strength cements can provide faster curing, weight and durability advantages over traditional paving materials when properly used and in the right conditions. Quick-curing concrete can reduce delays to traffic resulting from pavement repairs.

Pavement management and information systems are essential planning and resource allocation tools for maintenance and repair of pavements. An automated pavement management system developed by the Army Corps of Engineers is available for use by public works officials. It 
has the capability to store inventory and inspection data, analyze pavement condition, predict future pavement condition, compare costs of maintenance and repair, and plan budgets.

Advances in electronic sensors and system management software have great potential to speed up the condition assessment process and help set priorities for repair of pavements.

While new technologies for pavement design, maintenance and repair have been identified, many through the Strategic Highway Research Program (SHRP), and testing and demonstration projects have increased, a variety of barriers continue to inhibit and constrain the widespread rapid implementation of these technologies:,

- Lack of incentives for innovation and risk-taking

- Inhibiting codes, standards and regulations

- Liability concerns

- Inadequate funding and deferred maintenance

- Need for education and training for highway personnel

- Need for improved traffic management and enforcement of load limitations

- Need for life cycle quality design, construction, maintenance and repair

SOLID WASTE: Separation Technologies in Materials Recovery

The major goal applicable to this problem/need area is the reduction in waste and pollution. A related goal is the reduction in operation, maintenance and energy costs for handling and disposing of solid wastes.

About $10 \%$ of U.S. solid waste was recycled annually in the late 1980s, and the Environmental Protection Agency has been promoting a national recycling goal of 25 percent. The major roadblocks are not primarily technologies, although some technical refinements could provide measurable increases in recycling. Pricing and fluctuation in markets for 
recycled products is a major factor.

The type of separation equipment used depends on the type of municipal solid waste that is handled: mixed waste, co-mingled, or separated. In some areas, several types of recyclables, such as glass, aluminum and paper, are collected together and later separated.

Improvements in separation technologies for materials recovery will require a comprehensive systems planning approach, including integrated data bases and information systems for market demand, transport availability and cost, and bulk, toxicity and other characteristics of recyclable materials. New automation technologies that include robotics, advanced sensors, and computer aided design and operation of separation equipment and processes are also needed. Because advances in separation technologies have almost universal applications in municipal public works programs, cooperative research and development is the most costeffective approach to this challenging problem and need. The motivation for such cooperative work is strengthened by the growing public interest in and demand for sustainable communities and sustainable technologies.

\section{HAZARDOUS WASTE: Worker Safety in Materials Handling}

Two National Construction and Building Goals have application to this problem/need in public works infrastructure issues: reductions in waste and pollution, and reductions in construction work illnesses and injuries.

Reductions in materials handling of hazardous waste and pollutants in public works infrastructure begin with site selection and analysis. Construction sites that do not contain significant amounts of hazardous or toxic materials will reduce materials handling dangers during site excavation and preparation operations. Selection of construction materials for the construction project with characteristics that minimize the generation of hazardous wastes and pollutants can also improve worker safety in materials handling. Finally, where hazardous 
materials, such as explosives or toxic materials, are essential for a public works infrastructure project, comprehensive safety management practices and remote handling operations can improve worker safety.

Promising technologies and practices that can improve worker safety in handling hazardous materials, and reduce exposure to hazardous substances, include the following:

. Real time information systems and sensing equipment to monitor health and safety characteristics of the construction site environment;

Advanced automation and robotics equipment for hazardous materials handling;

Pre-construction education/training and strict enforcement of workforce safety standards and performance, with emphasis on dealing with hazardous materials;

- Selection and use of new materials that meet or exceed project specifications and exhibit reduced hazardous and toxic characteristics.

POWER \& ENERGY: Leak Detection for Utility Pipelines

Utility pipelines are an important component of public works support infrastructure, and this problem/need has applicability to the goals on more durability and flexibility, and reductions in operation, maintenance and energy costs.

Leaks in utility pipelines can cause significant damage to the public works support infrastructure and to the public served by these "lifeline" systems. Failure of a main water line and major electrical transformer in the nation's capital, and steam lines in New York, remind us how dependent we are on the services of infrastructure. 
Durability of utility pipelines can be improved by the use of high-performance construction materials. For example, high-performance concrete characteristics include early-age strength, toughness, long-term mechanical properties, and extended life. High-performance steel characteristics include strength, corrosion resistance and fire resistance. Flexibility of utility pipelines can be improved by combined conduits carrying facilities with additional capacity to increase or reduce load carrying capability as demand changes.

Promising technologies for detecting leaks in utility pipelines include measurement and nondestructive evaluation tools. High speed, noncontact, sensing technologies -- radar, infrared thermography, laser optics, ultra-sound, and others -- make it possible to survey hundreds of miles of piping with great accuracy in a single day. Non-destruction evaluation techniques for pipelines include electronic acoustic sensors and fiber optic probes.

Impediments to implementation of these technologies are the relatively high costs for routine field use, and the lack of expertise to operate the specialized equipment and analyze the results.

\section{WASTEWATER: Repair and Rehabilitation of Collection Systems}

The major goals related to this problem/need area include increases in durability and flexibility, and reductions in operation and maintenance costs. Reductions in delivery time for repair and rehabilitation are also important to shorten service stoppages.

Underground construction, rehabilitation and pipe replacement using trenchless technologies can be extremely cost-effective. Direct savings come from reduced trenching and shoring work and reduced surface restoration requirements.

Collection system technologies include sewer separation, inlet controls, sewer pipe controls, and severe flow control by overflow regulators. They can also include real-time control of sewer flow and pollutant routing by using peripheral monitoring and telemetry stations, and computer-based 
sewer and pollution flow prediction methods.

High-performance materials, with characteristics such as those described for concrete and steel earlier, can improve durability and reduce the frequency of repair and rehabilitation of collection systems. Similarly, advanced sensors and monitoring systems can provide for early identification of trouble spots and may reduce the magnitude and length of time for repair and rehabilitation.

\section{WATER RESOURCES: Safe Drinking Water Act Compliance for Potable Water}

While this problem/need does not have significant direct application to the National Construction and Building Goals, it was selected to illustrate the major impact of Federal regulation on public works infrastructure in general and the delivery of safe drinking water in particular. In this case, states and municipalities are faced with rigid requirements for testing and reduction of a bewildering array of potentially harmful drinking water contaminants, as an unfunded mandate, under conditions of risk and uncertainty.

For example, removing a contaminant from drinking water to meet a maximum contaminant level (MCL) standard can be more costly than preventing its introduction in the first place. Also, complex and specific EPA regulations for drinking water and sewage treatment may conflict with regulations of other Federal agencies, creating problems for operators and raising costs. To illustrate, if engineers adjust water disinfectants to reduce corrosion in distribution systems, the changes may reduce chlorine's effectiveness, yet adding more chlorine to achieve the same disinfection level will increase the carcinogenic trihalomethanes (THMs).

Development of new technologies for water treatment is difficult given the highly regulated and uncertain climate that currently exists. As new technologies are developed, careful evaluation will be required to ensure that new treatment methods will not create new difficulties. 
Summary and Recommendations

This white paper has offered a public works perspective on the applicability and potential impact of the proposed National Construction and Building Goals. It has focused primarily on the public works support infrastructure and "lifeline" systems, including transportation, water resources, power and energy, waste water, solid waste, and hazardous waste.

To provide a current framework for the public works perspective, the priority public works problems/needs identified through a survey of public works officials and professionals have been included. A priority issue was then selected from each of the above public works support infrastructure categories, described, and discussed in terms of its relationship to the goals, and as appropriate, promising technologies, and barriers to implementation. The issues were selected to illustrate the range and variety of public works problems and challenges that need to be addressed.

What follows is a set of recommendations that are designed to facilitate the achievement of the National Construction and Building Goals as they apply to the public works support infrastructure. A brief rationale is provided for each recommendation.

\section{PROMOTE AND ENCOURAGE INNOVATIVE ALTERNATIVE CONTRACT AND PROCUREMENT PRACTICES, SUCH AS DESIGN-BUILD, FOR MAJOR PUBLIC WORKS PROJECTS.}

Design-build contracts and related variations can contribute significantly to the goal of reducing delivery time by allowing some construction work to begin before final design details are completed, and by eliminating potential external conflicts between the designer and the builder. Design-build contracts permit the use of innovative designs, materials and construction systems to maximize efficiency, reduce costs, and increase durability. 
GOVERNMENT should broaden contracting requirements and specifications to allow and encourage alternative procurement procedures. INDUSTRY should document and share experience with design-build and other innovative procurement practices to improve understanding and broaden use of these practices. ACADEMIA should introduce knowledge of these alternative practices into the engineering curriculum.

2. IMPLEMENT FEDERAL CAPITAL BUDGETING FOR PUBLIC WORKS BY ESTABLISHING A PUBLIC WORKS INVESTMENT SECTION IN THE PRESIDENT'S BUDGET.

This recommendation would provide for a series of broad, flexible infrastructure trust funds, each funding a category of interrelated public works activities and supported by appropriate dedicated sources of revenue. It is designed to encourage multi-year stability in planning long-term investments and maintaining facilities cost-effectively. This would contribute to the goals of reducing delivery time and operation and maintenance costs for multi-year public works construction projects by assuring adequate continuous funding for construction and maintenance.

GOVERNMENT (the President) should introduce legislation for this recommendation.

3. PROMOTE THE DEVELOPMENT AND USE OF LIFE-CYCLE COST ANALYSIS FOR PUBLIC WORKS INVESTMENTS, INCLUDING STANDARD METHODOLOGIES AND APPLICATION.

Life-cycle cost analysis is a valuable economic analysis technique for evaluating public works programs that require long-term- capital and maintenance expenditures. The benefits and costs of infrastructure investment are measured and appropriately discounted over the full life cycle of each project. Life-cycle analysis can contribute to the goals of reducing operation, maintenance and energy costs, and increasing durability and flexibility by showing the cost-effectiveness of higher initial investment in quality when measured over the full project life. 
GOVERNMENT should establish policies which include life-cycle costing as an element of infrastructure investment analysis. (For example, the Federal Highway Administration has issued a temporary policy based on Executive Order 12893, "Principles of Federal Infrastructure Investment," calling for life-cycle analysis.)

INDUSTRY should include life-cycle analysis in evaluating public works project design alternatives, and educate clients on the benefits of investment decisions based on such analysis. ACADEMIA should integrate life-cycle analysis into the engineering curriculum.

\section{REDUCE REGULATORY BARRIERS TO PUBLIC WORKS INFRASTRUCTURE DEVELOPMENT AT ALL LEVELS OF GOVERNMENT.}

This recommendation can contribute significantly to the goal of reducing delivery time of public works projects, particularly in the planning, design and pre-construction permit phases. As an example, Presidential Executive Order 12873 is designed to reduce the imposition of unfunded mandates upon state and local governments, and to streamline the application process and increase the availability of waivers to such governments.

GOVERNMENTS (at all levels) should require all agencies to consolidate, streamline and integrate their multiple regulatory responsibilities. A single administrative processing/permitting agency should be established to shorten and improve the approval process for public works infrastructure projects.

5. PROMOTE THE DEVELOPMENT AND APPLICATION OF HIGH-PERFORMANCE CONSTRUCTION MATERIALS AND SYSTEMS FOR PUBLIC WORKS INFRASTRUCTURE THROUGH INCENTIVES FOR INNOVATIVE R\&D, USE OF PERFORMANCE STANDARDS, AND LIMITING AND SHARING OF RISK AND LIABILITY IN THE USE OF SUCH MATERIALS.

This recommendation can contribute significantly to the goals of increased durability and reduced 
operation, maintenance and energy costs for public works infrastructure. Benefits include improved performance and lower costs from materials with such characteristics as superior strength, toughness and ductility; enhanced durability and service life; resistance to abrasion, corrosion, chemicals and fatigue; and initial and life-cycle cost efficiencies.

GOVERNMENT should (1) authorize the establishment of a National Coordinating Council to provide industry leadership in planning and executing comprehensive research on highperformance construction materials, and expediting the commercialization of these new technologies; (2) create tax incentives that encourage private sector investment in innovative R\&D and its application; (3) propose legislation that will promote construction innovation by limiting liability and sharing risk; and (4) work with industry to develop and promote the use of performance standards which facilitate the application of high-performance construction materials and systems. INDUSTRY should unite through the National Coordinating Council and make 2 strong commitment to participate actively in and support the goals of the National HighPerformance Construction Materials and Systems Program. ACADEMIA should join with government and industry in a true partnership for the Program.

\section{INCORPORATE EVOLVING DEVELOPMENTS IN QUALITY, SUSTAINABILITY AND PARTNERING INTO PUBLIC WORKS INFRASTRUCTURE PLANNING, DESIGN AND CONSTRUCTION.}

This recommendation will contribute to the goals on reduction in delivery time and reduction in waste and pollution.

Because of their size and impact, major public works infrastructure projects are highly vulnerable to socio-environmental criticism and criticism due to lack of quality. Sustainable development requires conceptually new manufacturing processes and equipment, expanding use of recyclable materials, the development of regenerative/recyclable products, and reduced use of non-renewable resources. It requires focus on upstream pollution prevention rather than "end of the pipe" clean- 
up technologies.

Total quality management (TQM) concepts and applications are receiving increasing attention and application in the design and construction industry here and abroad. The ASCE Manual on Quality in the Constructed Project provided a milestone in this area in the United States, and the International Standards Organization (ISO) has published a series of five international standards on quality systems (ISO 9000-9004).

Evolving partnering concepts and practices apply to both sustainable development and quality. Expanded multidisciplinary partnerships are critical to ensure that sustainable technologies, processes, systems and human needs and concerns are reflected in the design and construction of the built environment. Partnerships between the owner, designer and builder are critical to the achievement of quality in the constructed project.

Successful public works infrastructure development now and in the future will require increasing understanding and application of the principles of sustainability, quality and partnering.

GOVERNMENT, INDUSTRY and ACADEMIA should work together to provide education and training on the purpose and application of these concepts and strategies for all people working in the construction and building industry. They should also work together to inform the public of the benefits of these developments and the commitment of the industry to their increasing utilization in meeting the future construction and building needs of the nation. 


